Diss. Nr. 4303

Ökologische und physiologische Untersuchungen an der planktischen Blaualge Oscillatoria rubescens D.C. unter besonderer Berücksichtigung von Licht und Temperatur

\author{
Abhandlung \\ zur Erlangung der Würde eines \\ Doktors der Naturwissenschaften \\ der \\ EIDGENOSSISCHEN TECHNISCHEN HOCHSCHULE \\ $\mathrm{ZURICH}$ \\ vorgelegt von \\ ULRICH ZIMMERMANN \\ dipl. sc. nat. ETH \\ geboren am 6. März 1937 \\ von Schwändi und Mitlödi, Kanton Glarus \\ Angenommen auf Antrag von \\ Prof. Dr. O. JAAG, Referent \\ Prof. Dr. H. KERN, Korreferent \\ Basel \\ Birkhäuser Verlag \\ 1969
}


Separatabdruck aus «Schweizerische Zeitschrift für Hydrologie», Band 31, Heft 1 (1969) Birkhäuser Verlag Basel 


\section{Ökologische und physiologische Untersuchungen an der planktischen Blaualge Oscillatoria rubescens D.C. unter besonderer Berücksichtigung von Licht und Temperatur}

von UlRICH ZIMMERMANN

Eidg. Anstalt für Wasserversorgung

Abwasserreinigung und Gewässerschutz an der Eidg. Techn. Hochschule Zürich Direktion: Prof. Dr. O. Jaag

Manuskript eingegangen am 20. Dezember 1968

\section{INHALTSVERZEICHNIS}

1. Einleitung und Problemstellung . . . . . . . . . . . . . . . . . . 2

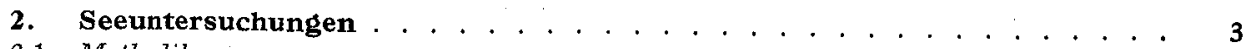

2.1 Methodik. . . . . . . . . . . . . . . . . . . . . . . . . 3

2.11 Probenahmen . . . . . . . . . . . . . . . . . . . . . 3

2.12 Physikalische Bestimmungsmethoden . . . . . . . . . . . . . . . . . . . . . . . . 4

2.13 Chemische Analysenmethoden . . . . . . . . . . . . . . . . . . . . . . . . . 4

2.14 Biologische Untersuchungsmethoden . . . . . . . . . . . . . . . . . . . . 5

2.2 Resullate. . . . . . . . . . . . . . . . . . . . . . . 5

2.21 Thermik. . . . . . . . . . . . . . . . . . . . . 5

2.22 Subaquatische Lichtverhältnisse . . . . . . . . . . . . . . . . . . . . . 8

2.23 Sauerstoff . . . . . . . . . . . . . . . . . . . . . . . . . . 11

2.24 Phosphor . . . . . . . . . . . . . . . . . . . . . . . . . . . . . 16

2.25 Stickstoff . . . . . . . . . . . . . . . . . . . . . . . . . . . . . 20

2.26 Vertikale und zeitliche Änderung der Phytoplanktonzusammensetzung. . . . . . . . . . . 22

2.261 Das Gesamtvolumen von Oscillatoria rubescens (GOV) und das restliche Phytoplanktonvolumen (RPV) in der beobachteten Wassersäulie im Verlauf der Untersuchungsperiode ................... 23

2.262 Die vertikale Verteilung von Oscillatoria rubescens . . . . . . . . . . . . . . 26

2.263 Das ubrige Phytoplankton . . . . . . . . . . . . . . . . . . . . . . . . . . . . 31

2.264 Die Veränderung der spektralen Transparenz im Laufe der Zeit unter Berücksichtigung des Phytoplanktons . . . . . . . . . . . . . . . . . . 35

2.265 Primärproduktion und vertikale Verteilung des Phytoplanktons . . . . . . . 37

2.3 Diskussion. . . . . . . . . . . . . . . . . . . . . 44

2.31 Oscillatoria rubescens-Maximum und Temperatur . . . . . . . . . . . . . . . . . 44

2.32 Oscillatoria mbescens-Maximum und Lichtklima. . . . . . . . . . . . . 45 
3. Experimentelle Untersuchungen . . . . . . . . . . . . . . . . . . . 48

3.1 Methodik. . . . . . . . . . . . . . . . . . . . . 48

3.2 Vorversuche . . . . . . . . . . . . . . . . . . . . . . . . . . . . 49

3.3 Kurzzeitversuche . . . . . . . . . . . . . . . . . . . . . . . . 51

3.4 Langzeitversuche . . . . . . . . . . . . . . . . . . . . . . . . 51

4. Diskussion und Schlussfolgerungen . . . . . . . . . . . . . . . . . . . . 54

5. Zusammenfassung .................... . . 56

Summary . . . . . . . . . . . . . . . . . . 56

Literaturverzeichnis. . . . . . . . . . . . . . . . 57

\section{Einleitung und Problemstellung}

In den letzten Jahren konnte die fortschreitende Eutrophierung in einer grossen Zahl von Alpenrandseen verfolgt werden. In Seen, die bis vor kurzem noch als nährstoffarm galten und nur eine geringe Phytoplanktonproduktion aufwiesen, veränderte sich offenbar das Nährstoffangebot derart, dass-sich die Phytoplanktonpopulation sowohl qualitativ als auch quantitativ wesentlich veränderte. Ein deutlicher Hinweis auf eine derartige Entwicklung ist das Utberhandnehmen von Oscillatoria rubescens D.C., welche als eigentlicher. Trophieanzeiger bezeichnet wird [1,2]. Diese Entwicklung konnte in jüngster Zeit in beinahe allen bisher noch als nährstoffarm bekannten Schweizerseen wie Genfersee [3], Luganersee [2,4], Thunersee [5] und Vierwaldstättersee [2] beobachtet werden. Untersuchungen in den erwähnten, aber auch in amerikanischen $[6,7]$, italienischen $[8,9]$ und vor allem in österreichischen Seen $[1,10,11,12$, $13,14,15,16,17,18$,] brachten - neben der erwähnten Rolle dieser Alge als Trophiezeiger - eine andere, ebenso beachtenswerte Eigenschaft zutage. Während der Sommerstagnation befindet sich der grösste Teil dieser Organismen nicht wie die meisten andern Phytoplankter nahe der Oberfläche, sondern in Tiefen bis über $20 \mathrm{~m}[1,8,18$, $19,20,21,22,23]$.

Im Extremfall werden dabei im Oberflächenwasser überhaupt keine Fäden, in der bevorzugten Tiefe jedoch eine sehr hohe Individuenzahl beobachtet. Während MARCHESONI [8], Thomas und Märki [20] und FindenEGg [21] die vertikale Verteilung von Oscillatoria rubescens im Zusammenhang mit der Temperatur untersuchten und ihr merkwürdiges Verhalten auch mit der chemischen Beschaffenheit des Gewässers in Zusammenhang zu bringen versuchten, stellte FINDENEGG $[1,10]$ eine Abhängigkeit der vertikalen. Verteilung von Temperatur und Strahlung fest. Auf Grund seiner Beobachtungen wäre Oscillatoria rubescens als eine oligotherme Schwachlichtform anzusprechen. Die von STAUB [24] an bakterienfreien Kulturen beobachteten Temperaturoptima von über $20^{\circ} \mathrm{C}$ brachten jedoch Zweifel an der Richtigkeit dieser Charakterisierung. Beobachtungen von relativ hohen epilimnischen Wassertemperaturen während Massenentwicklungen dieser Alge $[25,26]$ weisen darauf hin, dass unter natürlichen Umweltsbedingungen auch bei höheren Temperaturen günstige Voraussetzungen herrschen können. Es scheint, dass eine richtige Beurteilung dieses komplexen Sachverhaltes nur dann Aussicht auf Erfolg hat, wenn neben Freilandbeobachtungen im Experiment der Einfluss der einzelnen ökologischen Faktoren getrennt untersucht werden kann. 
Mit dieser Arbeit wurde beabsichtigt, die Umweltsbedingungen für Oscillatoria rubescens in verschiedenen Alpenrandseen in situ zu beobachten, wobei das Augenmerk vornehmlich auf die Temperatur und die Lichtbedingungen gerichtet war. Ferner sollten an Reinkulturen die optimalen Licht- und Temperaturbedingungen in vitro ermittelt werden.

Diese Arbeit wurde an der Eidgenössischen Anstalt für Wasserversorgung, Abwasserreinigung und Gewässerschutz an der ETH (EAWAG) in Zürich und im Hydrobiologischen Laboratorium in Kastanienbaum ausgeführt. Herrn Prof. Dr. O. Jaag, Direktor der EAWAG, möchte ich für den mir zur Verfügung gestellten Arbeitsplatz, die grosszügige finanzielle Unterstützung sowie für die Bereitschaft bei der Anschaffung der notwendigen Apparaturen herzlich danken. Herrn Dr. H. Ambühl, Leiter der Limnologischen Abteilung der EAWAG und des Hydrobiologischen Laboratoriums Kastanienbaum danke ich für die gründliche Durchsicht der Arbeit und die nützlichen Hinweise während der Ausführung dieser Arbeit; Herrn Dr. A.Zehnder für die Anregung zu dieser Arbeit und für die Utberlassung des Themas; Fräulein Dr. M. Pavoni für die zahlreichen planktologischen Hinweise.

$\mathrm{Zu}$ Dank verpflichtet bin ich Fräulein B. Egli für die laufende Bereithaltung von Impfmaterial; den Mitarbeitern der Radiólogischen Abteilung der EAWAG für die Messung der $\mathrm{C}^{14}$-Proben sowie den Mitarbeitern der Versuchsanlage Tüffenwies für die Herstellung vieler apparativer Teile. Danken möchte ich auch den Herren H. Bachmann, B. Ribi, P. Schlup, M. Schmid und E. Szabó für ihre Mithilfe im Labor und bei Probenahmen. Besonderer Dank gebührt Herrn Dr. R. Gächter für die vielen Anregungen, Hinweise und Ratschläge, welche sich aus zahlreichen Diskussionen mit ihm ergaben; danken möchte ich ihm im weiteren für die kritische Durchsicht des Manuskripts. Für die finanziellen Mittel, welche die Anschaffung des Licht-Brückenthermostaten ermöglichten, bin ich der Volkart-Stiftung, Winterthur, zu Dank verpflichtet.

\section{Seeuntersuchungen}

Die Probenahmen erfolgten vom verankerten Boot aus. Die Wasserproben wurden mit einem Friedinger-Wasserschöpfer entnommen; die Sauerstoffproben nach WINKLER [27], die Lugolproben nach UTERMÖHL [28] an Ort und Stelle fixiert.

\subsection{Methodik}

\section{2:11 Probenahmen}

Vierwaldstättersee - Horwer Bucht

Koordinaten $\left.{ }^{1}\right): 47^{\circ} 00^{\prime} 00^{\prime \prime}$ N, $8^{\circ} 19^{\prime} 20^{\prime \prime} \mathrm{E}$

Seetiefe: $71 \mathrm{~m}$

Vom September 1965 bis August 1967 wurden monatlich Wasserproben aus folgenden Tiefen $[\mathrm{m}]$ entnommen:

$0 ; 1 ; 2,5 ; 5 ; 7,5 ; 10 ; 12,5 ; 15 ;(17,5) ; 20 ; 30 ; 50 ; 71$.

1) Die Koordinaten wurden den entsprechenden Blättern der neuen Landeskarte der Schwejz entnommen. 
Thunersee

Koordinaten: $46^{\circ} 41^{\prime} 10^{\prime \prime} \mathrm{N}, 7^{\circ} 43^{\prime} 11^{\prime \prime} \mathrm{E}$

Seetiefe: $200 \mathrm{~m}$

Zeit der Probenahmen

1966: Juli und Oktober

1967: Januar, April und Juli.

Tiefenstufen $[\mathrm{m}]: 0 ; 1 ; 2,5 ; 5 ; 7,5 ; 10 ; 12,5 ; 15 ; 20 ; 50 ; 100 ; 200$.

\section{Luganersee}

Koordinaten: $45^{\circ} 59^{\prime} 53^{\prime \prime} \mathrm{N}, 8^{\circ} 58^{\prime} 10^{\prime \prime} \mathrm{E}$

Seetiefe : $220 \mathrm{~m}$

Zeit der Probenahmen

1966: August

1967: Januar, April und Juli

Tiefenstufen: wie Thunersee

Mauensee

Koordinaten: $47^{\circ} 10^{\prime} 22^{\prime \prime} \mathrm{N}, 8^{\circ} 04^{\prime} 24^{\prime \prime} \mathrm{E}$

Seetiefe: $7 \mathrm{~m}$

Zeit der Probenahmen

1967: Mai, Juni, Juli (nur Temperatur) und August

Tiefenstufen $[\mathrm{m}]: 0 ; 1 ; 2 ;(2,5) ; 3 ; 4 ; 5 ; 6,5$.

\subsection{Physikalische Bestimmungsmethoden}

Temperatur: Elektrometrische Temperaturbestimmung mit dem «Oxytester» [29].

Subaquatische Lichtmessungen: Mit Hilfe einer Sperrschichtphotozelle und vorgeschaltetem Schott-Filter der Firma Schenk, Wien, wurden die vertikalen Extinktionskoeffizienten verschiedener Wellenlängen gemessen (Tab. 1).

Tab. 1. Charakteristik der verwendeten Filter [30]

\begin{tabular}{llll}
\hline $\begin{array}{l}\text { Filter oder } \\
\text { Filterkombination }\end{array}$ & $\begin{array}{l}\text { optischer } \\
\text { Schwerpunkt }[\AA]\end{array}$ & $\begin{array}{l}\text { Durchlässigkeits- } \\
\text { maximum }[\AA]\end{array}$ & $\begin{array}{l}\text { Transmissionsgrenze } \\
(\mathbf{D}=1 \%)[\AA]\end{array}$ \\
\hline UG1+ BG 12 & 3700 & 3650 & $3150-4090$ \\
BG12 & 4230 & 4410 & $3100-5100$ \\
VG9 & 5330 & 5270 & $4350-6400$ \\
RG2 & 6750 & 6500 & $6380-8600$ \\
RG5 & 6950 & 6750 & $6420-8600$ \\
\hline
\end{tabular}

Transparenzmessungen: Weisse Scheibe, $30 \mathrm{~cm}$ Durchmesser.

\subsection{Chemische Analysenmethoden}

Sauerstoff: Bestimmung nach WINKLER [27], modifiziert nach ALSTERBERG [31]. Wasserstoffionenkonzentration $(\mathrm{pH})$ : Elektrometrisch mit $\mathrm{pH}$-Gerät, Typ PHM 24, "Radiometer", mit Glaselektrode.

Karbonathärte (SBV): Nach Vorschrift des Schweizerischen Lebensmittelbuches, modifiziert nach BERGER (mündliche Mitteilung). 
Gesamtkohlenstoff: Der anorganische Kohlenstoffgehalt wurde nach HARVEY und RHODE [32] aus ph und SBV berechnet.

Phosphat: Ammoniummolybdat-Zinnchlorid-Methode nach OHLE [33], modifiziert nach AmbüHL und ScHmid [34].

Gesamtphosphor: Methode nach OHLE [33], modifiziert nach ScHмID und AMBÜHL [35].

Nitrat: Salicylatmethode nach MüLLER und Widemann [36].

\subsection{Biologische Untersuchungsmethoden}

Quantitative Planktonuntersuchungen: Auszählmethode mit dem umgekehrten Mikroskop nach UTERMöHL (28).

Primärproduktionsmessungen: C14-Methode nach STEEmann-Nielsen (37). Die mit markiertem Kohlenstoff $\left(\mathrm{NaHC}^{14} \mathrm{O}_{3}\right)$ versehenen Proben wurden in der Zeit zwischen 10 und 14 Uhr in den entsprechenden Tiefen exponiert. Nachher wurden je $25 \mathrm{ml}$ durch Göttinger Membranfilter MF 20 filtriert, in Aluminiumschälchen geklebt, 20 min über rauchender Salzsäure exponiert, um Störungen durch adsorbiertes, anorganisches $\mathrm{C}^{14} \mathrm{zu}$ eliminieren, und die Aktivität der.Präparate im Methandurchflusszähler der Firma Frieseke und Höpfner FH 407 gemessen.

\subsection{Resultate}

\subsection{Thermik}

Die Konzentration der mineralischen Aufbaustoffe und die vertikale Verteilung des Planktons stehen in direktem Zusammenhang mit der thermischen Schichtung eines Sees. Die Geschwindigkeit der Photo- und Chemosynthese ist gemäss der Kroghschen Kurve [38] abhängig von der Temperatur, sofern nicht ein oder mehrere wesentliche Faktoren (Licht, Nährstoffe) unter ihre Wirksamkeitsgrenze (Gesetz des Minimums [39]) gesunken sind.

\section{Vierwaldstättersee: Abb. 1}

Der fliessende Úbergang von den warmen Oberflächentemperaturen zu den kälteren Temperaturen in grösseren Tiefen verhinderte eine klare Dreiteilung der Wassermasse in Epi-, Meta- und Hypolimnion in den Sommermonaten. Im Januar 1966 und Februar 1967 herrschte Homothermie bis zum Grund. Während der ganzen Untersuchungsperiode änderte sich die Temperatur in der grössten Tiefe um nur $0,7^{\circ} \mathrm{C}$ bei Extremwerten von 4,1 und $4,8^{\circ} \mathrm{C}$.

\section{Thunersee: Abb. 2}

Die erste Probenahme fiel auf das Ende der bis in den Sòmmer hinein recht kühlen Witterung. Die Oberflächentemperatur erreichte einen Maximalwert von nur $16,8^{\circ} \mathrm{C}$. Im Oktober 1966 zirkulierte der See bei einer Temperatur von $13,7^{\circ} \mathrm{C}$ bis in eine Tiefe von etwa $13 \mathrm{~m}$. Darunter lagen die Temperaturen jedoch bis auf $30 \mathrm{~m}$ hinunter höher als im Juli, was auf eine stärkere Erwärmung zwischen den beiden Probenahmen schliessen lässt. Ende Januar 1967 konnte ein Temperaturverlauf beobachtet werden, welcher einer Homothermie sehr nahe kam, unterschieden sich die Oberflächentemperaturen von denjenigen direkt über dem Grund doch um nur $0,6^{\circ} \mathrm{C}$. Im April 1967 reichte 


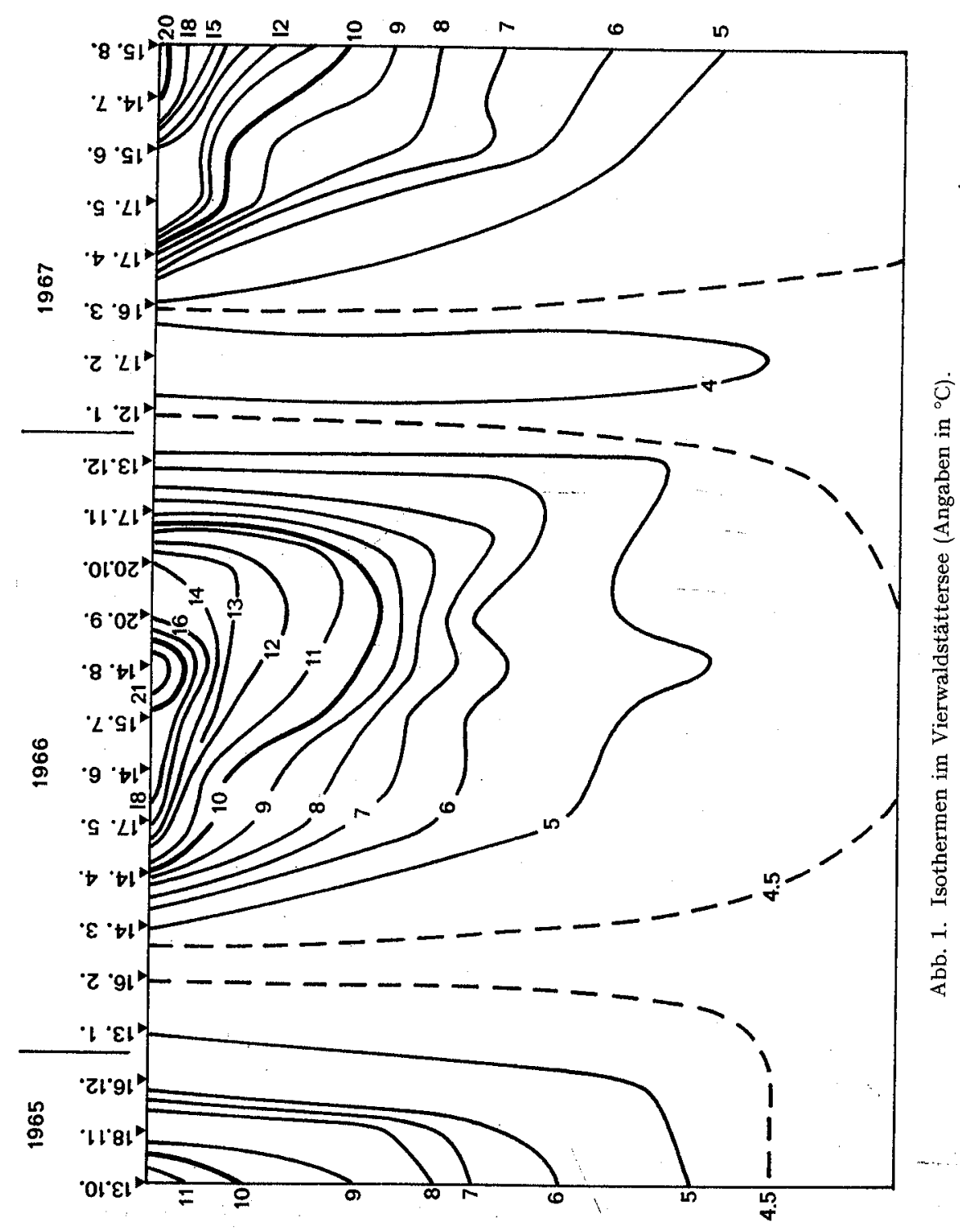

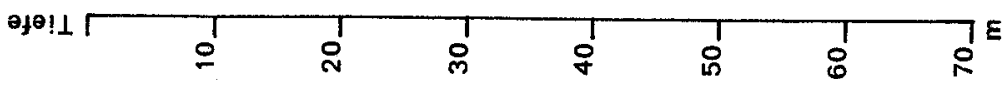


die Erwärmung des Wassers bis in eine Tiefe von $50 \mathrm{~m}$ hinab, wobei Temperaturen zwischen 6,1 und $4,6^{\circ} \mathrm{C}$ beobachtet werden konnten. Bedingt durch einen wärmeren Frühsommer als im Jahre zuvor wurde im Juli 1967 eine Oberflächentemperatur von $20,6^{\circ} \mathrm{C}$ ermittelt. Eine mit zunehmender Tiefe allmähliche Temperaturabnahme bewirkte eine sehr grosse Stabilität bis weit in die tropholytische Schicht hinein. Während der ganzen Untersuchungsperiode änderte sich die Temperatur am Grund um nur $0,8^{\circ} \mathrm{C}$ bei Extremwerten von 4,4 und $5,2^{\circ} \mathrm{C}$. Bei der Beurteilung der Thermik des Thunersees ist zu berücksichtigen, dass der Hauptzufluss aus dem Brienzersee erfolgt. Während der Erwärmungsperiode fliesst das erwärmte Oberflächenwasser aus dem Brienzersee durch die Aare in den Thunersee ab und bewirkt eine Erhöhung der Temperatur bis ins Hypolimnion hinein [30].
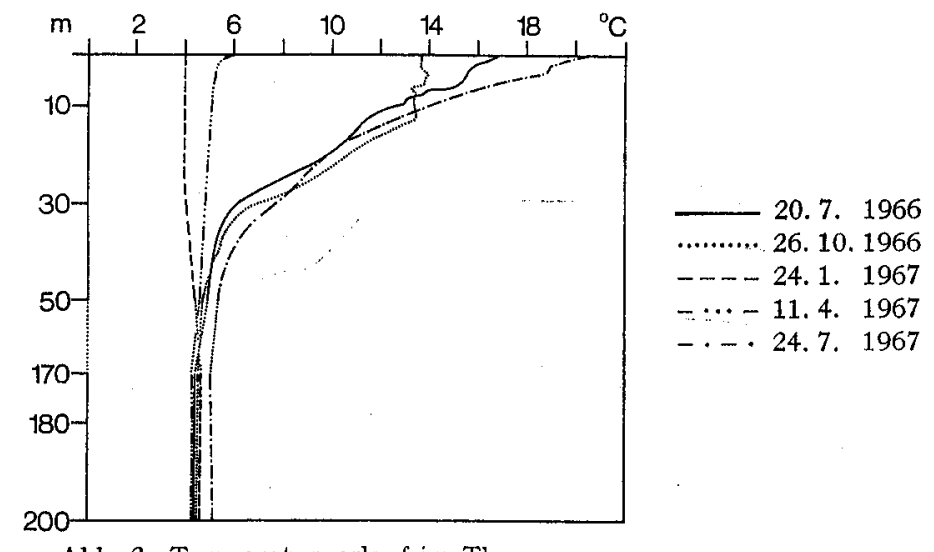

Abb. 2. Temperaturverlauf im Thunersee.

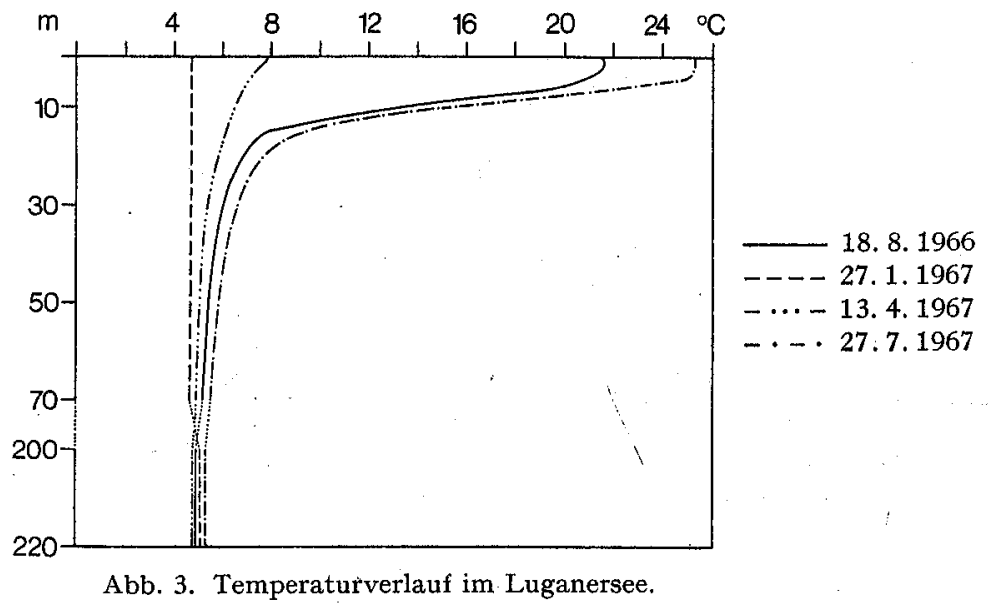

Luganersee: Abb. 3

Während der Sommerstagnation liess sich in diesem See eine deutliche Dreiteilung der Wasserschicht in Epi-, Meta- und Hypolimnion beobachten. Die beiden Sommer- 
kurven - August 1966 und Juli 1967 - unterschieden sich nur in ihren absoluten Werten, nicht aber in ihrer Charakteristik. Die hohen Oberflächentemperaturen sind für einen insubrischen See nicht ungewöhnlich. In über $80 \mathrm{~m}$ Tiefe blieb die Temperatur innerhalb sehr enger Grenzen. Die Temperaturdifferenz in der grössten Tiefe betrug während der ganzen Beobachtungszeit nur $0,8^{\circ} \mathrm{C}$ bei Extremwerten von 4,9 und $5,7^{\circ} \mathrm{C}$. Im Januar 1967 grenzte der Temperaturverlauf an Homothermie, konnte doch eine Differenz zwischen Oberfläche und Grund von nur $0,5^{\circ} \mathrm{C}$ beobachtet werden.

Mauensee: Abb. 4

Der Temperaturverlauf zur Zeit des Hochsommers zeichnete sich durch seine grossen Temperaturdifferenzen zwischen Oberfläche und Grund aus, die für einen See dieser Art und Lage typisch sind. Die Temperaturdifferenz am Grund, berechnet aus den beiden Werten November 1966 [40] und Juli 1967 , betrug $7,3^{\circ} \mathrm{C}$, diejenige an der Oberfläche, aus den Werten der gleichen Monate ermittelt, $21,8^{\circ} \mathrm{C}$. Ein Vergleich der Temperaturdifferenz an der Grenze Epi-/Hypolimnion mit derjenigen am Grund deutet auf eine starke Schichtung der Wassermassen in diesen Sommermonaten hin. Mit fortschreitender Erwärmung sank die Grenze des Epilimnions immer weiter gegen den Grund, wodurch in den Monaten Juli und August 1967 die Ausbildung eines Hypolimnions unterblieb.

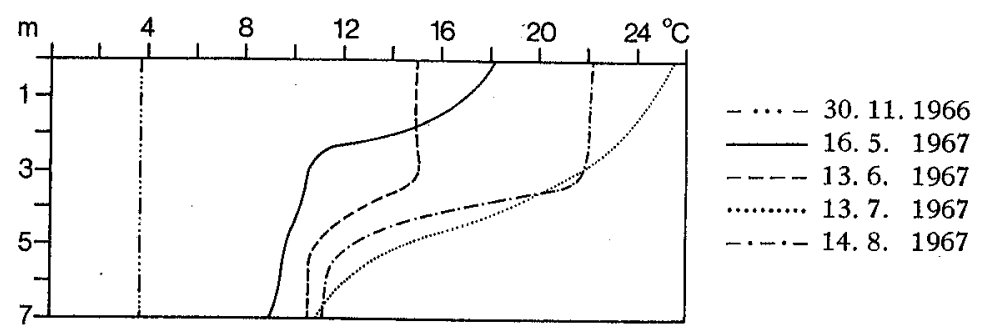

Abb. 4. Temperaturverlauf im Mauensee.

\subsection{Subaquatische Lichtverhältnisse}

Die Sonnenstrahlung ist die bedeutendste Energiequelle der Primärproduktion. Die Intensität von monochromatischem Licht nimmt in optisch homogenem Wasser exponentiell mit der durchdrungenen Wasserschicht ab. Wird die Intensität von Licht bestimmter Wellenlänge im halblogarithmischen Maßstab gegen die Tiefe aufgezeichnet, so muss eine Gerade entstehen, die ihren Ursprung im Punkte. $0 \mathrm{~m} / 100 \%$ hat. Das Wasser in Seen ist jedoch keineswegs homogen. Das Phytoplankton, während einer grossen Zeit des Jahres auf die trophogene Schicht konzentriert, vermag meistens die Extinktion zu beeinflussen. Eine Veränderung des vertikalen Extinktionskoeffizienten ist auch im Falle von Wasserschichten verschiedener Dichte (vor allem im Bereich der Thermokline) zu erwarten. Erweist sich dieser trotz der erwähnten Inhomogenitäten des Seewassers als konstant, so ist die Ursache verschiedenen Ursprungs, wie Trägheit des Systems Selenzelle-Ampèremeter, Schwankungen der Intensität in $0,05 \mathrm{~m}$ Tiefe, hervorgerufen durch Wellenbewegungen der Wasseroberfläche, Intensitätsschwankungen des Sonnenlichtes, verursacht durch Wolkenfelder. 
Die unterschiedliche Transparenz in den verschiedenen Spektralbereichen ist auf die Konzentrationsänderung von gelösten und suspendierten Teilchen zurückzuführen.

Bildet man den Quotienten aus der im Laufe eines Jahres beobachteten maximalen und minimalen Tiefe, in welcher die Intensität des jeweiligen Spektralbereiches $1 \%$ des Oberflächenwertes $\left(\mathrm{I}_{0,05}\right)$ beträgt, so ergibt sich daraus die relative Transparenz. Ist $a$ die minimale, $a+b$ die maximale Transparenz in Metern, so erhalten wir dafür folgenden Ausdruck:

$$
\text { relative Transparenz } T_{r}=\frac{a+b}{a}, \text { oder } T_{r}=1+\frac{b}{a} .
$$

Dieser Ausdruck berücksichtigt also die Lage der beiden Extremwerte in ihrer absoluten Grösse.

In Tab. 2 sind die relativen Transparenzen des Vierwaldstätter-, des Thuner- und Luganersees aufgeführt. Die Werte wurden aus den Untersuchungen vom Juli bzw. August 1966 bis Juli 1967 berechnet.

Tab. 2. Relative Transparenzen des Vierwaldstätter-, Thuner- und Luganersees

\begin{tabular}{lllll}
\hline $\begin{array}{l}\text { Filter } \\
\text { bzw. Filterkombination }\end{array}$ & $\begin{array}{l}\text { optischer } \\
\text { Schwerpunkt } \AA\end{array}$ & Vierwaldstättersee & Thunersee & Luganersee \\
\hline UG1+ BG12 & 3700 & 5,0 & 1,7 & 4,6 \\
BG12 & 4230 & 3,4 & 2,3 & 7,4 \\
VG9 & 5330 & 2,9 & 2,7 & 3,3 \\
RG2 & 6750 & 2,1 & 1,4 & 2,7 \\
RG5 & 6950 & 1,7 & 1,4 & 1,9 \\
\hline
\end{tabular}

Bei relativ grossen Minima waren im Thunersee die maximalen Transparenzen nicht ungewöhnlich tief. Die relativen Transparenzen waren dementsprechend klein und wurden in allen Spektralbereichen von den beiden andern beobachteten Seen ïbertroffen. Besonders auffällig war der kleine Wert $(1,7)$ im nahen UV, der in den beiden andern Seen bedeutend höher ausfiel.In allen untersuchten Seen wurde im Bereich von RG 5 die kleinste relative Transparenz beobachtet, während die grössten Werte in den drei Spektralbereichen unter $6000 \AA$ lagen.

Vierwaldstättersee: Abb. 5

Die Transparenz bezüglich aller fünf Wellenbereiche nahm, generell gesehen, im Laufe des Winters zu und erreichte im Spätwinter und Frühjahr ihr Maximum. Im Bereich von VG9 drang die Strahlung während der ganzen Untersuchungsperiode am tiefsten ein, gefolgt von BG12. Für die übrigen Spektralbereiche variierte die Reihenfolge im Verlaufe der Zeit. Dadurch ergaben sich qualitative Veränderungen in der spektralen Zusammensetzung des subaquatischen Lichtes zu verschiedenen Zeitpunkten. Die Transparenz im nahen UV übertraf im Zeitabschnitt Januar bis März 1967 jene des ferneren Rot (RG5) und im Januar 1967 sogar jene des näheren Rót (RG2) deutlich, was in den übrigen Monaten nicht beobachtet wurde.

Thunersee: Abb. 5

Die Transparenz war in allen untersuchten Wellenbereichen grösser als diejenige im Vierwaldstättersee. Die grössten Eindringtiefen lagen ebenfalls im Bereich von 

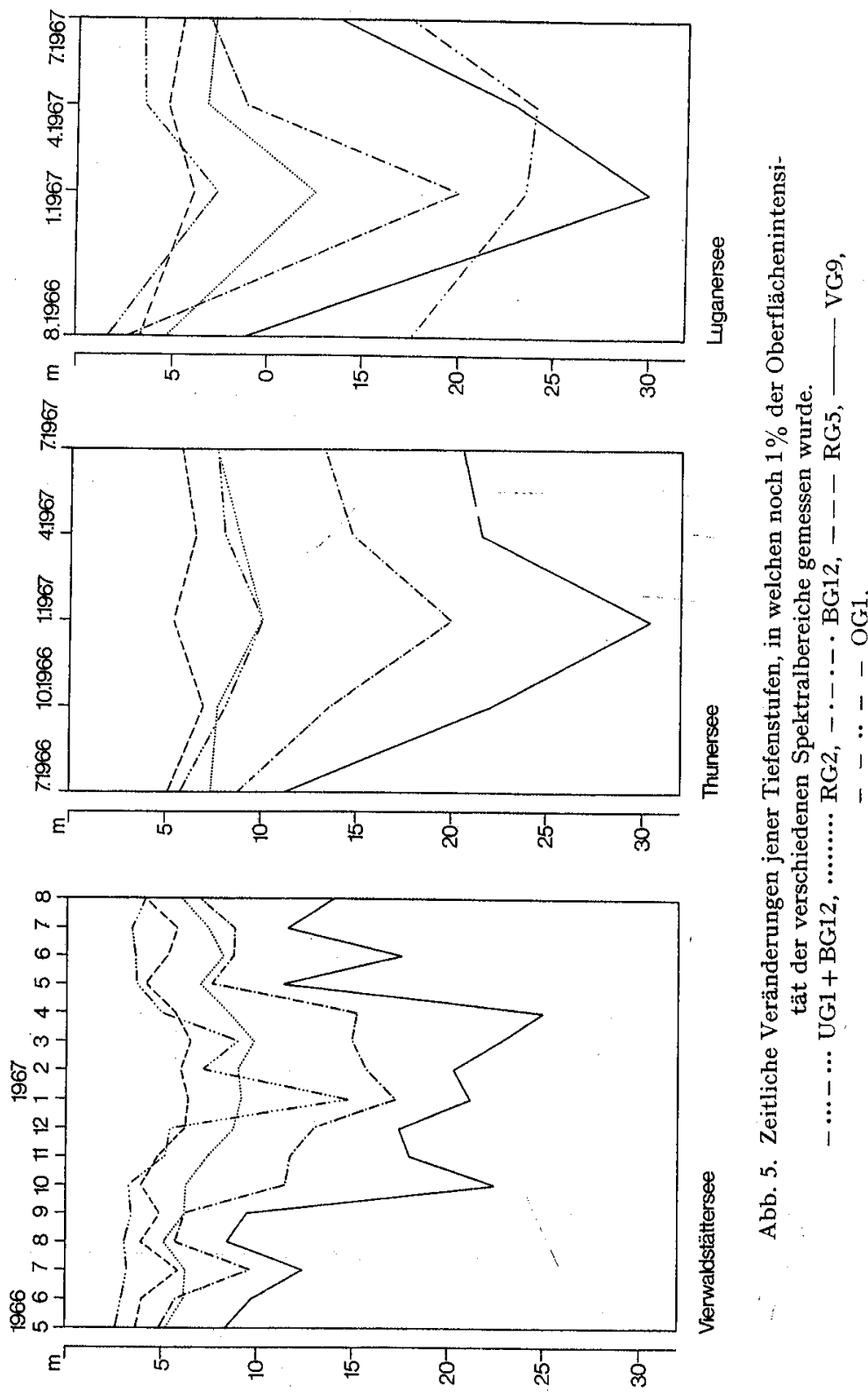
VG9 und BG 12. Die UV-Transparenz bewegte sich im gleichen Rahmen wie im nahen Rot (RG2), übertraf jedoch bei jeder Untersuchung jene des ferneren Rot (RG5). Beinahe während allen Untersuchungszeiten blieb die Reihenfolge ansteigender Durchsichtigkeit bezüglich des Spektralbereiches dieselbe. Nur im Juli 1966 blieb die Transparenz im nahen UV etwas hinter dem Rot von RG2, während die Abweichung im April 1967 minimal war.

Luganersee: Abb. 5

Zusätzlich zu den normalerweise verwendeten Filtern wurde hier noch der Orangefilter OG 1 mit folgender Charakteristik gebraucht:

optischer Schwerpunkt $5150 \AA$

Transmissionsgrenze $(\mathrm{D}=1 \%) \quad 5000-5300 \AA$

Die Transparenz in diesem Wellenbereich war im April 1967 und besonders in den Monaten August 1966 und Juli 1967 grösser als diejenige von VG9. Lediglich im Januar 1967 drang der grüne Anteil des Lichtes am tiefsten ein. In allen Spektralbereichen änderte sich die Reihenfolge ansteigender Transparenz im Laufe des Untersuchungsjahres, was von einer starken Veränderung der Zusammensetzung und Verteilung der im Wasser schwebenden Teilchen im Laufe der Zeit herrührte.

\section{Mauensee:}

Die starke Entwicklung von Oscillatoria rubescens im Mai 1967 verhinderte zu jenem Zeitpunkt eine Lichtmessung, da in allen zu messenden Spektralbereichen die Transmissionskoeffizienten sehr klein waren, was auch aus der Sichttiefe von nur $0,3 \mathrm{~m}$ zu schliessen ist. Die spektralen Extinktionskoeffizienten der Monate Juni und August sind in Tabelle 3 dargestellt. Im Juni wurde die grösste Eindringtiefe im Bereich von RG 2 beobachtet, während das nahe UV (UG 1+BG 12) den grössten $A b$ sorptionskoeffizienten (99\%) aufwies. Im August drang das grüne und orange Licht am stärksten ein, gefolgt vom Spektralbereich der Filter RG 2 und RG5.

Tab. 3. Spektrale Extinktionskoeffizienten im Mauensee

\begin{tabular}{lll}
\hline & 13.6 .1967 & 14.8 .1967 \\
\hline UG1+ BG 12 & 1,82 & 0,98 \\
BG12 & 1,46 & 0,86 \\
VG9 & 0,67 & 0,63 \\
RG2 & 0,54 & 0,69 \\
RG5 & 0,67 & 0,75 \\
\hline
\end{tabular}

\subsection{Sauerstoff}

Der Sauerstoffgehalt hängt im wesentlichen von der oxydierbaren organischen Substanz im Wasser ab. Ein grosser Teil dieser organischen Substanz - autochtoner wie allochtoner Herkunft - wird schon während des Absinkens mineralisiert, ein Vorgang, welcher Sauerstoff aus der unmittelbaren Umgebung benötigt und sich in Sauerstoffzehrung äussert. Diese ist abhängig von der Menge der organischen Substanz, der Sinkgeschwindigkeit derselben, der Wassertemperatur, den subaquatischen Lichtverhältnissen, der Lage, Form und Tiefe eines Sees sowie von den hydrographischen Verhältnissen. Dadurch, dass in der trophogenen Schicht durch das synthetisierende 
Phytoplankton Sauerstoff produziert wird, bleibt hier die Sauerstoffbilanz trotz der bereits beginnenden Mineralisierung organischer Substanzen positiv. Im Hypolimnion hingegen erhalten wir durch den Betrag der Sauerstoffzehrung ein relatives Mass für die in der aufbauenden Zone produzierten organischen Substanzen, wobei der oben erwähnte schon oxydierte Teil unberücksichtigt bleibt. Das allochtone organische Material, welches ebenfalls mineralisiert wird, täuscht dagegen einen zu hohen Betrag der Primärproduktion vor. Daher ist das hypolimnische Sauerstoffdefizit kein absolutes Mass für den Trophiegrad eines Sees, kann aber in erster Näherung über die Belastung an organischen Stoffen orientieren.

Vierwaldstättersee: Abb. 6

Die Sauerstoffkonzentrationen am Grund schwankten im Verlauf des Jahres zwischen den Werten 5,6 mg/l im September 1966 und 10,7 mg/l im März 1967. Die Werte am Ende der Zirkulation (März 1967; 86\% Sättigung) lassen erkennen, dass eine vollständige Sättigung bei weitem nicht erreicht wurde. Dies bedeutet den Eintritt des Sees in eine neue Vegetationsperiode, bevor sein Sauerstoffdefizit vollständig ausgeglichen ist.

Der generelle Verlauf der Sauerstoffkurven kann nach ÅBERG und RHODE [41] als klinograd bis leicht minus-heterograd gewertet werden. Es ist jedoch zu beachten, dass während der Zeit der grössten Produktion infolge der Assimilatonstätigkeit des Phytoplanktons oft ein Anstieg der Sauerstoffkonzentration im mittleren Epi- und im Metalimnion beobachtet werden kann, was zu einem plus-heterograden Verlauf führt. Typisch sind in dieser Hinsicht die Kurvenbilder der Monate August bis Oktober 1966, wobei die Spitzen vom August und Oktober 1966 wie auch die hohe Konzentration an der Oberfläche im Oktober 1965 eindeutig von den Sauerstoff produzierenden Oscillatoria rubescens herrührten, die sich im ersten Fall in 7,5 m bis $10 \mathrm{~m}$ eingeschichtet hatten und in den beiden letzten als Wasserblüte im Oberflächenwasser massenhaft in Erscheinung traten.

Die prozentuale Sauerstoffsättigung an der Oberfläche blieb während der Zeit vom April bis Oktober 1966 über 100\%, mit Spitzen von mehr als 140\% im August und Oktober. Der generelle Verlauf der Sauerstoffkurven während der Stagnationsperiode deutet darauf hin, "dass dieser Seeteil als «U'bergangssee) in der Skala oligotropheutroph irgendwo zwischen diesen beiden Polen einzuordnen ist "(nach GäcHTER [44]).

\section{Thunersee: Abb. 7}

Während das Kurvenbild der Sauerstoffkonzentrationen eher dem Typus eines fast oligotrophen Sees entspricht, so überraschen die zum Teil recht niedrigen Sättigungskonzentrationen am Grund (Tabelle 4), die auch nach Beendigung der Zirkulation nur knapp 70\% erreichten. Da sich dieser Wert jedoch einerseits bis Ende Juli 1967 kaum verändert hatte - demnach keine Zehrung durch einen Abbau von organischen Stoffen stattfand - und andererseits nur kleine Übersättigungen in der trophogenen Schicht beobachtet wurden, kann der Trophiegrad dieses Sees auf Grund der Sauerstoffverhältnisse dennoch als oligotroph angesehen werden. Das im Oktober 1966 beobachtete metalimnische Minimum beruhte sehr wahrscheinlich zum 


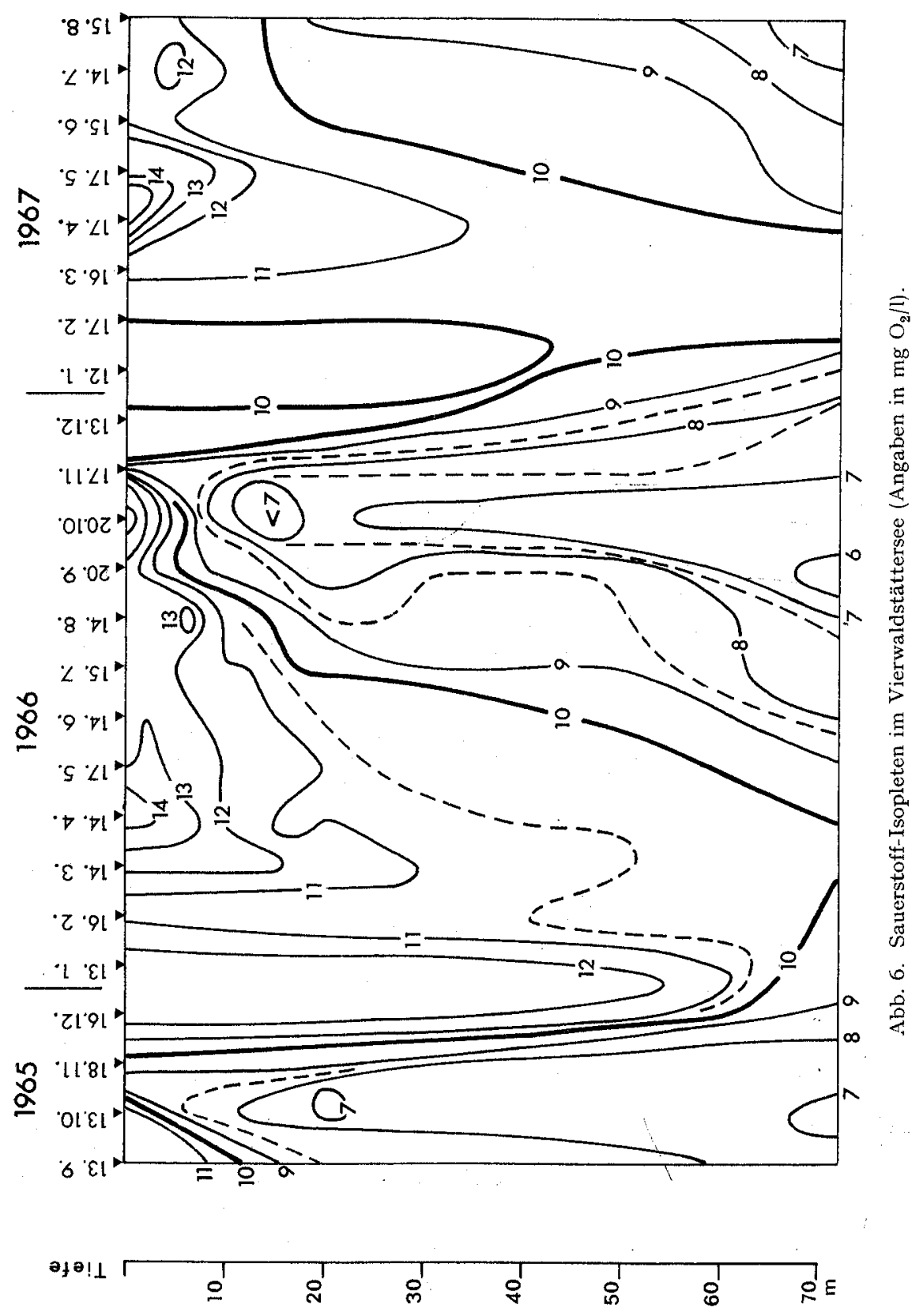




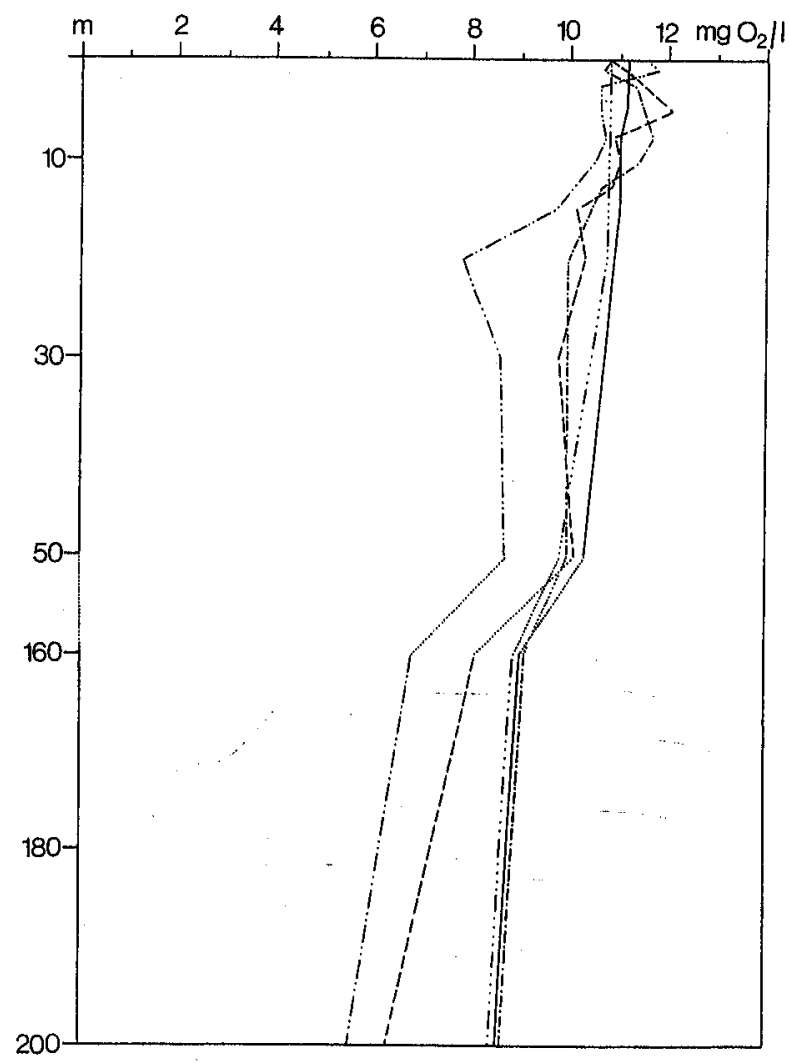

Abb. 7. Verlauf der Sauerstoffkonzentration im Thunersee.

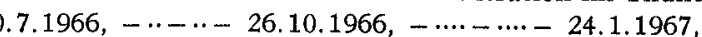

grossen Teil auf einem Temperatureffekt, der dann eintritt, wenn der Bereich der Thermokline unterhalb der trophogenen Schicht liegt (RUTTNER [42] S. 97).

Luganersee: Abb. 8

Der markant minus-heterograde Verlauf der Sauerstoffkonzentrationskurven.lässt auf einen eutrophen Charakter schliessen. Sowohl im Sommer 1966 wie auch im darauffolgenden Sommer bildete sich ein starkes metalimnisches Minimum aus, als dessen eine Ursache - wie im Thunersee - der starke Temperaturabfall unterhalb der trophogenen Schicht vermutet werden muss. Obwohl an Hand des Temperaturverlaufs vom Januar 1967 eine beinahe vollständige Durchmischung des Sees zu erwarten war, blieben die Wassermassen in Tiefen unter $150 \mathrm{~m}$ während eines vollen Jahres mit einer nahezu gleichbleibenden Sauerstoffkonzentration befrachtet. Die Dauer der Homothermie war demnach zu kurz, um eine Vollzirkulation zu erwirken. Dieselbe Erscheinung trat bekanntlich auch im viel weniger tiefen Vierwaldstättersee auf. 


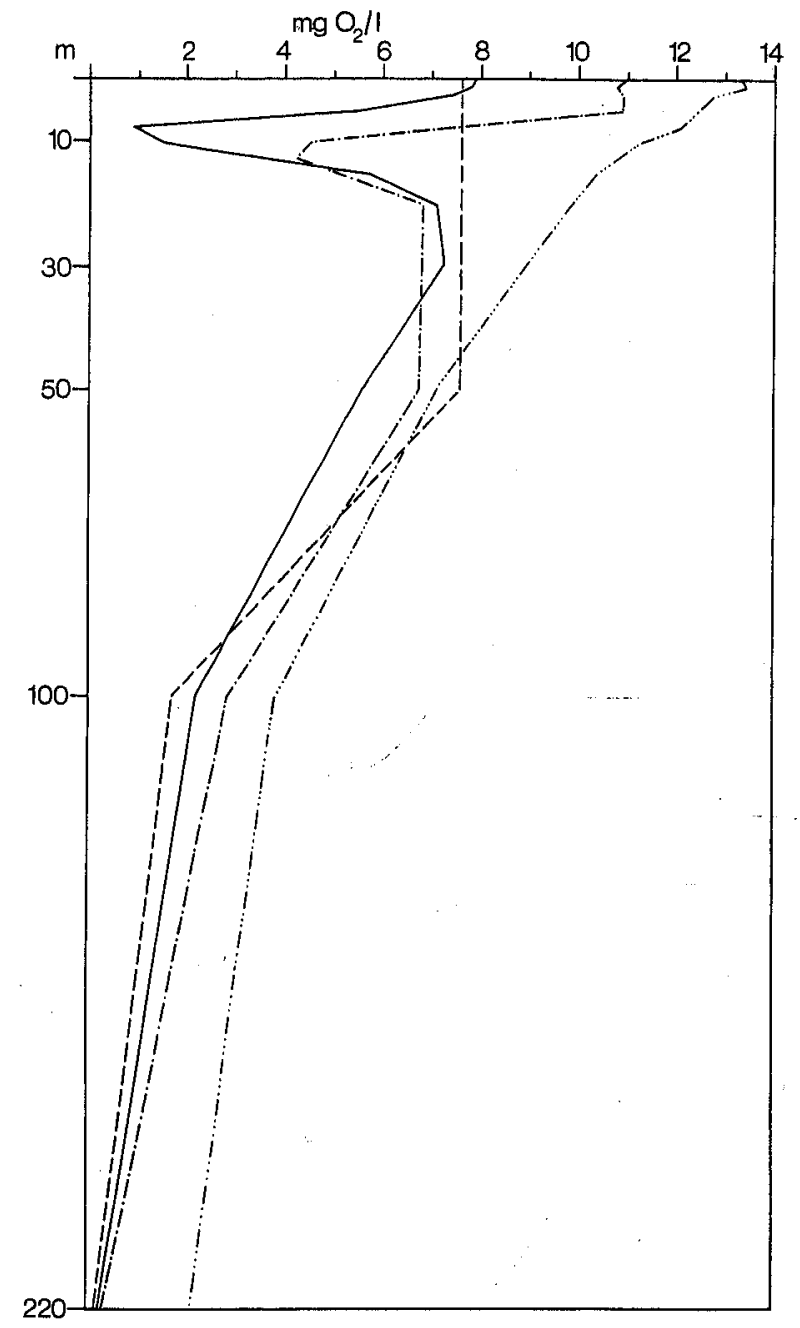

Abb. 8. Verlauf der Sauerstoffkonzentration im Luganersee.

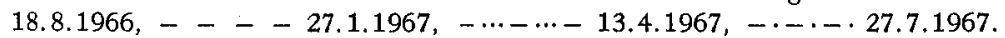

Tab. 4. Sauerstoffverhältnisse an der Oberfläche und am Grund des Thunersees in den Jahren. 1966 und 1967

\begin{tabular}{lllll}
\hline Datum & \multicolumn{2}{l}{ Aktuelle $\mathrm{O}_{\mathbf{2}}$-Konzentration [mg/l] } & \multicolumn{2}{l}{ Sättigungskonzentration [\%] } \\
& Grund & Oberfläche & Grund & Oberfläche \\
\hline 20.7 .1966 & 6,3 & 10,8 & 51 & 115 \\
26.10 .1966 & 5,5 & 11,3 & 45 & 115 \\
24.1 .1967 & 8,5 & 10,8 & 69 & 87 \\
11.4 .1967 & 8,4 & 11,2 & 68 & 94 \\
24.7 .1967 & 8,5 & 10,8 & 71 & 124 \\
\hline
\end{tabular}


Tab. 5. Sauerstoffverhältnisse an der Oberfläche und am Grund des Luganersees in den Jahren 1966 und 7967

\begin{tabular}{llccc}
\hline Datüm & \multicolumn{2}{c}{$\begin{array}{c}\text { Aktuelle } \\
\text { Grund }\end{array}$} & $\begin{array}{c}\mathrm{O}_{2} \text {-Konzentration }[\mathrm{mg} / \mathrm{l}] \\
\text { Oberfläche }\end{array}$ & \multicolumn{2}{c}{$\begin{array}{c}\text { Sättigungskonzentration [\%] } \\
\text { Grund }\end{array}$} & Oberfläche \\
\hline 18.8 .1966 & 0,2 & 7,9 & 1 & 89 \\
27.1 .1967 & 0,3 & 7,6 & 3 & 60 \\
13.4 .1967 & 1,1 & 13,3 & 9 & 113 \\
27.7 .1967 & 0,2 & 11,0 & 2 & 132 \\
\hline
\end{tabular}

Mauensee: Abb. 9

Die eigenen Untersuchungen begannen im Mai 1967, zu einer Zeit, während wel cher der See mit einer enormen Wasserblüte $\left(1,5 \cdot 10^{7}\right.$ Fäden $\left./ 1\right)$ von Oscillatoria rubescens bedeckt war; diese war denn auch die Ursache für die ungewöhnlich hohe Sättigung an der Oberfläche von $195 \%\left(17,8 \mathrm{mg} \mathrm{O} \mathrm{O}_{2} / 1\right.$ bei $\left.18,1^{\circ}\right)$. Der natürlicherweise eutrophe Charakter eines derartigen Flachgewässers wird durch das Bild der $0_{2}$-Kurven (Abb. 9) und der Sättigungskonzentrationen bestätigt. In Tabelle 6 sind die Sättigungswerte an der Oberfläche und am Grund während der Untersuchungsperiode zusammengestellt, wobei die Werte vom November 1966 aus unveröffentlichten Untersuchungen der EAWAG stammen.

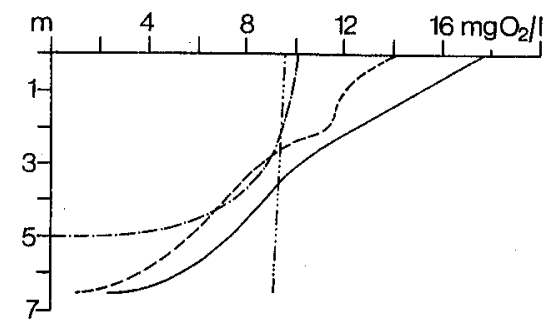

Abb. 9. Verlauf der Sauerstoffkonzentration im Mauensee.

-... - 30.11.1966, _ 16.5.1967, _ _ _ - 13.6.1967

Tab. 6. Sauerstoffsättigungskonzentrationen an der Oberfläche und am Grund des Mauensees in den Jahren 1966 und 1967

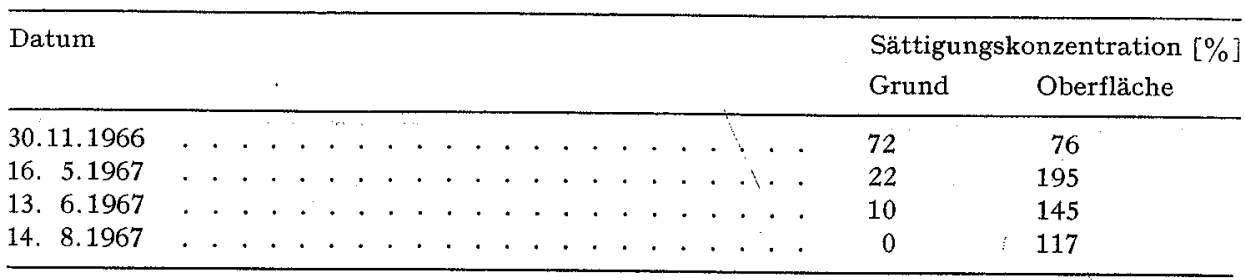

\subsection{Phosphor}

Der Phosphor liegt in unseren Seen als Orthophosphat ("soluble reactive phosphorus» [43]), als sogenannte gelöste organische P-Verbindung ("soluble unreactive phosphorus" [43]) oder in partikulärer Form vor. Im Vergleich zu den Stickstoffver- 
bindungen sind Phosphate in Wasser schlecht löslich. Die natürliche $\mathrm{PO}_{4}-\mathrm{P}-\mathrm{Kon}-$ zentration, entstanden durch die Verwitterung des Gesteins (Apatit) und Rücklösung aus dem Sediment, ist daher viel kleiner als die Nitratkonzentration. Da während der Vegetationsperiode die $\mathrm{PO}_{4}-\mathrm{P}$-Werte oft unter $1 \mu \mathrm{g} / \mathrm{l}$ fallen, wird allgemein gefolgert, dass in diesen Fällen der Phosphor begrenzender Faktor für die Primärproduktion sei, was von GÄCHTER [44] für den Vierwaldstättersee experimentell nachgewiesen wurde.

Phosphat

Vierwaldstättersee: Tabelle 7

Das Phosphat war auch während der Vollzirkulation nie vollständig homogen verteilt. Besonders zwischen $50 \mathrm{~m}$ und dem Grund $(71 \mathrm{~m})$ konnte ein Anstieg beobachtet werden. Im Januar 1966 wurden bis in $50 \mathrm{~m}$ Tiefe Werte zwischen 5,2 und $6,0 \mu \mathrm{g} \mathrm{PO}_{4}-\mathrm{P} / \mathrm{l}$, im Januar 1967 um 6,0 $\mu \mathrm{g} \mathrm{PO}_{4}-\mathrm{P} / 1$ gemessen. Die Phosphatzehrung wirkte sich während der Periode grösster Produktion bis über $30 \mathrm{~m}$ aus. Häufig fiel die $\mathrm{PO}_{4}-\mathrm{P}$-Konzentration unter $1 \mu \mathrm{g} / \mathrm{l}$, oft aber auch auf $0 \mu \mathrm{g} / \mathrm{l}$, das heisst, sie lag unter der Erfassungsgrenze der Analysenmethode $(0,2 \mu \mathrm{g} / 1)$.

Tab. 7. Phosphatkonzentrationen $[\mu \mathrm{g} \mathrm{P} / \mathrm{l}]$ im Vierwaldstättersee in den Jähren 1965 bis 1967

\begin{tabular}{rrrrrrrrrrrrrr}
\hline $\begin{array}{l}\text { Tiefe } \\
{[\mathrm{m}]}\end{array}$ & 1965 & 13.9. & 13.10. & 17.11. & 16.12. & 13.1. & 16.2. & 14.3. & 14.4 & $\mathbf{1 7 . 5 .}$ & $\mathbf{1 3 . 6 .}$ & $\mathbf{1 5 . 7 .}$ & 14.8. \\
\hline 0,0 & 1,0 & 0,5 & 1,8 & 2,4 & 5,2 & 5,0 & $\mathbf{5 , 8}$ & 1,4 & 2,2 & 2,4 & 0,6 & 0,0 \\
2,5 & 0,8 & 0,7 & 1,7 & 1,0 & 5,2 & 5,0 & 6,0 & 1,4 & 2,0 & 1,2 & 0,6 & 0,2 \\
5,0 & 0,8 & 0,2 & 1,4 & 2,6 & 5,2 & 5,0 & 7,2 & 1,3 & 1,9 & 1,2 & 0,6 & 0,8 \\
7,5 & 0,9 & 0,5 & 1,5 & 1,8 & 5,2 & 5,8 & 6,0 & 1,0 & $1,2$. & 1,9 & 0,6 & 0,8 \\
10,0 & 0,9 & 0,4 & 1,1 & 1,7 & 5,8 & 5,8 & 6,4 & 1,2 & 1,5 & 1,1 & 0,6 & 0,8 \\
12,5 & 1,0 & 0,9 & 2,0 & 2,4 & - & - & 5,8 & 1,1 & 1,3 & 1,0 & 0,6 & 0,2 \\
15,0 & 1,0 & 1,5 & 1,9 & 4,1 & - & 4,6 & 6,0 & 0,6 & 1,3 & 0,7 & 0,3 & 0,2 \\
20,0 & 2,2 & 0,7 & 1,9 & 2,6 & 6,0 & 5,2 & 6,6 & 2,0 & 1,3 & 1,3 & 0,9 & 0,4 \\
30,0 & - & 0,9 & 3,9 & 3,4 & 6,0 & 5,5 & 7,8 & 3,6 & 3,2 & 3,2 & 1,6 & 0,4 \\
50,0 & 10,0 & 2,6 & 6,9 & 6,8 & 7,5 & 7,0 & 11,0 & 5,1 & 7,0 & 6,8 & 11,3 & 9,3 \\
71,0 & 21,6 & 18,6 & 31,1 & 18,2 & 15,0 & 9,3 & 11,8 & 12,6 & 11,5 & 16,0 & 21,6 & 20,0 \\
\hline
\end{tabular}

\begin{tabular}{|c|c|c|c|c|c|c|c|c|c|c|c|c|}
\hline $\begin{array}{l}\text { Tiefe } \\
{[\mathrm{m}]}\end{array}$ & $\begin{array}{l}1966 \\
20.9\end{array}$ & 20.10 & 17.11 & 13.12 & $\begin{array}{l}1967 \\
11,1 .\end{array}$ & 17.2. & 16.3. & 17.4. & 17.5 & 14.6 & 14.7. & 15.8. \\
\hline 0,0 & 1,9 & 0,0 & 2,5 & 3,9 & 6,1 & 4,0 & 4,3 & 2,0 & 1,9 & 2,1 & 1,3 & 1,9 \\
\hline 2,5 & 1,9 & 0,0 & 2,5 & 3,5 & 6,0 & 4,0 & 4,6 & 1,5 & 2,6 & 1,3 & 0,4 & 1,9 \\
\hline 5,0 & 1,8 & 0,4 & 2,5 & 3,5 & 6,0 & 4,1 & 4,6 & 2,0 & 1,8 & 2,1 & 0,2 & 0,9 \\
\hline 7,5 & 0,9 & 0,6 & 3,0 & 3,5 & 6,0 & 4,1 & 5,7 & 3,0 & 2,3 & 4,4 & 0,1 & 1,2 \\
\hline 10,0 & 0,9 & 1,5 & 3,0 & 3,5 & 6,0 & 4,0 & 5,4 & 3,0 & 2,6 & 4,4 & 0,3 & 1,1 \\
\hline 12,5 & 0,4 & 2,6 & 4,0 & 3,5 & 6,0 & 4,0 & 6,5 & 3,0 & 1,5 & 4,4 & 0,0 & 1,2 \\
\hline 15,0 & 0,6 & 3,0 & 6,0 & 3,5 & 6,0 & 4,0 & 6,1 & 3,0 & 1,5 & 5,1 & 0,2 & 0,3 \\
\hline 20,0 & 0,6 & 3,9 & 6,5 & 3,5 & 6,0 & 3,8 & 9,8 & 3,0 & 4,9 & 5,0 & 0,7 & 1,4 \\
\hline 30,0 & 1,4 & 5,4 & 8,3 & 3,6 & 6,2 & 4,0 & 9,5 & 4,0 & 5,8 & 6,5 & 6,2 & 2,6 \\
\hline 50,0 & 7,0 & 7,6 & 12,3 & 11,5 & 6,1 & 4,1 & 8,9 & 9,0 & 13,3 & 9,6 & 10,8 & 13,2 \\
\hline 71,0 & 46,0 & 25,4 & 19,5 & 20,0 & 6,9 & 7,6 & 8,9 & 11,0 & 18,0 & 16,9 & 21,6 & 20,8 \\
\hline
\end{tabular}


Thunersee: Tabelle 8

Im Januar 1967 glich die $\mathrm{PO}_{4}-\mathrm{P}-$ Verteilung derjenigen des Vierwaldstättersees, das heisst, die Werte der untersten Schicht stiegen bis auf $7,7 \mu \mathrm{g} / 1$ an, während sie in den obersten $30 \mathrm{~m}$ zwischen 0,8 und $1,3 \mu \mathrm{g} / \mathrm{l}$ lagen. Die Phosphatzehrung, verursacht durch die Assimilation des Phytoplanktons, wirkte sich im Jahre 1966 bis in eine Tiefe von über $100 \mathrm{~m}$ aus. Während der Sommerstagnation existierten demnach vertikale Zirkulationsbewegungen, die durch den fliessenden Temperaturübergang vom Epi- zum Hypolimnion und unter Umständen durch Turbulenz in grösseren Tiefen, verursacht durch Zuflüsse [45], möglich wurden. Dieselbe Erscheinung trat in geringerem Masse auch im Vierwaldstättersee auf.

Tab. 8. Phosphatkonzentrationen ( $\mu \mathrm{g} \mathrm{P} / 1$ ] im Thunersee in den Jahren 1966 und 1967

\begin{tabular}{rccccc}
\hline $\begin{array}{l}\text { Tiefe } \\
{[\mathrm{m}]}\end{array}$ & 20.7 .66 & 26.10 .66 & 24.1 .67 & 11.4 .67 & 24.7 .67 \\
\hline 0,0 & 1,6 & 0,0 & 1,3 & 0,0 & 0,6 \\
1,0 & 3,7 & 0,0 & 1,2 & 0,0 & 0,5 \\
2,5 & 1,8 & 0,0 & 0,8 & 0,3 & 0,5 \\
5,0 & 1,0 & 0,0 & 1,2 & $0,5 \cdots$ & 0,6 \\
7,5 & 1,0 & 0,0 & 1,2 & 0,5 & 1,0 \\
10,0 & 1,0 & 0,0 & 1,1 & $0,6 \ldots$ & 0,6 \\
12,5 & 1,6 & 0,0 & 1,3 & 0,7 & 0,6 \\
15,0 & 0,8 & 0,0 & 0,8 & 0,8 & 0,9 \\
20,0 & 1,0 & 0,3 & 1,2 & 0,8 & 1,0 \\
50,0 & 2,6 & 0,3 & 1,9 & 2,3 & 3,5 \\
100,0 & 3,8 & 1,0 & 2,4 & 3,2 & 5,0 \\
200,0 & 16,0 & 27,8 & 7,7 & 5,6 & 8,0 \\
\hline
\end{tabular}

Tab. 9. Phosphatkonzentrationen $[\mu \mathrm{g} \mathrm{P} / 1]$ im Luganersee in den Jahren 1966 und 1967

\begin{tabular}{|c|c|c|c|c|}
\hline Tiefe $[\mathrm{m}]$ & 18.8 .66 & 27.1 .67 & 13.4 .67 & 27.7 .67 \\
\hline 0,0 & 4,4 & 44,0 & 22,0 & 2,7 \\
\hline 1,0 & 4,4 & 43,6 & 22,0 & 2,9 \\
\hline 2,5 & 5,3 & 44,0 & 22,0 & 2,9 \\
\hline 5,0 & 12,4 & 43,0 & 26,0 & 3,6 \\
\hline 7,5 & 10,4 & 43,2 & 29,0 & 53,3 \\
\hline 10,0 & 12,2 & 43,7 & 33,0 & 13,3 \\
\hline 12,5 & 15,3 & 42,9 & 35,0 & 24,4 \\
\hline 15,0 & 33,0 & 43,2 & 36,0 & 38,5 \\
\hline 20,0 & 40,4 & 43,3 & 38,0 & 48,2 \\
\hline 50,0 & 45,5 & 43,5 & 45,0 & 48,1 \\
\hline 100,0 & 47,2 & 46,5 & 47,0 & 48,5 \\
\hline 150,0 & 47,1 & - & - & - \\
\hline 200,0 & - & 44,2 & 45,0 & 50,0 \\
\hline
\end{tabular}

Luganersee: Tabelle 9

Die Phosphatkonzentration im Januar 1967 war über die ganze Wassersäule praktisch gleich, lag aber mit durchschnittlich 44,0 $\mu \mathrm{g} / 1 \mathrm{um}$ ein Vielfaches höher als vergleichbare Werte des Thuner- und Vierwaldstättersees. Die minimalste epilimnische 
$\mathrm{PO}_{4}-\mathrm{P}$-Konzentration wurde im Juli 1967 bei einem Wert von rund $3 \mu \mathrm{g} / \mathrm{l}$ beobachtet. Der starke Konzentrationsanstieg im Bereich des metalimnischen Sauerstoffminimums im Juli 1967 lässt auf eine starke Abbautätigkeit schliessen.

Manensee: Tabelle 10

Die Phosphatkonzentrationen waren bei allen Probenahmen sehr niedrig und übertrafen die Werte vom Thunersee nur unwesentlich. Die hohen Werte der tiefsten Proben vom Juni und August 1967 scheinen auf eine zu tiefe Entnahme zurückzuführen $z u$ sein; dadurch wurde aufgewirbeltes Sediment mitanalysiert.

Tab. 10. Phosphatkonzentrationen [ $\mu \mathrm{g} \mathrm{P} / 1]$ im Mauensee in den Jahren 1967 und 1968

\begin{tabular}{llccc}
\hline Tiefe $[\dot{\mathrm{m}}]$ & 16.5 .67 & 13.6 .67 & 14.8 .67 & $9.12 .68[40]$ \\
\hline 0,0 & 1,5 & 3,0 & 2,0 & 0,5 \\
1,0 & 1,5 & 2,0 & 2,2 & 0,5 \\
2,0 & - & - & 2,0 & 0,5 \\
2,5 & 0,5 & 2,0 & - & 0,5 \\
3,0 & - & 2,0 & 2,6 & 0,5 \\
4,0 & - & 8,0 & 4,0 & 0,5 \\
5,0 & 0,4 & - & 4,0 & 0,5 \\
6,5 & 1,9 & 47,0 & 518,0 & 0,5 \\
\hline
\end{tabular}

Partikulärer Phosphor (PP)

Der geformte oder partikuläre Phosphor stellt diejenige P-Komponente dar, die in organischem Material, das heisst zum grössten Teil im Phytoplankton, in geringem Masse auch in den tierischen Schwebeorganismen und in den Bakterien, inkorporiert worden ist. Obwohl angesichts der wechselnden Artenzusammensetzung keine konstante Beziehung zwischen PP und dem Phytoplanktonvolumen zu erwarten ist, dürfte diese Komponente in den vier untersuchten Seen doch ein approximatives Bild des "standing-crop" ergeben.

Stellen wir die höchsten und die tiefsten Mittelwerte [ $\mu \mathrm{g} P / 1]$ der trophogenen Schicht der einzelnen Seen in demselben Jahr einander gegenuiber, so erhalten wir folgendes Bild:

\begin{tabular}{lllrr}
\hline & & min. & $\max$. & $\Delta \mu \mathrm{g} P / 1$ \\
\hline Thunersee & $1966 / 67$ & 5,3 & 1,3 & 3,0 \\
Vierwaldstättersee & 1966 & 5,2 & 20,5 & 15,3 \\
& 1967 & 8,2 & 21,3 & 13,1 \\
Luganersee & $1966 / 67$ & 4,3 & 20,5 & 16,2 \\
Mauensee & $1967 / 68$ & 65,0 & 135,0 & 70,0 \\
\hline
\end{tabular}

Die Winterwerte aller Seen sind trotz der grossen Konzentrationsunterschiede der gelösten Nährstoffe ungefähr gleich, das heisst, die klimatischen Faktoren waren offenbar produktionsbegrenzend. Bemerkenswert sind die grossen Unterschiede der 
Maxima und der Differenzen der beiden Extremwerte. Es zeichnet sich dabei folgender Zusammenhang ab:

Je höher der absolut höchste Wert der durchschnittlichen PP-Konzentration der trophogenen Schicht, und je grösser die Differenz zwischen der höchsten und der tiefsten PP-Konzentration eines Jahres ist, desto höher ist die Produktion bzw. der Trophiegrad eines Sees.

\subsection{Stickstoff}

Der Stickstoff, wichtigster Baustein bei der Biosynthese der Eiweisskörper, kommt im See in drei verschiedenen Oxydationsstufen vor, nämlich als Ammonium, Nitrit und Nitrat. Dabei bildet das Nitrat den Hauptteil der im Wasser gelösten Stickstoffverbindungen, sofern in der ganzen Wassersäule des Sees genügend Sauerstoff vorhanden ist. Diese Tatsache sowie der Umstand, dass zum Zeitpunkt der Untersuchungen keine befriedigende Arbeitsmethode zur Analyse von gebundenem und gelöstem organischem Stickstoff in den vorhandenen verhältnismässig sehr niedrigen Konzentrationen vorlag, veranlasste uns, nur das Nitrat zu bestimmen.

Tab. 11. Nitvatkonzentrationen im Vievwaldstättersee in den Jahren 1965 bis 1967 (Angaben in $\left.\mathrm{mg} \mathrm{NO} \mathrm{NO}_{3} \mathrm{~N} / 1\right)$

\begin{tabular}{|c|c|c|c|c|c|c|c|c|c|c|c|}
\hline $\begin{array}{l}\text { Tiefe } \\
{[\mathrm{m}]}\end{array}$ & $\begin{array}{l}1965 \\
13.9\end{array}$ & 13.10 & 17.11 & $\begin{array}{l}1966 \\
13.1\end{array}$ & 16.2 & 14.3. & 14.4 . & 17.5 & 13.6 & 14.8 & 20.9 \\
\hline 0,0 & 0,20 & 0,15 & 0,23 & 0,37 & 0,32 & 0,33 & 0,21 & 0,15 & 0,15 & 0,10 & 0,05 \\
\hline 2,5 & 0,20 & 0,17 & 0,23 & 0,36 & 0,32 & 0,32 & 0,20 & 0,22 & 0,20 & 0,06 & 0,05 \\
\hline 5,0 & 0,21 & 0,26 & 0,24 & 0,26 & 0,37 & 0,32 & 0,23 & 0,26 & 0,23 & 0,12 & 0,11 \\
\hline 7,5 & 0,20 & 0,27 & 0,24 & 0,36 & 0,32 & 0,34 & 0,31 & 0,27 & 0,25 & 0,10 & 0,15 \\
\hline 10,0 & 0,24 & 0,27 & 0,24 & 0,37 & 0,32 & 0,32 & 0,34 & 0,28 & 0,26 & 0,16 & 0,19 \\
\hline 12,5 & 0,25 & 0,29 & 0,24 & 0,36 & 0,35 & 0,33 & 0,36 & 0,32 & 0,26 & 0,18 & 0,20 \\
\hline 15,0 & 0,27 & 0,32 & 0,25 & 0,37 & 0,35 & 0,34 & 0,36 & 0,32 & 0,27 & 0,20 & 0,25 \\
\hline 20,0 & 0,35 & 0,33 & 0,24 & 0,37 & 0,35 & 0,36 & 0,40 & 0,34 & 0,33 & 0,29 & 0,29 \\
\hline 30,0 & 0,40 & 0,37 & 0,35 & 0,37 & 0,35 & 0,38 & 0,39 & 0,41 & 0,38 & 0,37 & 0,42 \\
\hline 50,0 & 0,40 & 0,38 & 0,38 & 0,37 & 0,35 & 0,40 & 0,39 & 0,45 & 0,41 & 0,40 & 0,44 \\
\hline 71,0 & 0,40 & 0,40 & 0,39 & 0,40 & 0,37 & 0,42 & 0,42 & 0,45 & 0,41 & 0,45 & 0,44 \\
\hline Tiefe & 1966 & & & 1967 & & & & & & & \\
\hline$[\mathrm{m}]$ & 20.10 & 17.11. & 13.12 & 11.1. & 17.2 & 16.3. & 17.4. & 17.5 & 14.6. & 14.7 & 15.8 . \\
\hline 0,0 & 0,05 & 0,19 & 0,33 & 0,33 & 0,33 & 0,36 & 0,18 & 0,17 & 0,24 & 0,18 & 0,20 \\
\hline 2,5 & 0,05 & 0,19 & 0,32 & 0,34 & 0,33 & 0,36 & 0,17 & 0,17 & 0,24 & 0,26 & 0,10 \\
\hline 5,0 & 0,05 & 0,19 & 0,32 & 0,34 & 0,36 & 0,35 & 0,33 & 0,17 & 0,27 & 0,24 & 0,19 \\
\hline 7,5 & 0,21 & 0,20 & 0,32 & 0,34 & 0,34 & 0,39 & 0,31 & 0,23 & 0,27 & 0,30 & 0,21 \\
\hline 10,0 & 0,28 & 0,20 & 0,32 & 0,33 & 0,35 & 0,38 & 0,33 & 0,26 & 0,27 & 0,31 & 0,13 \\
\hline 12,5 & 0,33 & 0,24 & 0,34 & 0,33 & 0,35 & 0,38 & 0,33 & 0,26 & 0,30 & 0,35 & 0,21 \\
\hline 15,0 & 0,37 & 0,32 & 0,33 & $.0,34$ & 0,36 & 0,38 & 0,33 & 0,29 & 0,30 & 0,36 & 0,27 \\
\hline 20,0 & 0,43 & 0,33 & 0,35 & 0,33 & 0,35 & 0,38 & 0,33 & 0,35 & 0,36 & 0,39 & 0,36 \\
\hline 30,0 & 0,46 & 0,36 & 0,32 & 0,35 & 0,36 & 0,39 & 0,33 & 0,38 & 0,37 & 0,39 & 0,36 \\
\hline 50,0 & 0,47 & 0,36 & 0,41 & 0,35 & 0,35 & 0,39 & 0,38 & 0,43 & 0,40 & 0,42 & 0,36 \\
\hline 71,0 & 0,45 & 0,36 & 0,43 & 0,36 & 0,38 & 0,40 & 0,38 & 0,40 & 0,40 & 0,43 & 0,35 \\
\hline
\end{tabular}


Vierwaldstättersee: Tabelle 11

Der mittlere Gehalt an Nitrat-Stickstoff während der Vollzirkulation betrug knapp 0,4 mg/1. Die im Frühjahr einsetzende zunehmende Erwärmung des Wassers hatte zur Folge, dass eine bis in $20 \mathrm{~m}$ Tiefe reichende, durch die Assimilation des Phytoplanktons bewirkte Zehrung eintrat. Als minimalste Werte an der Oberfläche konnten im September und Oktober 1966 0,05 mg/l ermittelt werden.

Thunersee: Tabelle 12

Die Vollzirkulationswerte im Januar 1967 zeigten fast gleiche Werte wie diejenigen des Vierwaldstättersees, die Zehrung hingegen war mit $0,27 \mathrm{mg} \mathrm{NO}_{3}-\mathrm{N} / \mathrm{l}$ beinahe um $0,1 \mathrm{mg} \mathrm{NO}-\mathrm{N} / 1$ kleiner, liess sich dagegen bis weit in das Hypolimnion hinunter verfolgen. Aus diesem kleineren Nährstoffverbrauch und der grösseren Mächtigkeit der trophogenen Schicht lässt sich schliessen, dass der Thunersee oligotropher ist als der Vierwaldstättersee.

Tab. 12. Nitratkonzentrationen im Thunersee in den Jahren 1966 und 1967 (Angaben in $\mathrm{mg} \mathrm{NO}_{3}-\mathrm{N} / \mathrm{l}$ )

\begin{tabular}{clllll}
\hline Tiefe $[\mathrm{m}]$ & 20.7 .66 & 26.10 .66 & 24.1 .67 & 11.4 .67 & 24.7 .67 \\
\hline 0,0 & 0,11 & 0,18 & 0,35 & 0,32 & 0,08 \\
1,0 & 0,10 & 0,17 & 0,35 & 0,33 & 0,15 \\
2,5 & 0,10 & 0,15 & 0,33 & 0,32 & 0,10 \\
5,0 & 0,13 & 0,18 & 0,33 & 0,35 & 0,08 \\
7,5 & 0,13 & 0,17 & 0,35 & 0,36 & 0,09 \\
10,0 & 0,14 & 0,15 & 0,36 & 0,38 & 0,09 \\
12,5 & 0,17 & 0,19 & 0,36 & 0,36 & 0,17 \\
15,0 & 0,15 & 0,23 & 0,35 & 0,38 & 0,18 \\
20,0 & 0,20 & 0,36 & 0,34 & 0,36 & 0,23 \\
50,0 & 0,28 & 0,48 & 0,36 & 0,39 & 0,27 \\
100,0 & 0,30 & 0,46 & 0,39 & 0,42 & 0,29 \\
200,0 & 0,31 & 0,52 & 0,41 & 0,44 & 0,33 \\
\hline
\end{tabular}

Tab. 13. Nitratkonzentrationen im Luganersee in den Jahren 1966 und 1967 (Angaben in mg $\left.\mathrm{NO}_{3}-\mathrm{N} / 1\right]$

\begin{tabular}{cllll}
\hline Tiefe $[\mathrm{m}]$ & 18.8 .66 & 27.1 .67 & 13.4 .67 & 27.7 .67 \\
\hline 0,0 & 0,03 & 0,43 & 0,32 & 0,0 \\
1,0 & 0,02 & 0,43 & 0,34 & 0,0 \\
2,5 & 0,02 & 0,43 & 0,33 & 0,0 \\
5,0 & - & 0,41 & 0,38 & 0,0 \\
7,5 & 0,09 & 0,43 & 0,34 & 0,11 \\
10,0 & 0,18 & 0,46 & 0,38 & 0,22 \\
12,5 & 0,29 & 0,47 & 0,39 & 0,34 \\
15,0 & 0,38 & 0,48 & 0,40 & 0,40 \\
20,0 & 0,38 & 0,46 & 0,39 & 0,40 \\
50,0 & 0,41 & 0,46 & 0,47 & 0,38 \\
100,0 & 0,38 & 0,43 & 0,47 & 0,34 \\
150,0 & 0,33 & 0,39 & 0,45 & 0,26 \\
200,0 & - & 0,31 & 0,35 & 0,18 \\
\hline
\end{tabular}


Luganersee: Tabelle 13

Die Durchschnittskonzentration während der Homothermie im Winter lag mit etwa $0,45 \mathrm{mg} \mathrm{NO}-\mathrm{N} / 1$ deutlich über derjenigen unserer beiden nördlichen Alpenrandseen. Die Nitratzehrung im Hochsommer war so stark, dass im Jahre 1967 bis in $5 \mathrm{~m}$ Tiefe kein Nitrat gefunden wurde. Die deutliche Nitratabnahme am Grund ist dagegen, bei gleichzeitigem starkem Sauerstoffschwund, auf Denitrifikationsvorgänge zurückzuführen.

\section{Mauensee: Tabelle 14}

Die kleinsten Nitratwerte an der Oberfläche wurden zur Zeit der enormen Wasserblüte von Oscillatoria rubescens im Mai und Juni 1967 beobachtet. Ausgehend vom Wert, welcher während der Vollzirkulation im November 1966 durch die EAWAG (unveröffentlicht) ermittelt worden war, bedeutet dies eine Zehrung von 1,14 mg $\mathrm{NO}_{3}-\mathrm{N} / 1$. Obwohl der See im Mai 1967 schon stark geschichtet war, fand bis zur JuniProbenahme eine starke Nitratzufuhr zur Oberfläche statt, die aber sofort für die Assimilation gebraucht wurde. Daher wurde im Juni in der ganzen Wassersäule eine fast gleich hohe Nitratkonzentration beobachtet.

Tab. 14. Nitratkonzentrationen im Mauensee in den Jahren 1966 und 1967 (Angaben in mg $\mathrm{NO}_{3}-\mathrm{N} / \mathrm{ll}$

\begin{tabular}{lllll}
\hline Tiefe $[\mathrm{m}]$ & $30.11 .66[40]$ & 16.5 .67 & 13.6 .67 & 14.8 .67 \\
\hline 0,0 & 1,20 & 0,06 & 0,06 & 0,10 \\
1,0 & 1,20 & 0,06 & 0,05 & $\cdots$ \\
2,0 & 1,20 & - & 0,06 & 0,09 \\
2,5 & 1,20 & 0,25 & - & - \\
3,0 & 1,20 & - & 0,06 & 0,09 \\
4,0 & 1,20 & - & 0,05 & 0,08 \\
5,0 & 1,20 & 0,35 & - & 0,10 \\
6,5 & 1,20 & 0,29 & 0,05 & 0,10 \\
\hline
\end{tabular}

\subsection{Vertikale und zeitliche Änderung der Phytoplanktonzusammensetzung}

Jeder See ist den verschiedensten Einflüssen exogener Natur unterworfen, von denen wir generell zwei Gruppen unterscheiden können: 1. Einflüsse, die, über eine lange Zeitspanne gesehen, als konstant angenommen werden können (z.B. Sonnenlicht), und 2. Einflüsse, die sich schlagartig oder allmählich ändern, wie zum Beispiel die Wasserzufuhr oder die organische Belastung, welche hervorgerufen wird durch die Einleitung von Abwässern oder durch Umleitungen von Fliessgewässern, welche entweder im Zusammenhang mit Wasserkraftwerken oder mit einer FluBsanierung stehen. Die Gesamtheit der Einflüsse, die regelmässig und mit gleicher Intensität auf einen See einwirken, kann als Grundlage für eine dem See eigene Zusammensetzung seiner Lebewelt betrachtet werden. Da jeder See jedoch eine mehr oder weniger grosse, vom Wasservolumen und von der Durchflutung abhängige "Pufferwirkung» besitzt, mïssen die einzelnen, in ihrem Betrag veränderten Faktoren längere Zeit ihren Einfluss auf das Gewässer ausüben, bis die gesamten Wassermassen verändert sind. 
Die ersten Anzeichen einer Konzentrationsänderung der Nährstoffe kommt im veränderten Bild der Phytoplanktongesellschaft zum Ausdruck, die sich meistens insofern vom vorhergehenden unterscheidet, als für wenige oder vielfach nur eine Spezies derart ideale Bedingungen vorliegen, dass es zu einer Massenentwicklung derselben kommen kann. Tritt ein Organismus in derart grosser $Z$ ahl auf, dass er eine auffällige Verfärbung der Wasseroberfläche bewirkt, so spricht man von einer Wasserblüte. Ein solcher Zustand, der das Wachstum von Oscillatoria rubescens in einem solchen Ausmasse begünstigte, dass an der Oberfläche eine Fadenzahl von $1,5 \cdot 10^{7}$ je Liter gemessen wurde, konnte während der ersten beiden Probenahmen im Mauensee beobachtet werden. Oscillatoria rubescens tritt nur in Seen von fortgeschrittenem Eutrophierungsgrad auf und wird deshalb oft als Trophiezeiger angesehen. Um ihre ökologischen Ansprüche zu klären, wurden neben den chemischen Proben stets auch Planktonproben erhoben, mit lugolscher Lösung fixiert und im umgekehrten Mikroskop nach UTERMÖHL [28] ausgezählt. Dabei wurden nur diejenigen Arten zahlenmässig erfasst, die in einer statistisch gesicherten Anzahl vorhanden waren. Um das Phytoplankton der verschiedenen Seen untereinander vergleichen zu können, wurden dessen Volumina (Biomasse) berechnet $[5,46]$. Mehrere Male wurde darüber hinaus auch der normalerweise nicht erfasste Teil mitgezählt. Dabei machten diese Volumina im Maximum 5\% des gesamten Phytoplanktons aus.

2.261 Das Gesamtvolumen von Oscillatoria rubescens (GOV) und das restliche Phytoplanktonvolumen (RPV) in der beobachteten Wassersäule (Höhe $20 \mathrm{~m}$, Oberfläche $1 \mathrm{dm}^{2}$ ) im Verlauf der Untersuchungsperiode

Vierwaldstättersee: Abb. 10

In Abb. 10 fällt bei der Betrachtung des GOV auf, dass die kleinsten und die grössten Volumina in einem zeitlichen Abstand von 16 bzw. 15 Monaten auseinanderliegen, wenn davon ausgegangen wird, dass das grösste GOV des Jahres $1965 \mathrm{im}$ Juli auftrat (Untersuchungsbeginn). Die Zu- bzw. Abnahme des GOV erfolgte in den Jahren 1966 und 1967 sehr uneinheitlich. Relativ kurze Perioden positiver Bilanz aus Zuwachs, Zuwanderung, Auflösung und Sedimentation folgten auf ebenso kurze Zeitabschnitte, in denen eine ständige Verminderung des GOV zu verzeichnen war. Im Jahre 1965 dagegen blieb die Bilanz bis ans Jahresende negativ, was aus Abb. 11 gut ersichtlich ist. $\mathrm{Da}$ in den Wintermonaten die Alge infolge der Zirkulation auf eine grosse Wassersäule verteilt war, sank das GOV auf 15 bzw. 7•107 $\mu^{3} / 1$ in den Jahren 1966 bzw. 1967. Mit zunehmender Stabilität der Wassermassen wurde ein grosser Teil der Fäden in der trophogenen Schicht beobachtet. Der stetige zu jenen Zeiten erfolgte Anstieg der Wassertemperaturen bewirkte, dass nicht nur eine Verlagerung der Fäden, sondern auch ein stärkerer Zuwachs derselben an dieser Verschiebung schuld war. Auf Grund der Isothermen (Abb. 1) liess sich in den Jahren 1966 und 1967 eine Stabilisierung des Wasserkörpers im April feststellen. In den folgenden Monaten war das Wasser bis weit über eine Tiefe von $20 \mathrm{~m}$ geschichtet und erlaubte demnach keine grösseren Zirkulationsströmungen. Unter dieser Voraussetzung ist anzunehmen, dass ein erhöhtes GOV das Resultat einer positiven Bilanz aus Zuwachs, Auflösung und Sedimentation bedeutet. Der Verlauf des Gesamtvolumens des Phytoplanktons ohne Oscillatoria rubescens (RPV) zeigt, dass auch hier eine streng jährliche Periodi- 


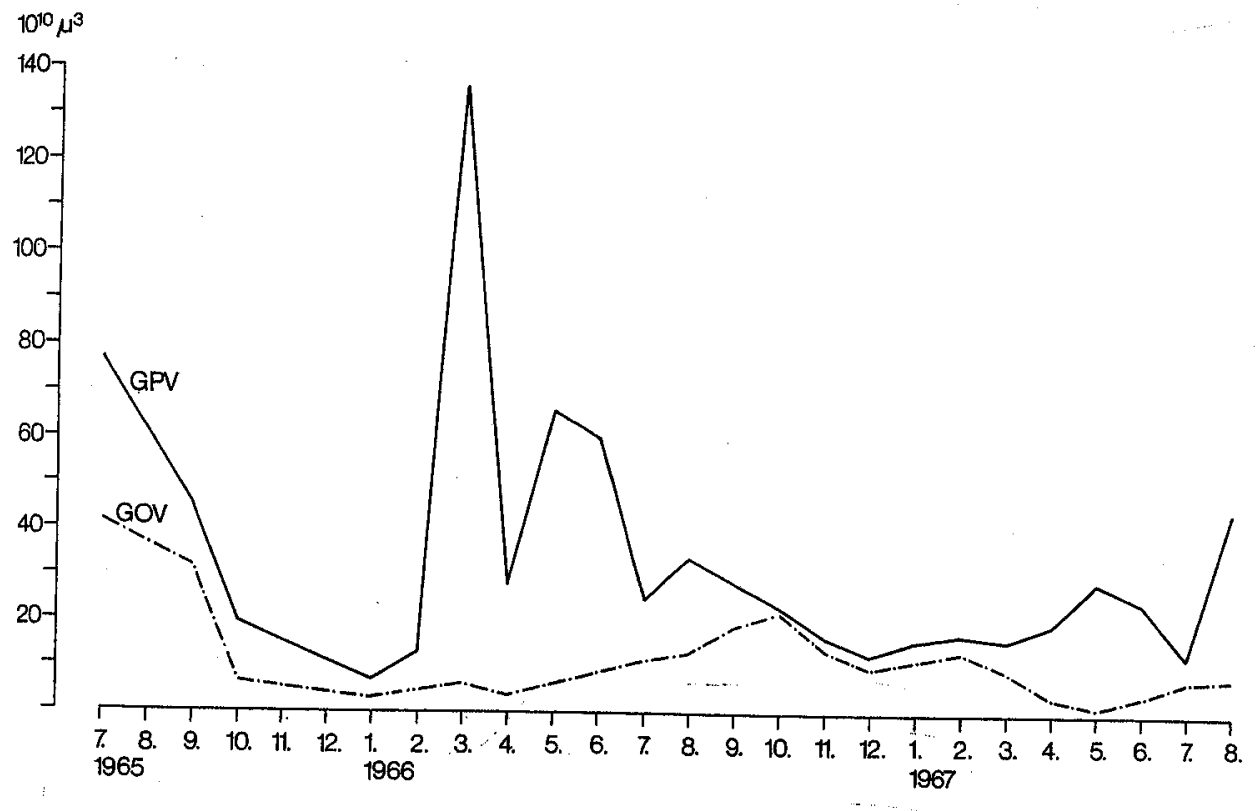

Abb. 10. Gesamtphytoplanktonvolumen (GPV) und Gesamt-Oscillatoria rubescens-Volumen (GOV) im Vierwaldstättersee in der Wassersäule von $20 \mathrm{~m}$ und $1 \mathrm{dm}^{2}$ Seeoberfläche in den Jahren 1965-1967.

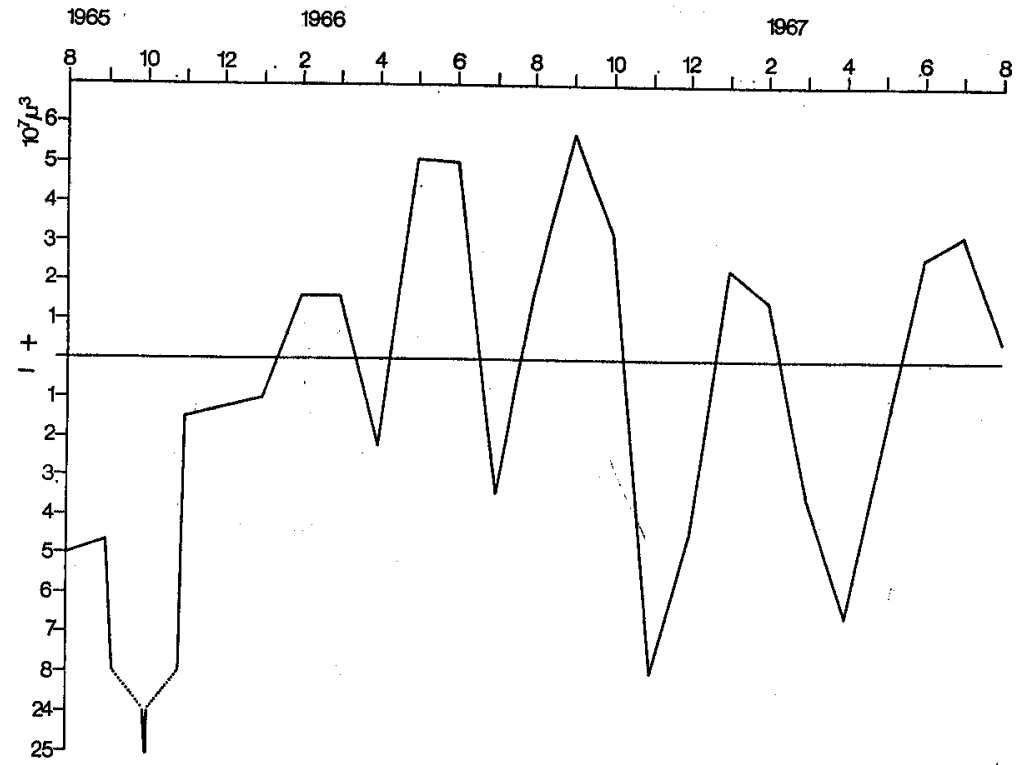

Abb. 11. Bilanz aus monatlichem Zuwachs und Sedimentation von Oscillatoria rubescens in der Wassersäule von $20 \mathrm{~m}$ und $1 \mathrm{dm}^{2}$ Seeoberfläche. 
zität der Minima und Maxima fehlt, was angesichts der heterogenen Zusammensetzung der Arten nicht verwunderlich ist. Man darf jedoch bei Folgerungen, die aus dieser graphischen Darstellung hervorgehen, nicht vergessen, dass die einzelnen Werte den "standing crop» einer einzigen Probenahme im Laufe eines Monats darstellen. Phytoplankter mit einer kurzen Generationszeit können zwischen zwei Probenahmen zu einer Massenentfaltung kommen, wieder verschwinden und sich so der Beobachtung entziehen. Der prozentuale Volumenanteil von Oscillatoria rubescens am Phytoplankton schwankte zwischen 95\% im Oktober 1966 und 4,5\% in den Monaten. März 1966 und Mai 1967. Während im Jahre 1965 über drei Monate hinweg ein Anteil von mehr als 50\% zu verzeichnen war, wurde diese Grenze im Winter 1966/67 während sechs Monaten übertroffen.

\section{Thunersee: Abb. 12}

Das GOV der Monate Juli und Oktober 1966 war mit 7640 bzw. $17060 \cdot 10^{7} \mu^{3}$ beinahe gleich gross wie dasjenige der Monate Juni und Oktober 1965 [49]. Der Wert vom Oktober 1966 bedeutete das höchste beobachtete GOV, lag jedoch etwa 60\% unter dem Maximalwert im Vierwaldstättersee vom Juli 1965. Auffallend war die darauffolgende stetige Verminderung des GOY, das während der letzten Probenahme im Juli 1967 nur noch $277 \cdot 10^{7} \mu^{3}$ betrug. Die prozentualen Anteile am Gesamtphytoplanktonvolumen (GPV) erreichten nie 50\% und lagen meistens unter 20\%. Somit kann im Vergleich zum Vierwaldstättersee gesagt werden, dass die damaligen Bedingungen für ein Überhandnehmen dieser Alge nicht vorhanden waren. Das RPV lag auf fast derselben Höhe wie im Vierwaldstättersee, wenn auch Spitzenvolumen fehlten oder angesichts der grossen Probenahmeabstände möglicherweise nicht erfasst worden waren.

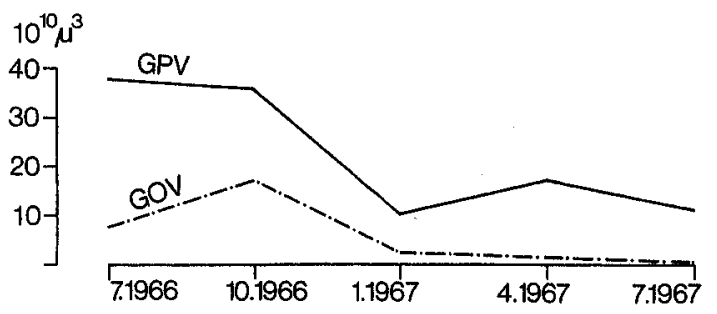

Abb. 12. Gesamtphytoplanktonvolumen (GPV) und Gesamt-Oscillatoria rubescens-Volumen (GOV) im Thunersee in der Wassersäule von $20 \mathrm{~m}$ und $1 \mathrm{dm}^{2}$ Seeoberfläche in den Jahren 1966 und 1967.

Luganersee: Abb. 13

Im Luganersee wurde das grösste GOV im August 1966 mit $3320 \cdot 10^{7} \mu^{3}$ gemessen. Es sank bis Januar 1967 unter den zehnten Teil und blieb sowohl im April wie auch im Juli 1967 auf diesem Stand. Der höchste prozentuale Anteil von Oscillatoria rubescens am GPV wurde ebenfalls im August 1966 mit 7\% beobachtet. Dieser Anteil sank bis Januar 1967 auf etwa 2\% ab. Im April und Juli 1967 lagen die Werte mit un-' gefähr $1 \%$ am tiefsten. 


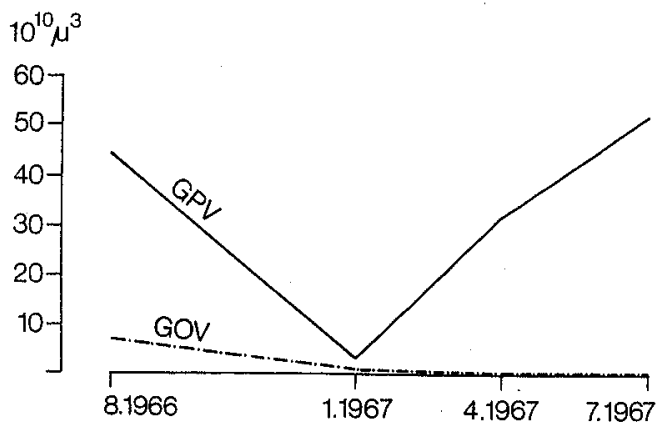

Abb. 13. Gesamtphytoplanktonvolumen (GPV) und Gesamt-Oscillatoria rubescens-Volumen (GOV) im Luganersee in der Wassersäule von $20 \mathrm{~m}$ und $1 \mathrm{dm}^{2}$ Seeoberfläche in den Jahren 1966 und 1967.

\section{Mauensee}

Die mikroskopischen Untersuchungen der Lugolproben ergaben eine Breite mancher Oscillatoriafäden um $4 \mu$. Dies bedeutet die untere Grenze für Oscillatoria rubescens. Das GOV in der Wassersäule von $7 \mathrm{~m}$ erreichte im Mai 1967 einen Wert von über $152 \cdot 10^{7} \mu^{3}$. Im Juni betrug es immer noch $133 \cdot 10^{7} \mu^{3}$, doch hatte sich fast die ganze Algenmasse auf eine Wasserschicht von $4 \mathrm{~m}$ verteilt. Die Proben vom August 1967 enthielten nur noch eine geringe Anzahl Fäden, was sich im kleinen GOV von $85 \cdot 10^{7} \mu^{3}$ manifestierte. Die prozentualen Anteile am GPV sanken von anfänglich 98\% im Mai auf 1\% im August 1967.

\subsection{Die vertikale Verteilung von Oscillatoria rubescens}

Eine ausgeprägte Verhaltensweise von Oscillatoria rubescens stellt die mit fortschreitender Stabilisierung der Wassermassen einsetzende Einschichtung dar $(1,8,16$, 20, 22), welche anhand der Abbildungen 14-17 verfolgt werden kann.

\section{Vierwaldstättersee: Abb. 14}

Im Sommer 1965 konnte ein ausgeprägtes Maximum beobachtet werden, bei dem der Hauptanteil in Tiefen zwischen 7,5 m und 12,5 m gefunden wurde. Diese Schicht wurde durch eine verminderte Fadenzahl in $10 \mathrm{~m}$ Tiefe in zwei Spitzen geteilt. Am Ende der Stagnation (September 1965) hatte sich ein einziges scharfes Maximum in $10 \mathrm{~m}$ Tiefe gebildet, wobei aber durch die nun schon einsetzende Teilzirkulation ein Teil der Fäden bis an die Oberfläche befördert worden war. Bewegten sich im Juli die Oscillatoria rubescens-Volumina oberhalb der ausgeprägten Schicht noch zwischen $8 \cdot 10^{7}$ und $44 \cdot 10^{7} \mu^{3} / 1$, so lagen sie nun oberhalb $7,5 \mathrm{~m}$ durchwegs über $100 \cdot 10^{7} \mu^{8} / 1$. Die in den folgenden Monaten in immer grössere Tiefen reichende Zirkulation verteilte die Alge bis in den März 1966 hinein mehr oder weniger gleichmässig $\left(15 \cdot 10^{7}\right.$ bis $\left.30 \cdot 10^{7} \mu^{3} / 1\right)$. Vom April 1966 an wurde eine immer stärker werdende Tendenz zur Einschichtung bemerkt. Gleichzeitig sank das Maximum von 5-7,5 m im Juli auf

Abb. 14. Vertikale Verteilung von Oscillatoria rubescens $(\longrightarrow$ ) und des restlichen Phytoplanktons (- -) im Vierwaldstättersee. 


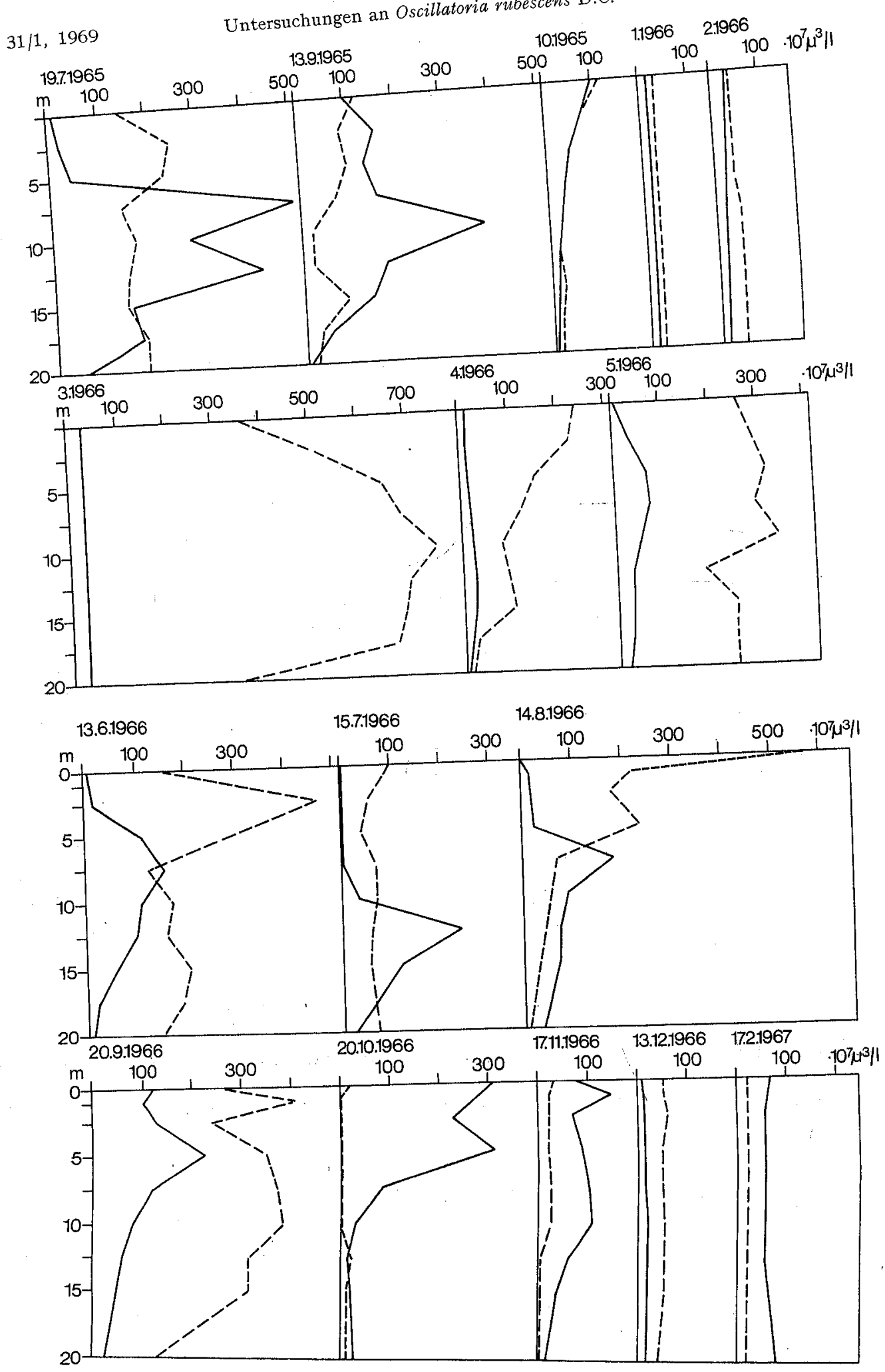



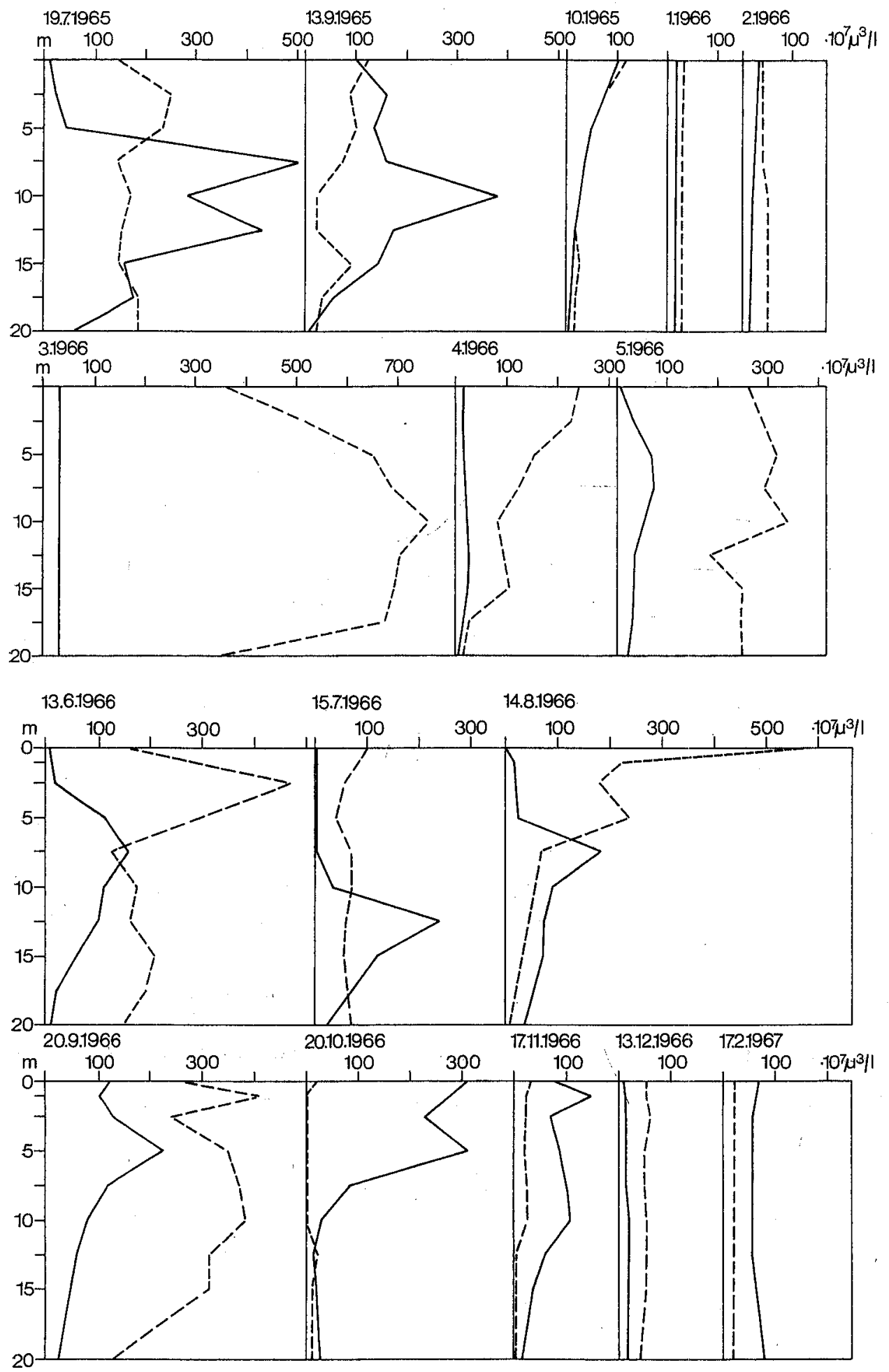


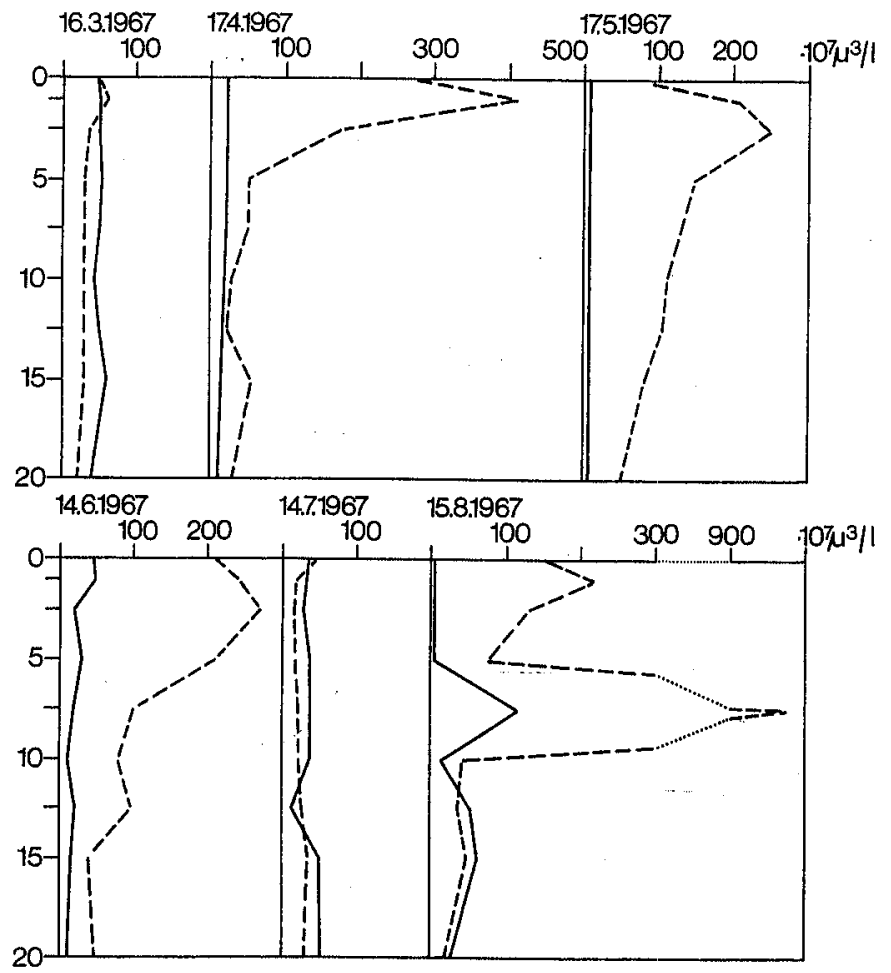

$12,5 \mathrm{~m}$, womit es die tiefste Lage erreicht hatte. Vom August bis Oktober zeichnete sich die umgekehrte Entwicklung ab; das Maximum stieg allmählich bis auf $5 \mathrm{~m}$ an. Die noch stabilen Wassermassen wurden im Oktober durch einen Sturm kurz vor der Probenahme aus dem Gleichgewicht gebracht, wobei ein Teil der Algen, die sich in einer etwa $5 \mathrm{~m}$ Tiefe gelegenen Schicht befanden, teilweise an die Oberfläche gebracht wurden. In den folgenden Monaten wurde die Alge durch die Zirkulation zusehends gleichmässiger über einen grossen Teil der gesamten Wassersäule verteilt. Im Gegensatz zum Vorjahr blieb diese Verteilung bis Mitte Mai 1967 vollständig erhalten. $\mathrm{Zu}$ diesem Zeitpunkt bewegte sich das GOV um $6 \cdot 10^{7} \mu^{3}$. Im Juni zeichnete sich der Beginn einer Wachstumsperiode ab, wobei aber noch keine Aussage über die Tiefenlage eines sich bildenden Maximums erkennbar war. Erst im August hatte sich ein kleines; aber eindeutiges Maximum in 7,5 m gebildet, an das sich ein zweites, schwächeres mit der grössten Dichte zwischen 12,5 und $15 \mathrm{~m}$ anschloss.

\section{Thunersee: Abb. 15}

Die vierteljährlich erfolgten Probenahmen erlaubten keine strenge Verfolgung der vertikalen Verteilung. Trotzdem war eine gleichsinnige Verschiebung der Maxima festzustellen. Lag das grösste Oscillatoria rubescens-Volumen mit ungefähr $102 \cdot 10^{7} \mu^{3}$ im Juli 1966 in 12,5 m, so stieg es im Laufe des Spätsommers bis in Tiefen zwischen 2,5 und $5 \mathrm{~m}$ auf. Nach der völlig gleichmässigen Verteilung im Januar 1967 mit 
durchschnittlich $9 \cdot 10^{7} \mu^{3} / 1$ hatte sich im folgenden April erst ein schwaches Maximum in 2,5 m Tiefe gebildet. Im Juli lag ein Maximum in $15 \mathrm{~m}$ vor, doch erreichte das dortige Oscillatoria rubescens-Volumen nur $6 \cdot 10^{7} \mu^{3} / 1$. Oberhalb 7,5 $\mathrm{m}$ konnten überhaupt keine Fäden mehr nachgewiesen werden.

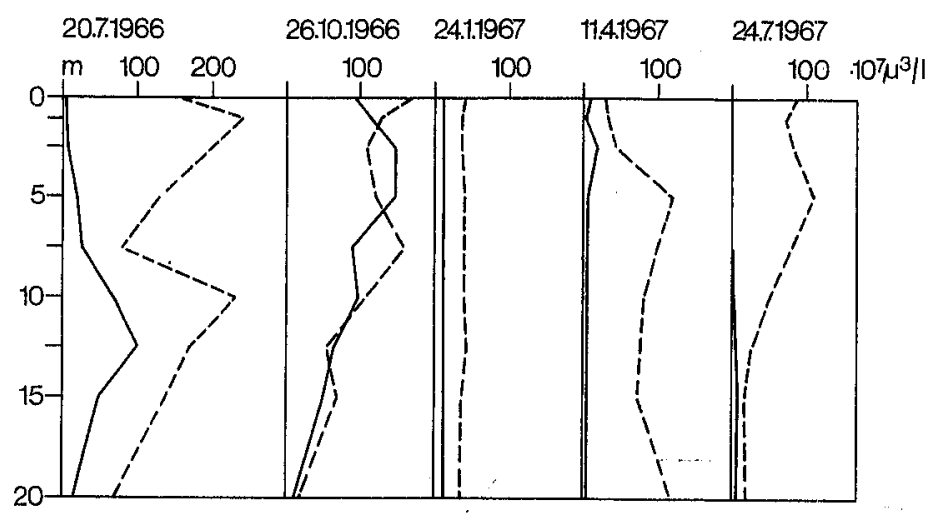

Abb. 15. Vertikale Verteilung von Oscillatoria rubescens (___-) und des restlichen Phytoplank tons (- - ) im Thunersee.

Luganersee: Abb. 16

Das Maximum im August 1966 war viel schwächer und weniger ausgeprägt als im Thuner- und Vierwaldstättersee und lag zwischen 7,5 und $10 \mathrm{~m}$ Tiefe $\left(40 \cdot 10^{7} \mu^{3} / 1\right)$. Während der zwei folgenden Probenahmen im Januar und April 1967 verteilte sich die Alge gleichmässig über die gesamte untersuchte Wassersäule mit Konzentrationen von ungefähr $0,5 \cdot 10^{7} \mu^{3} / 1$. Entgegen allen bisherigen Beobachtungen hatte sich im Juli 1967 ein Maximum mit etwa $13 \cdot 10^{7} \mu^{3} / 1$ an der Oberfläche gebildet. Da in den drei folgenden Tiefenstufen keine Fäden beobachtet werden konnten, kann die Ursache nicht - wie im Oktober 1966 im Vierwaldstättersee (Abb. 14) - in einer Störung der stabilen Wassermassen durch einen äussern Einfluss gesucht werden. Die Fäden waren kurz und mit dem für Oscillatoria rubescens charakteristischen, sehr ausgeprägten Köpfchen versehen, einem Merkmal, das erfahrungsgemäss während einer Wachstumsphase der Alge vorhanden ist. Ungewiss bleibt, wie wieit diese Fäden noch völlig intakt waren. Unterhalb $10 \mathrm{~m}$ lagen die Volumina um $10^{5} \mu^{3} / 1$.

Mauensee: Abb. 17

In den Monaten Mai und Juni 1967 wurden die obersten Wasserschichten durch eine grosse Massenentfaltung der Alge stark rot gefärbt. So konnten an der Oberfläche $15 \cdot 10^{6} \mathrm{bzw} .9 \cdot 10^{6}$ Fäden pro Liter gezählt werden, was bei Berücksichtigung der verschiedenen durchschnittlichen Längen Volumina von $68 \cdot 10^{9} \mathrm{bzw} .46 \cdot 10^{9} \mu^{3} / 1$ ergab. Die Proben vom August enthielten nur noch eine geringe Anzahl Fäden $\left(2 \cdot 10^{3}-6 \cdot 10^{3} / 1\right)$, die mehr oder weniger gleichmässig auf die Wassersäule verteilt waren. 


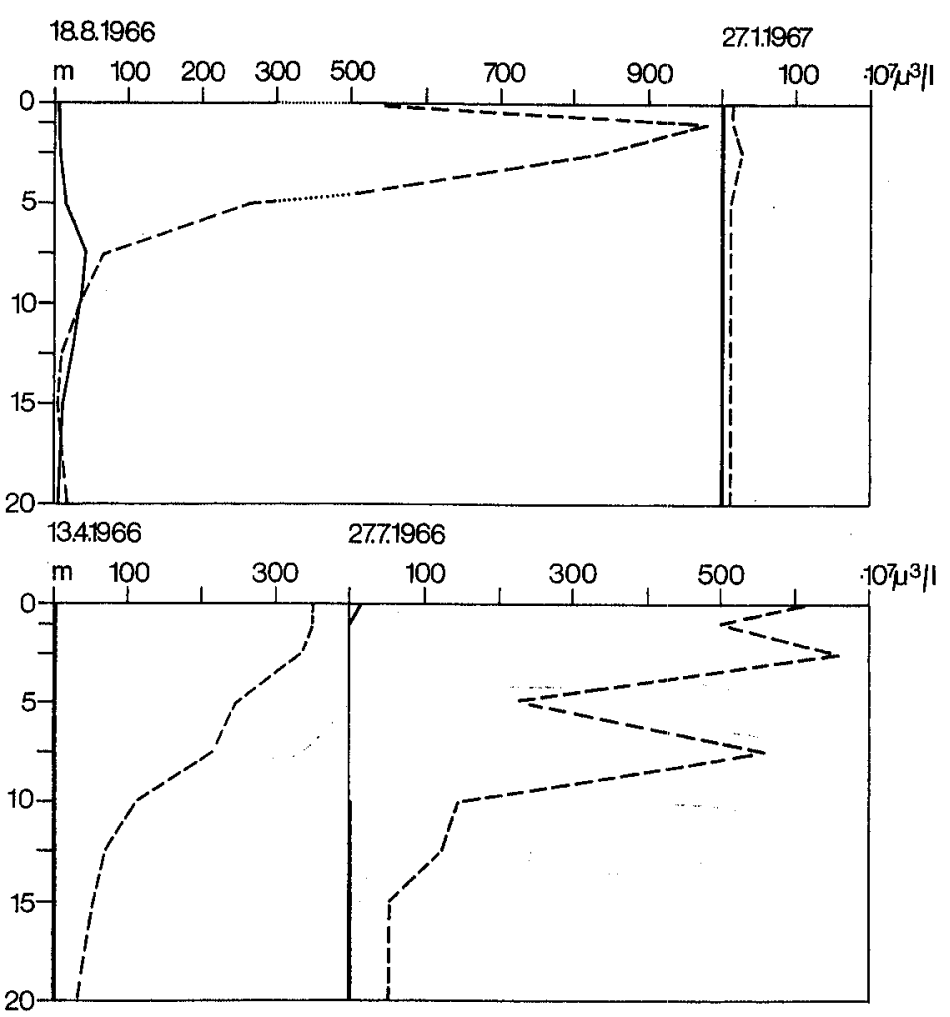

Abl. 16. Vertikale Verteilung von Oscillatoria rubescens (-) und des restlichen Phytoplanktons (-- ) im Luganersee.
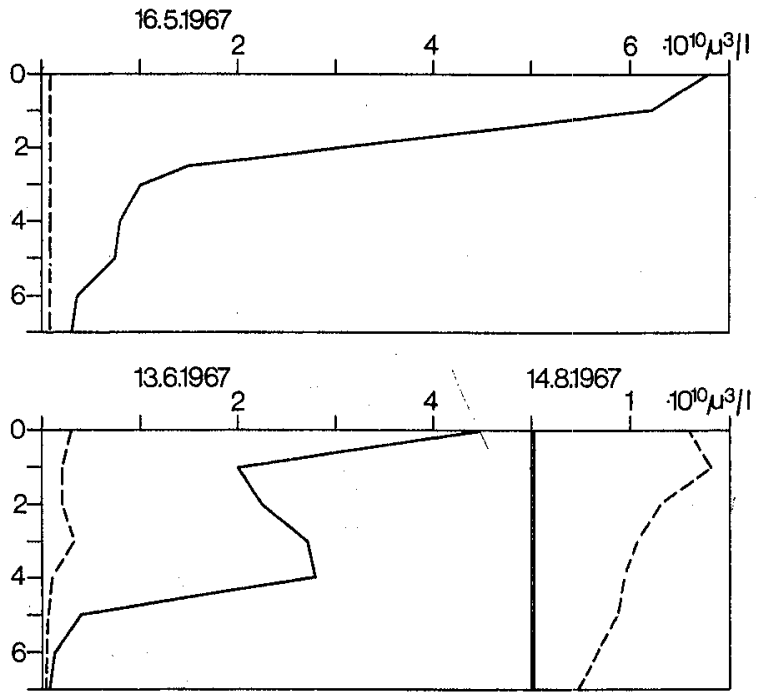

Abb. 17. Vertikale Verteilung von Oscillatoria rubescens (-) und des restlichen Phytoplanktons (- - ) im Mauensee. 


\subsection{Das übrige Phytoplankton}

Vierwaldstättersee: Tabelle 15

Die Cyanophyta waren in grösseren Mengen nur durch Oscillatoria rubescens D.C. vertreten. Nur in einigen Proben der Monate September 1965 und August 1966 fanden sich eine Anzahl Gomphosphaeria lacustris Chod. und Anabaena flos-aquae (Lyngb.) Bréb., im Januar 1966 nur Anabaena flos-aquae. Einen verhältnismässig kleinen Anteil am RPV hatten die Chlorophyta, welche nur im August und September 1966 eine dominierende Rolle spielten. Ulothrix amphigranulata Skuja, Coelastrum reticulatum (Dang.) Senn., Scenedesmus quadricauda Turp.em.Chod., Scenedesmus obliquus (Turp.) Kütz., Oocystis lacustris Chod. und die als « $\mu$-Algen» bezeichneten kleinen, kugeligen, meist zur Gattung der Chlovella gehörenden Grünalgen waren die volumenmässig am stärksten ins Gewicht fallenden Arten im August. Im September 1966 kam es zu einer Massenentfaltung von Ulothrix amphigranulata Skuja, bei der das durchschnittliche Volumen, berechnet auf eine $15 \mathrm{~m}$ hohe Wassersäule, $320 \cdot 10^{7} \mu^{3} / 1$ betrug. Unter den Chrysophyta waren die Diatomeen immer vertreten. Neben Tabellaria fenestrata (Lyngb.) Kg. fanden sich Stephanodiscus hantzschii Grun. (März 1966), Cyclotella spp. (März 1966), Synedra acus var. delicatissima (W. Sm.) Grun. und Synedra ulna (Nitzsch) Ehrnb., Asterionella formosa Hasall und Fragilaria crotonensis Kitton dagegen blieben zahlen- und volumenmässig weit hinter den oben genannten Arten zurück. Im Frühsommer 1966 entwickelte sich Dinobryon spp. während der Monate Mai, Juni und Juli sehr stark, verschwand jedoch bis zur August-Probenahme ganz.

Auffallend war die immerwährende Präsenz der Flagellaten, die meistens Rhodomonas lacustris Pascher et Ruttner, Cryptomonas ovata Ehrnb. und die unter der Bezeichnung "diverse Flagellaten» figurierenden kleinen, oft farblosen Arten umfassten. Die ebenfalls zu den Pyrrophyta gehörenden Peridineen waren durch Ceratium hirudinella (O. V. Müller) (September 1965) und Gymnodinium helveticum Penard (Juli bis Oktober 1965 und Mai 1966) vertreten, wobei ihr RPV-Anteil in einem sehr bescheidenen Rahmen blieb.

\section{Thunersee: Tabelle 16}

Oscillatoria rubescens spielte in diesem See die dominierende Rolle unter den Cyanophyta. Einen wesentlichen Unterschied zum Vierwaldstättersee machte das relativ häufige Vorkommen von Anabaena flos-aquae in den Sommermonaten aus. Im Juli 1967 wurden ausserdem Pseudoanabaena catenata Lauterb. in kleinen Mengen beobachtet. Sehr schwach vertreten waren die Chlorophyta. Einzig Mougeotia sp. (Oktober 1966 und Januar 1967) und die «p-Algen» traten im Juli 1967 etwas stärker hervor. Beachtenswert war die ständige Anwesenheit von Diatomeen (Chrysophyta), die in drei der fünf Probenahmen volumenmässig dominierten. Waren im Vierwaldstättersee Tabellaria fenestrata, Stephanodiscus hantzschii und Cyclotella spp. weitaus am häufigsten vertreten, so dominierten im Thunersee neben Tabellaria fenestrata die Formen Synedra acus var. delicatissima, Diatoma elongatum (Lyngb.) Ag. und Fragilaria crotonensis. Die Flagellaten waren in jeder Beobachtungszeit durch die Arten Rhodomonas lacustris, Rhodomonas lens, Cryptomonas ovata und die «diversen Flagellaten» vertreten, eine Erscheinung, die sich mit den Beobachtungen im Vierwald- 


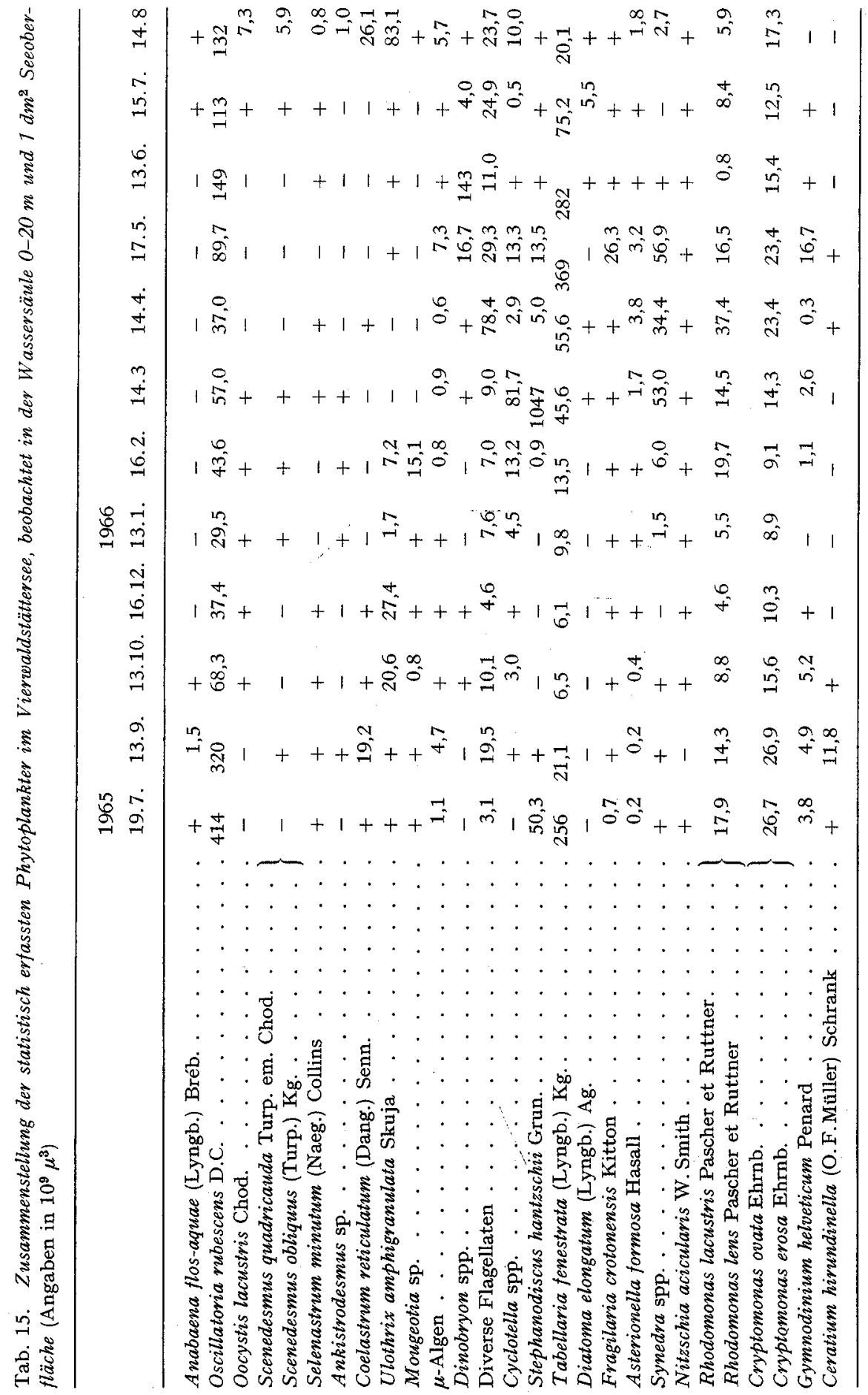




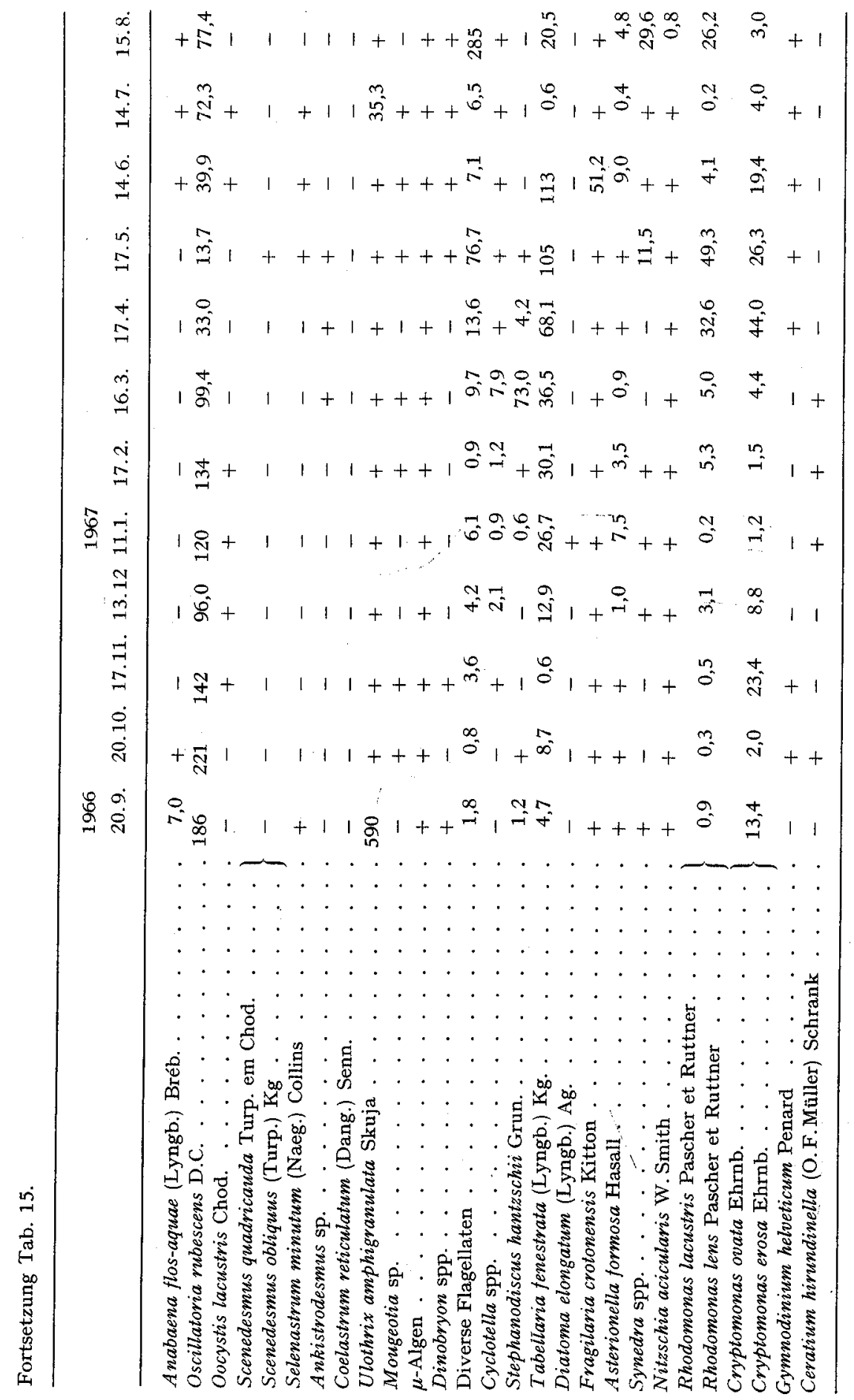


34

U. Zimmermann

Hydrologie

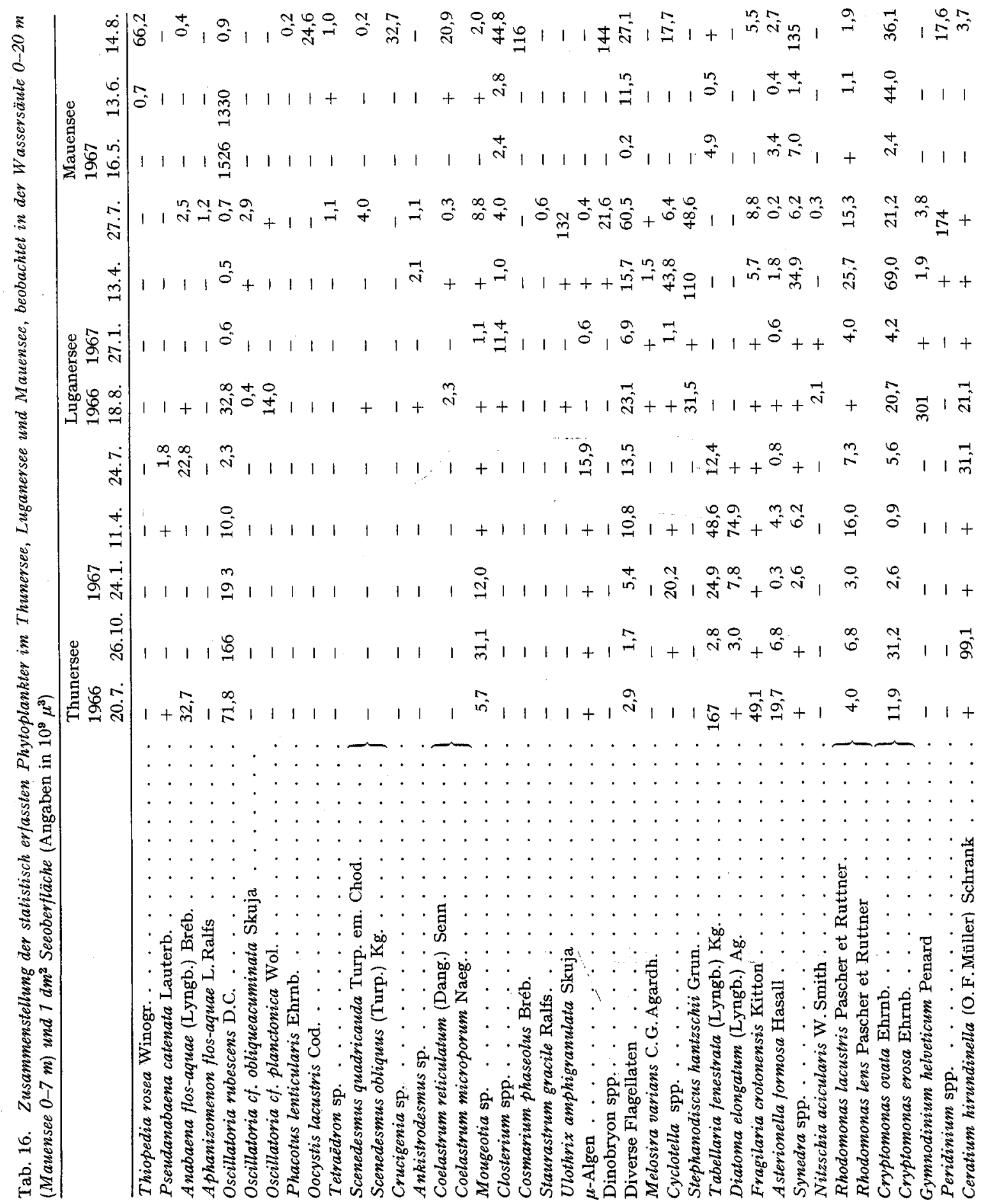


stättersee deckt. Im Oktober 1966 traten grosse Mengen von Ceratium hirudinella auf, welche volumenmässig über das RPV dominierten. Eine wesentlich kleinere Anzahl Individuen kam ausserdem im Juli 1967 vor, während in den Januar- und Aprilproben nur vereinzelte Exemplare vorhanden waren.

\section{Luganersee: Tabelle 16}

Bei den Cyanophyta traten im August 1966 neben Oscillatoria rubescens die beiden andern zur Gattung der Oscillatoriaceen gehörenden Arten Oscillatoria cf. obliqueacuminata Skuja und Oscillatoria cf. planctonica Wol. stärker auf, wobei die zuletztgenannte Art volumenmässig weit hinter der anderen Form zurückblieb. Im Juli 1967 konnten neben Oscillatoria rubescens, Oscillatoria cf. obliqueacuminata und Aphanizomenon flos-aquae (Lyngb.) Bréb. beobachtet werden, wobei sie ein wesentlich grösseres Volumen - berechnet auf die $20 \mathrm{~m}$ mächtige Wassersäule - aufwiesen als Oscillatoria rubescens. Im Januar 1967 traten keine, im folgenden April nur vereinzelte Individuen dieser beiden Blaualgen auf. Die Chlorophyta blieben bis auf den Juli 1967, als eine grössere Anzahl Ulothrix amphigranulata vorhanden war, auf einer bescheidenen Individuenzahl. Die Diatomeen (Chrysophyta) traten nur-im April 1967 dominierend auf. Die Hauptformen waren Stephanodiscus hantzschii, Stephanodiscus alpinus, Synedra acus var. delicatissima und Cyclotella spp. Im Gegensatz zum Vierwaldstätterund Thunersee war Tabellaria fenestrata nur vereinzelt anzutreffen.- Eine auffallende Häufigkeit von Fragilaria crotonensis wurde im Juli 1967 beobachtet. Die Pyrrophyta waren sehr zahlreich vertreten. Eine Massenentwicklung von Gymnodinium helveticum wurde im August 1966 angetroffen mit einem Spitzenvolumen von $750 \cdot 10^{7} \mu^{3} / 1$ in $1 \mathrm{~m}$ Tiefe. Im Januar 1967 war diese Alge fast gänzlich verschwunden. Erst im April und Juli desselben Jahres konnte sie - wenn auch in viel kleinerer Zahl - wieder beobachtet werden. An ihre Stelle trat im Juli Peridinium spp., wobei das höchste Gesamtvolumen in $2,5 \mathrm{~m}$ Tiefe $240 \cdot 10^{7} \mu^{3} / 1$ betrug. Relativ hohe Volumenwerte wurden in den Proben vom Juli 1966, April und Juli 1967 durch die Flagellaten erreicht, wobei die Arten Cryptomonas ovata, Cryptomonas erosa, Rhodomonas lacustris, Rhodomonas lens sowie die "diversen Flagellaten" vorherrschten.

\section{Mauensee: Tabelle 16}

Zur Zeit der Massenentfaltung von Oscillatoria rubescens waren andere Phytoplanktonarten relativ schwach vertreten. Das RPV machte in den beiden Monaten nur etwa $2 \%$ bzw. $5 \%$ des GPV aus. Bemerkenswert war die fast vollständige Abwesenheit der Grünalgen. Die qualitative Zusammensetzung glich eher den andern drei untersuchten Seen während der Wintermonate als einem eutrophen Flachgewässer. Mit der starken Abnahme des GOV im Laufe des Juli und August stieg das RPV auf $75 \cdot 10^{10} \mu^{3}$ an, was beinahe $100 \%$ des GPV ausmachte. Davon waren mehr als $35 \%$ Grünalgen, je ein Viertel Dinobryon spp. und Diatomeen, und knapp 10\% Flagellaten. Der Rest entfiel auf Anabaena flos-aquae, Peridinium spp. und Thiopediarosea Winogr.

2.264 Die Veränderung der spektralen Transparenz im Laufe der Zeit unter Berücksichtigung des Phytoplanktons.

Das Ausmass der Eindringtiefe des monochromatischen Lichtes im Laufe des Jahres ist, als wichtigste Ursache, auf eine Vermehrung oder Verminderung des Phyto- 
planktons und auf eine Gehaltsänderung an gelösten Stoffen zurückzuführen. Um die Lichtverhältnisse in den verschiedenen Monaten $\mathrm{zu}$ vergleichen, wurde der Verlauf derjenigen Tiefe verfolgt, in der die Intensität des jeweiligen Spektralbereiches auf $1 \%$ der Oberflächenintensität $I_{0,05}$ abgesunken war (Abb. 5).

\section{Vierwaldstättersee:}

Die maximalen Eindringtiefen der verschiedenen Lichtqualitäten wurden auffallenderweise nicht zur selben Zeit erreicht, ein Hinweis darauf, dass die jeweils im Wasser vorherrschenden Substanzen und Organismen verschiedene Absorptionsmaxima besitzen. Der Vergleich von Abb. 5 mit Abb. 10 lässt folgendes aussagen: Die Lichtabsorption aller fünf Spektren lief von Mai bis August 1966 mehr oder weniger gleichsinnig wie das GPV derselben Zeit, welches aus weniger als 50\% Oscillatoria rubescens bestand. Das sehr grosse RPV im September, verursacht durch eine starke Entwicklung von Ulothrix amphigranulata, hatte keinerlei Auswirkung auf die optischen Eigenschaften des Wassers, die Transmissionswerte erhöhten sich sogar noch. Im Oktober ging das GPV stark zurück. Dies hatte eine zum Teil starke Vergrösserung des Transmissionskoeffizienten der Spektralbereiche von BG12, VG9 und RG2 zur Folge. Im November 1966 und später folgten die Eindringtiefen mehr oder weniger dem Verlauf des GOV bis zu jenem Moment, in dem der GOV-Anteil unter 50\% fiel (März/April 1967). Das Lichtklima wurde daraufhin hauptsächlich durch das RPV beeinflusst.

\section{Thunersee:}

Bei der Gegenüberstellung der beiden Abbildungen 5 und 12 zeigte sich eine mehr oder weniger gute Úbereinstimmung zwischen dem RPV und der Transparenz im Wellenbereich $3700 \AA$ bis $6750 \AA$. Die Verdoppelung des GOV im Oktober 1966 gegenüber demjenigen vom Juli 1966 wirkte sich überhaupt nicht aus, obwohl sich das GPV auf fast derselben Höhe hielt. Der Anstieg der 1\%-Transmissionsgrenze bei niedrigerem GPV im Juli 1967 könnte auf eine Erhöhung der anorganischen Trübstoffe, vorwiegend hervorgerufen durch die biogene Entkalkung, zurückzuführen sein.

\section{Luganersee:}

Hatte das GOV im Thunersee keinen Einfluss auf die Transparenz der verschiedenen Wellenlängen, so galt dies auch für den Luganersee (Abb. 5), denn die GOVWerte blieben noch erheblich unter denjenigen des Thunersees (Abb. 12). Die Eindringtiefen der verschiedenen Filterbereiche verhielten sich bis im April 1967 ähnlich dem Verlauf des GPV. Die einzige Abweichung war im Filterbereich von OG.1 zu beobachten. Die grösste Transparenz wurde im April 1967 gemessen. Im Juli 1967 hingegen war nur bei den Wellenlängen von VG 9 und $O G 1$ eine dem zunehmenden GPV entsprechende Verminderung der Transparenz zu verzeichnen. UG $1+$ BG 12 und BG 12 wiesen nur noch eine kleine Abschwächung der Transparenz auf, während bei RG2 und RG 5 sogar eine Abnahme derselben erfolgte. Ulothrix amphigranulata und Peridinium spp. stellten den Hauptanteil an der Vergrösserung des GPV (Tabelle 16). Da Ulothrix amphigranulata unter den Bedingungen, die im Vierwaldstättersee im September 1966 herrschten, keinen Einfluss auf die optischen Verhältnisse des Wassers hatte (siehe S.10), kann auch hier angenommen werden, dass die Verminderung 
der Durchlässigkeit in den Wellenlängen zwischen $4230 \AA$ und $6500 \AA$ auf Peridinium spp. zurückzuführen ist.

\section{Mauensee:}

In Tabelle 17 wurden die spektralen Eindringtiefen $\left(1 \% I_{0,05}\right)$ der Monate Juni und August 1967 und die dazugehörenden GPV und GOV einander gegenübergestellt. Im Juni bestand das GPV zu 96\% aus Oscillatoria rwbescens, während im August diese Alge praktisch verschwunden war. Es ist nun interessant, die spektrale Absorption in den Monaten Juni und August miteinander zu vergleichen, da damals qualitativ ganz verschiedene Phytoplanktonpopulationen vorlagen. Es wurden nun diejenigen $1 \%$ Intensitätstiefen theoretisch ermittelt, die - bei gleicher qualitativer Phytoplanktonzusammensetzung wie im Juni - bei einem GPV von $75 \cdot 10^{10} \mu^{3}$ (Augustwert) beobachtet worden waren. Es zeigte sich, dass im Juni die Absorption in allen Spektralbereichen ausser im nahen UV bedeutend grösser war als im August.

Tab. 17. Spektrale Eindringtiefen $[\mathrm{m}](I=1 \%)$ und Phytoplanktonvolumen $(G P V, G O V)$ im Mauensee

\begin{tabular}{|c|c|c|c|c|c|c|c|}
\hline & $\begin{array}{c}\text { GPV } \\
{\left[\mu^{s}\right]}\end{array}$ & $\begin{array}{l}\text { GOV } \\
{\left[\mu^{3}\right]}\end{array}$ & $\begin{array}{l}\mathrm{UG} 1+\mathrm{BG} 12 \\
(3700 \AA) \\
{[\mathrm{m}]}\end{array}$ & $\begin{array}{l}\text { BG12 } \\
(4230 \AA) \\
{[\mathrm{m}]}\end{array}$ & $\begin{array}{l}\text { VG9 } \\
(5330 \mathrm{~A}) \\
{[\mathrm{m}]}\end{array}$ & $\begin{array}{l}\mathrm{RG} 2 \\
(6750 \AA) \\
{[\mathrm{m}]}\end{array}$ & $\begin{array}{l}\text { RG5 } \\
(6950 \AA) \\
{[\mathrm{m}]}\end{array}$ \\
\hline Juni 1967 & $140 \cdot 10^{10}$ & $133 \cdot 10^{10}$ & 0,75 & 0,9 & 1,3 & 1,5 & 1,3 \\
\hline August 1967 & $75 \cdot 10^{10}$ & $85 \cdot 10^{7}$ & 1,25 & 2,3 & 4,8 & 4,0 & 3,4 \\
\hline $\begin{array}{l}\text { Theoretischer Juniwert } \\
\text { Differenz theoretischer }\end{array}$ & $75 \cdot 10^{10}$ & $3,8 \cdot 10^{10}$ & 1,45 & 1,8 & 2,4 & 2,8 & 2,4 \\
\hline Juniwert - Augustwert & & & $-0,20$ & $+0,5$ & $+2,4$ & $+1,2$ & $+1,0$ \\
\hline
\end{tabular}

\subsection{Primärproduktion und vertikale Verteilung des Phytoplanktons}

Mit der C14-Technik wurden, beginnend im Juni 1966, monatlich die Kohlenstoffassimilationsraten des Phytoplanktons in verschiedenen Tiefenstufen gemessen.

\section{Vierwaldstättersee:}

In Abb. 18 wurden der im Vierwaldstättersee beobachtete maximale Betrag der Kohlenstoffassimilation und das Phytoplanktonvolumen in der betreffenden Tiefe eingetragen. Die kleinsten bzw. grössten Assimilationswerte wurden im Dezember 1966 (2,2 mg C/m $\mathrm{m}^{3} \mathrm{~h}$ ) bzw. April 1967 (95 mg C/m³ h) gemessen. Das entsprechende Phytoplanktonvolumen betrug $75 \cdot 10^{7}$ bzw. $290 \cdot 10^{7} \mu^{3} / 1$. Die Zusammensetzung des Phytoplanktons in diesen Tiefen vom Oktober 1966 bis März 1967 ist in Tabelle 18 aufgeführt.

Da in den Tiefen maximaler C-Assimilation optimale Lichtverhältnisse angenommen werden konnten, war es interessant, die jeweiligen Aktivitätskoeffizienten ( $\mathrm{mg} \mathrm{C} \cdot \mathrm{m}^{-3} \cdot \mathrm{h}^{-1} / \mathrm{mg}$ Frischgewicht des Phytoplanktons) in Zusammenhang mit der aktuellen Temperatur zu bringen (Abb. 19). Auf Grund dieser Abbildung kann man schliessen, dass das ökologische Temperaturoptimum der Proben höher als $13,6^{\circ} \mathrm{C}$ lag, da in qualitativer Hinsicht ähnliche Phytoplanktonzusammensetzungen vorlagen. Ob Oscillatoria rubescens im Verhältnis ihres prozentualen Anteils an der Assimilation beteiligt war, konnte nicht beurteilt werden. 


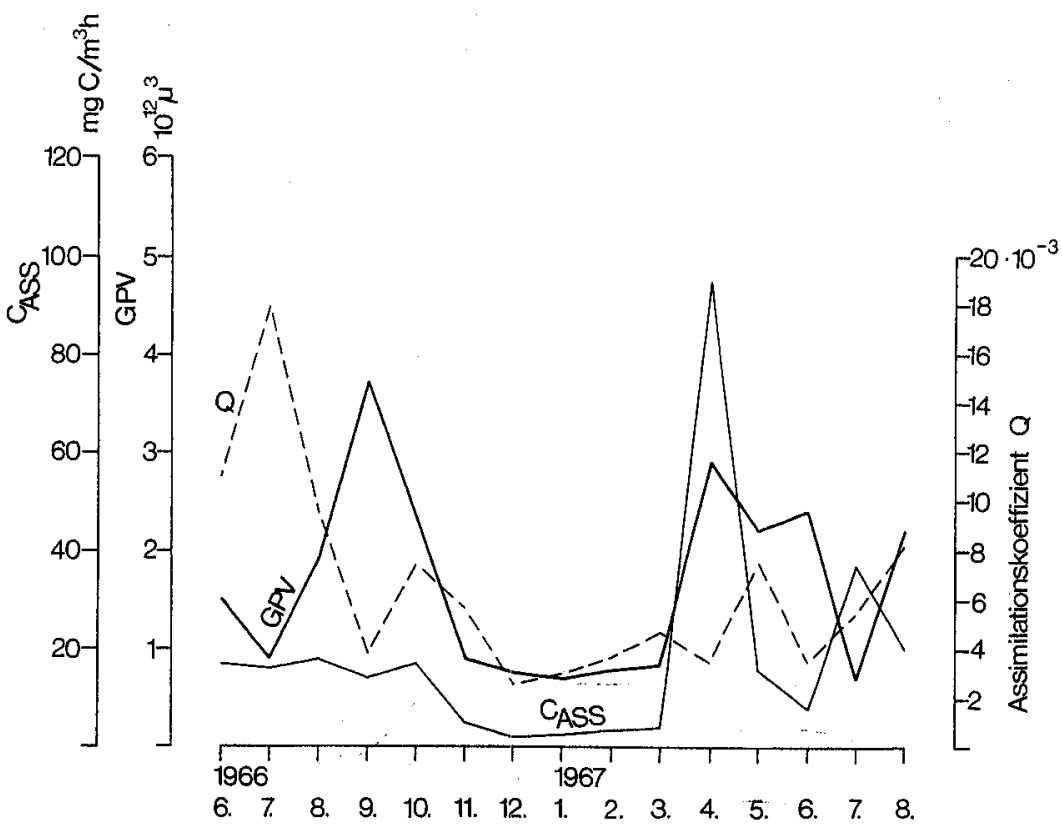

Abb. 18. Gesamt-Phytoplanktonvolumen (GPV), Assimilationsleistung $\left(\mathrm{C}_{a s s}\right)$ und Assimilationskoeffizient $(Q)$ in der Tiefe maximaler Assimilation.

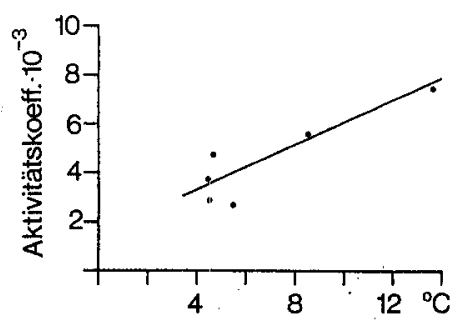

Abb. 19. Abhängigkeit des Aktivitätskoeffizienten $\left(Q=\mathrm{C}_{a s s} \max . /\right.$ Biomasse $)$ von der aktuellen Temperatur im Vierwaldstättersee.

Tab. 18. Temperatur, Aktivitatskoeffizient und prozentuale Zusammensetzung des Phytoplanktons in Tiefen maximaler $C$-Assimilation im Vierwaldstattersee in den Monaten Ohtober 1966 bis März 1967

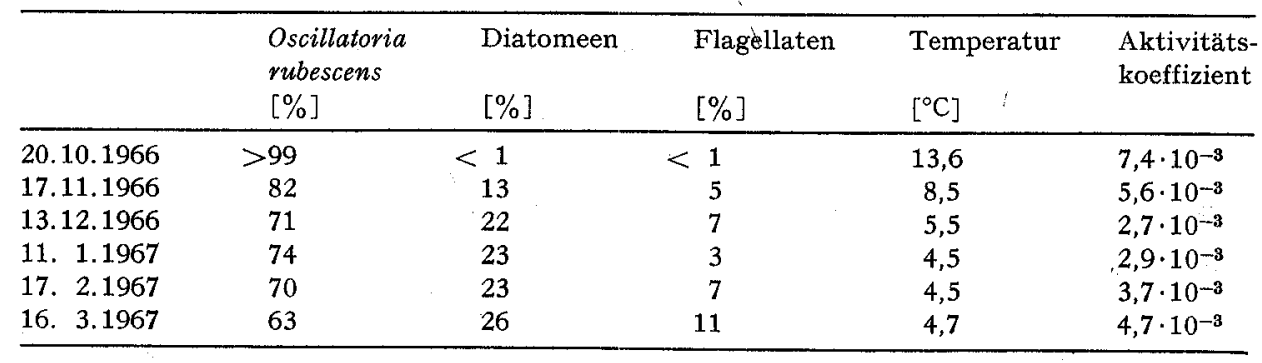




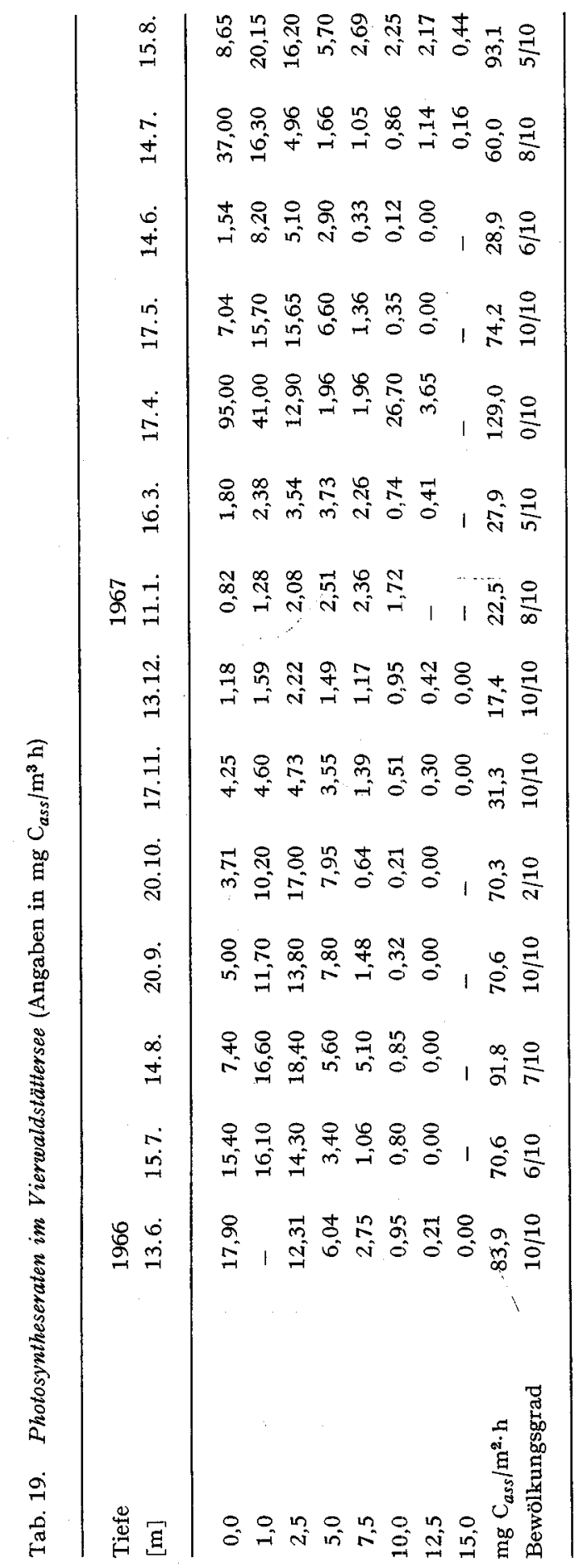


RHODE [47] stellte in seinen Untersuchungen fest, dass die relativen Photosyntheseraten, halblogarithmisch aufgezeichnet, parallel mit demjenigen Lichtanteil abfallen, der den grössten Transmissionskoeffizienten $\left(I_{m p c}\right)$ aufweist. Auf Grund dieser Beobachtung muss der Kompensationspunkt (Grenze der positiven Assimilationsbilanz) mit jener Tiefe zusammenfallen, in der noch $1 \%$ der an der Oberfläche gemessenen Intensität von $I_{m p c}$ vorhanden ist. Während der ganzen Untersuchungsperiode lag im Vierwaldstättersee als $I_{m p c}$ das grüne Licht (VG9) vor. Es zeigte sich aber, dass

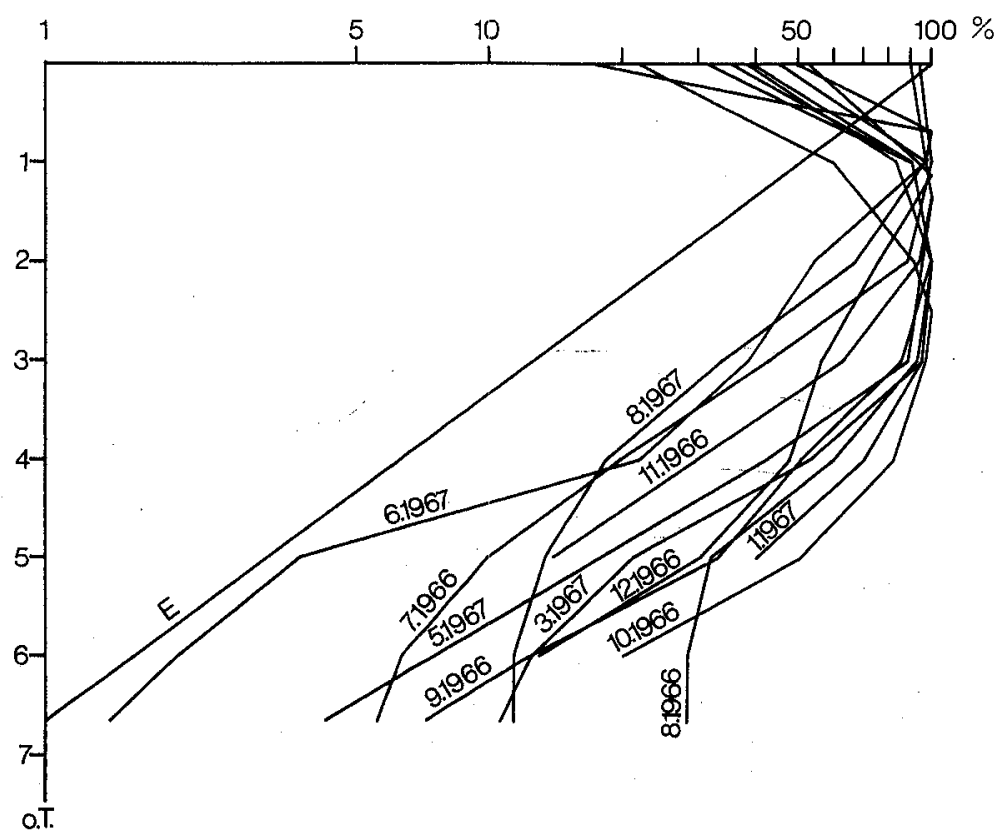

Abb. 20. Assimilationskurven vom Vierwaldstättersee, aufgetragen im halblogarithmischen Maßstab gegen die optische Tiefe.

die von RHODE festgestellte Parallelität - wie schon Gächter [44] feststellte - nicht generell beobachtet werden konnte, da das $I_{m p c}$ etwas langsamer abfiel als die relativen Photosyntheseraten. Dagegen konnte eine Parallelität zwischen der Gesamtenergie $E$ (weisses Licht) und dem Verlauf der relativen Photosyntheseraten festgestellt werden (Abb. 20). In den Monaten Juli und August 1966, April, Juli und August 1967 wurden in den Tiefen zwischen 7,5 $\mathrm{m}$ und $15 \mathrm{~m}$ höhere C-Assimilationswerte gemessen als theoretisch erwartet worden wären (Tabelle 19). In den Sommermonaten beider Jahre wurden in diesen Tiefen Oscillatoria rubescens-Maxima beobachtet, die diese relativ erhöhten Assimilationswerte verursacht haben mussten. Die hohen Photosyntheseraten in $10 \mathrm{~m}$ Tiefe, welche im April 1967 registriert worden waren, konnten in keinen Zusammenhang mit dem sich dort befindenden Phytoplankton gebracht werden.

Thunersee: Abb. 21

Die Photosyntheseraten (Tabelle 20) nahmen in den Monaten Januar und Juli 1967 etwas stärker ab als die Gesamtenergie E; im Juli 1966 und April 1967 bestand da- 
gegen unterhalb der optischen Tiefe 7 bzw. 5 eine Parallelität zwischen diesen beiden Parametern. Die langsamere Abnahme der Photosyntheseraten im Juli 1966, die bis in die optische Tiefe 7 reichte, konnte mit einer Anhäufung von Oscillatoria rubescens Fäden in den Wasserschichten zwischen $10 \mathrm{~m}$ und $15 \mathrm{~m}$ in Zusammenhang gebracht werden. Das RPV jener Schicht bestand beinahe ausnahmslos aus Diatomeen, die kaum mehr photosynthetisch aktiv waren, erreichte doch die Gesamtenergie $E$ nur mehr $1 \%$ des an der Oberfläche gemessenen Wertes.

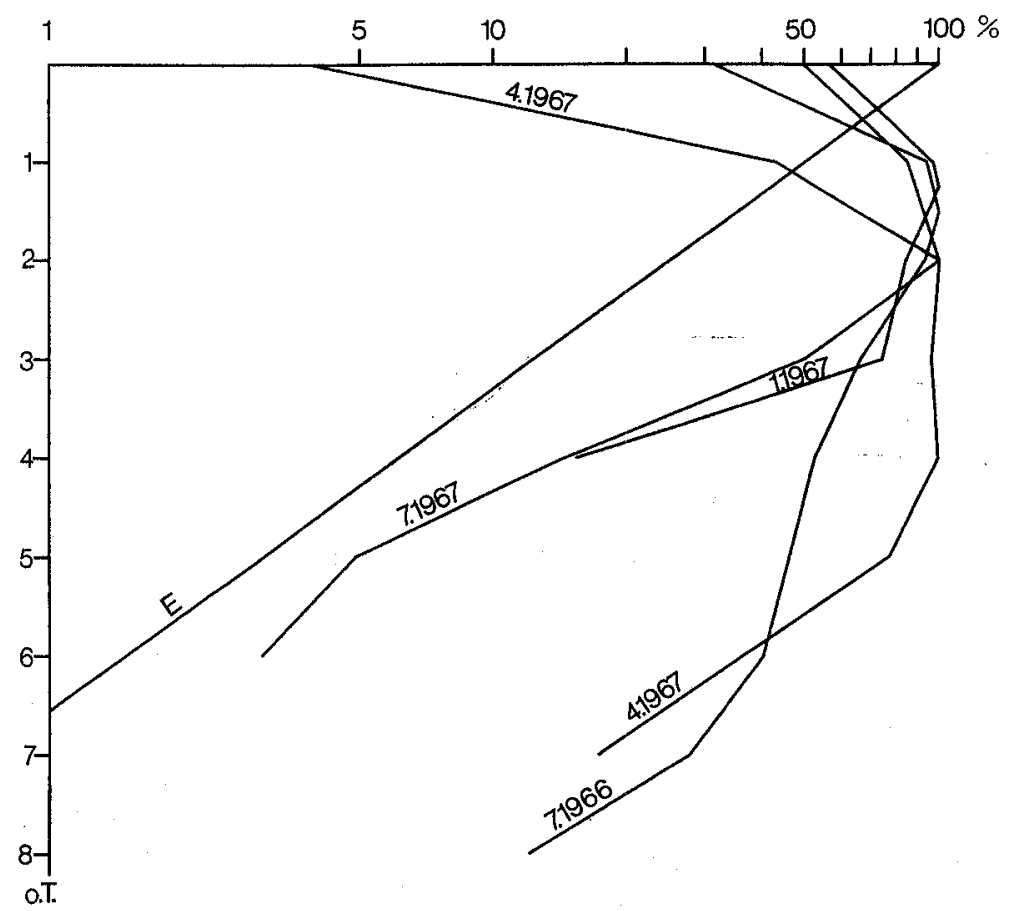

Abb. 21. Assimilationskurven vom Thunersee, aufgetragen im halblogarithmischen Maßstab gegen die optische Tiefe.

Tab. 20. Photosyntheseraten im Thunersee (Angaben in $\mathrm{mg} \mathrm{C}_{\text {ass }} / \mathrm{m}^{3} \cdot \mathrm{h}$ )

\begin{tabular}{lllllr}
\hline Tiefe $[\mathrm{m}]$ & 20.7 .1966 & 26.10 .1966 & 24.1 .1967 & 11.4 .1967 & 24.7 .1967 \\
\hline 0,0 & 2,60 & 4,35 & 1,29 & 0,73 & 5,03 \\
1,0 & 6,60 & 3,40 & 1,43 & 2,45 & 7,30 \\
2,5 & 8,10 & 2,45 & 1,95 & 9,40 & 8,60 \\
5,0 & 5,25 & 1,13 & 2,25 & 18,40 & 10,10 \\
7,5 & 3,90 & 0,42 & 1,86 & 17.50 & 3,80 \\
10,0 & 3,20 & 0,11 & 1.80 & 18,30 & 0,95 \\
$\mathbf{1 2 , 5}$ & 1,70 & 0,0 & 1,00 & 10,70 & 0,45 \\
$\mathbf{1 5 , 0}$ & 0,0 & - & - & - & 0,28 \\
mg C & 61,20 & 15,50 & 22,40 & 184,0 & 68,10 \\
Bewölkungsgrad & $4 / 10$ & $10 / 10$ & $10 / 10$ & $1 / 10$ & $5 / 10$ \\
\hline
\end{tabular}


Luganersee: Abb. 22

Ein Zusammenhang zwischen dem Intensitätsabfall der am tiefsten eindringenden Lichtkomponente (OG 1 bzw. VG9) und dem Verlauf der Photosyntheseraten konnte nicht festgestellt werden. Eine recht gute Parallelität bestand jedoch zwischen dem Verlauf der Gesamtenergie und den Assimilationsraten. Das schwache Oscillatoria rubescens-Maximum im August 1966 in 7,5 m Tiefe lag unterhalb des Kompensationspunktes und war demzufolge photosynthetisch inaktiv. Die Photosyntheseraten sind in Tabelle 21 aufgeführt.

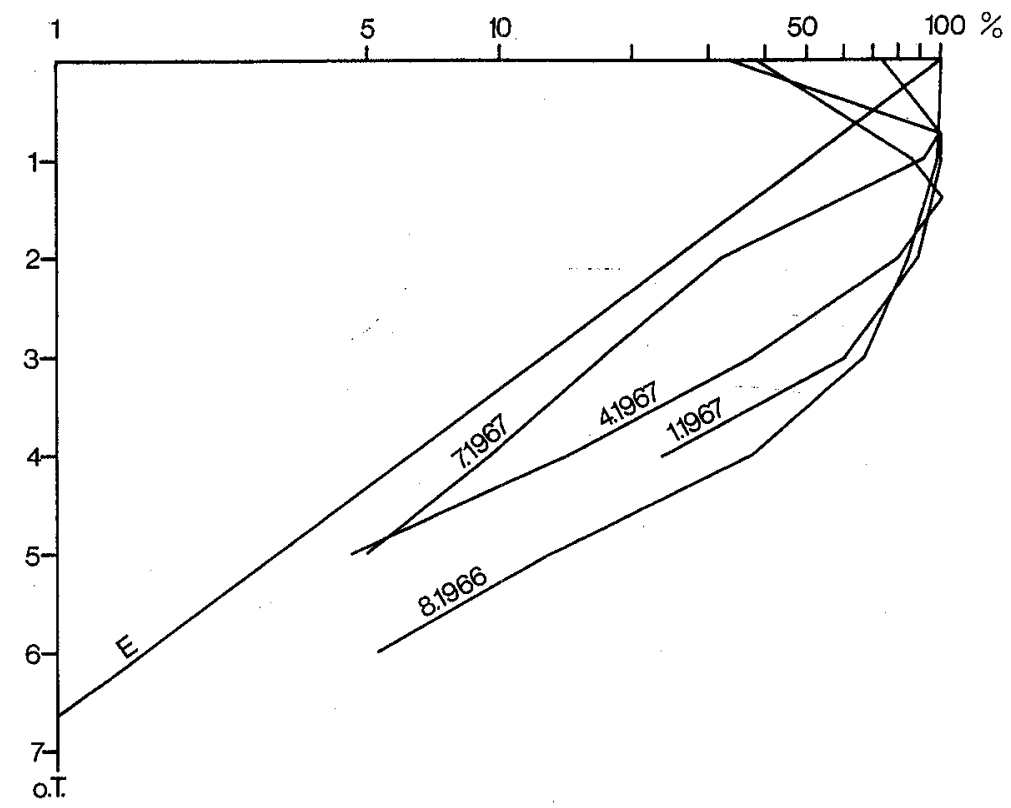

Abb. 22. Assimilationskurven vom Luganersee, aufgetragen im halblogarithmischen Maßstab gegen die optische Tiefe.

Tab. 21. Photosyntheseraten im Luganersee (Angaben in $\mathrm{mg} \mathrm{C}_{a s s} / \mathrm{m}^{\mathrm{3}} \cdot \mathrm{h}$ )

\begin{tabular}{lcccc}
\hline Tiefe $[\mathrm{m}]$ & 18.8 .1966 & 27.1 .1967 & 13.4 .1967 & 27.7 .1967 \\
\hline 0,0 & 30,50 & 0,44 & 8,5 & 44,0 \\
1,0 & 28,40 & 0,93 & 13,8 & 59,5 \\
2,5 & 13,00 & 1,28 & 21,9 & 25,5 \\
5,0 & 0,67 & 1,28 & 8,7 & 7,5 \\
7,5 & 0,00 & 1,19 & 2,7 & 2,1 \\
10,0 & - & 0,85 & 0,0 & 0,3 \\
12,5 & - & 0,57 & - & 0,1 \\
15,0 & - & 0,24 & - & - \\
mg C $_{\text {ass }} / \mathrm{m}^{2} \cdot \mathrm{h}$ & 78,5 & 14,0 & 93,7 & 172,6 \\
Bewölkungsgrad & $3 / 10$ & $1 / 10$ & $0 / 10$ & $6 / 10$ \\
\hline
\end{tabular}




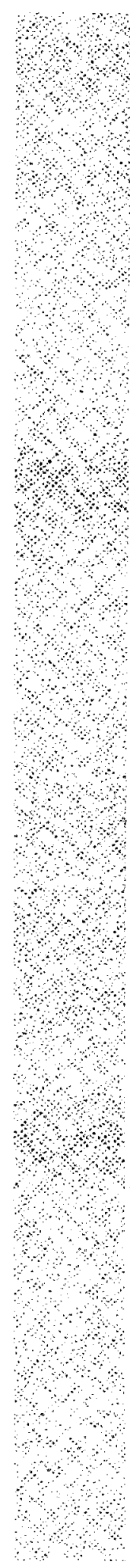

\begin{tabular}{|c|c|c|}
\hline $0 \mathfrak{T} / 8$ & $0 \tau / 0$ & $0 \tau / \mathrm{I}$ \\
\hline $6^{\prime} 9 \varepsilon I$ & $\angle 9 S$ & $0^{\prime}$ โ9 I \\
\hline $0 I^{\prime} \mathcal{E} \mathrm{I}$ & - & - \\
\hline$L Z^{\prime} I$ & $0^{\circ} 0$ & - \\
\hline$\varsigma 6^{\prime} 9$ & $Z^{\prime} 0$ & $0^{\prime} 0$ \\
\hline- & - & $\varepsilon 9^{\circ} 0$ \\
\hline $0 L^{\prime} \mathrm{I} Z$ & $t^{\prime} 0$ & - \\
\hline$O \mathcal{E}^{\prime}+9^{i}$ & $z^{\prime} 0 z$ & $\mathcal{S E}^{\prime} 8$ \\
\hline $09^{\prime} \mathrm{T} L$ & $S^{\prime} z L$ & $0^{\circ} 00 \varepsilon$ \\
\hline $96 I^{\circ} 8^{\circ} \mathrm{tI}$ & $\angle 96 T^{\circ} 9^{\circ} \varepsilon I$ & $\angle 96 I^{\prime} \mathrm{S}^{\circ} 9 \mathrm{I}$ \\
\hline
\end{tabular}

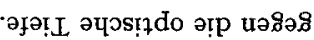

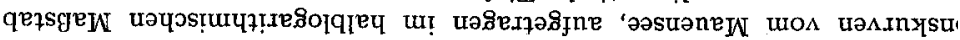

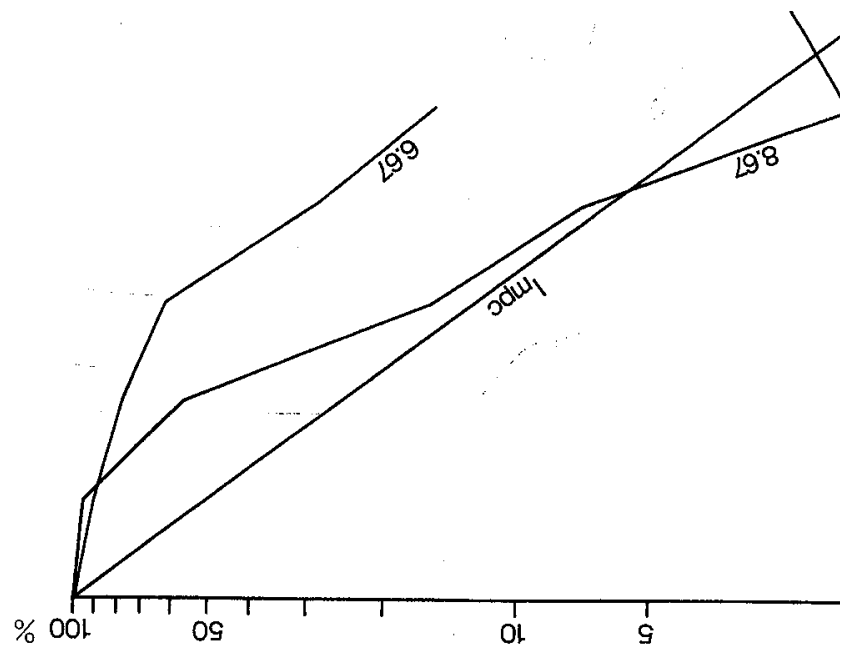

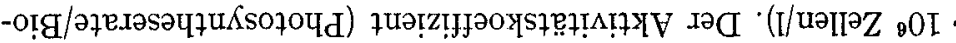

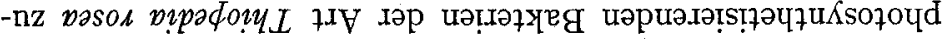

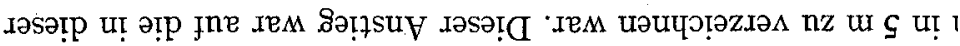


Mauensee: Abb. 23

Die Photosyntheseraten (Tabelle 22) nahmen im Juni mit zunehmender Tiefe parallel der im gleichen logarithmischen Maßstab aufgetragenen Intensitäten des am tiefsten eingedrungenen Lichtanteiles (RG2) ab. Dieselbe Erscheinung konnte auch im August beobachtet werden, mit Ausnahme des untersten Teiles der trophogenen Schicht, wo - vorgängig einer rascheren Abnahme in $4 \mathrm{~m}$ - eine starke Zunahme der Photosyntheseraten in $5 \mathrm{~m}$ zu verzeichnen war. Dieser Anstieg war auf die in dieser Tiefe festgestellten photosynthetisierenden Bakterien der Art Thiopedia rosea zurückzuführen $\left(540 \cdot 10^{6}\right.$ Zellen/1). Der Aktivitätskoeffizient (Photosyntheserate/Bio-

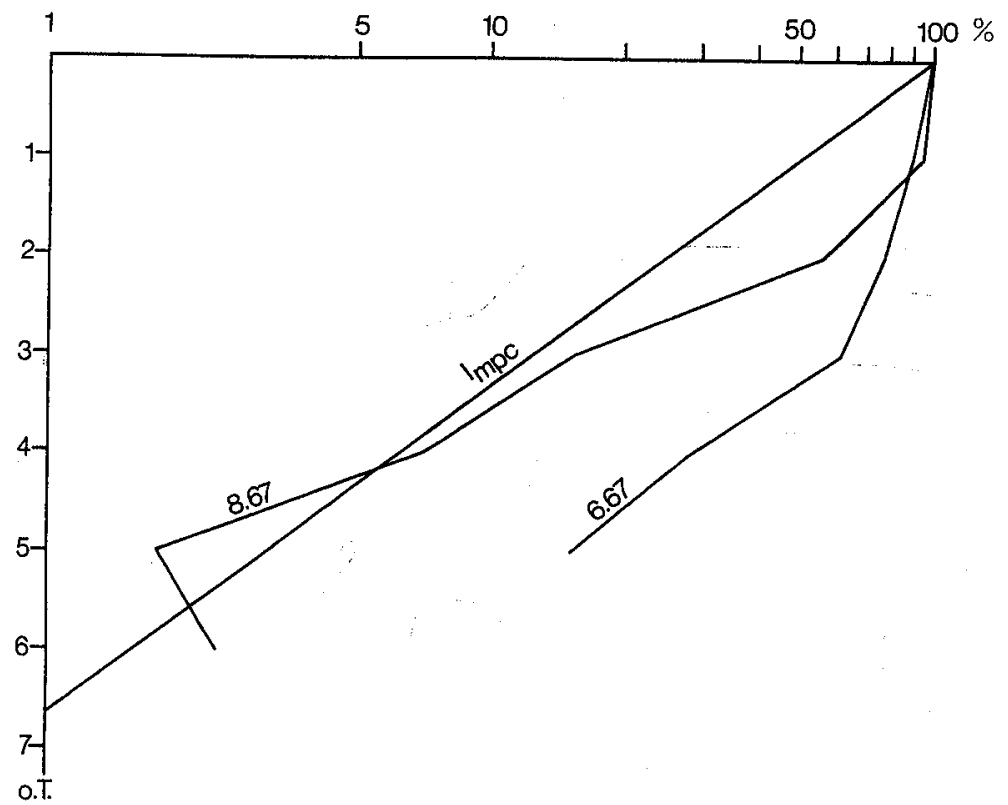

Abb. 23. Assimilationskurven vom Mauensee, aufgetragen im halblogarithmischen Maßstab gegen die optische Tiefe.

Tab. 22. Photosyntheseraten im Mauensee (Angaben in $\mathrm{mg} \mathrm{C}_{\text {ass }} / \mathrm{m}^{3} \cdot \mathrm{h}$ )

\begin{tabular}{lccc}
\hline Tiefe $[\mathrm{m}]$ & $16,5.1967$ & 13.6 .1967 & 14.8 .1967 \\
\hline 0,0 & 300,0 & 72,5 & 71,60 \\
1,0 & 8,35 & 20,2 & 64,30 \\
2,0 & - & 0,4 & 21,70 \\
2,5 & 0,63 & 0,2 & 6,95 \\
3,0 & 0,0 & 0,0 & 1,27 \\
4,0 & - & - & 13,10 \\
5,0 & - & 56,7 & 136,9 \\
m C $_{\text {ass }} / \mathrm{m}^{2} \cdot \mathrm{h}$ & 161,0 & $0 / 10$ & $8 / 10$ \\
Bewölkungsgrad & $1 / 10$ & & \\
\hline
\end{tabular}


masse) des Monats Mai war, bei ebenfalls wolkenlosem Himmel, mit 1,04 $\cdot 10^{-3}$ mehr als doppelt so hoch wie im folgenden Monat $\left(0,43 \cdot 10^{-3}\right)$. Dieser Abfall der Photosyntheseleistung der fast ausschliesslich aus Oscillatoria rubescens bestehenden Phytoplanktongesellschaft muss auf einen Zerfall eines Teils der Trichome zurückzuführen sein.

\subsection{Diskussion}

Die vertikale Verteilung des Phytoplanktons in der trophogenen Schicht ist, abgesehen von Zeiten der Homothermie, meistens nicht gleichmässig. Das Vorhandensein von Individuenmaxima in einer bestimmten Tiefe, wie es besonders ausgeprägt bei Oscillatoria rubescens beobachtet werden kann, lässt vermuten, dass die Gesamtheit aller äusserer Einflüsse auf eine Algenart in jener Tiefe optimal war. Da jedoch ein grosser Teil des Phytoplanktons keine Eigenbewegung besitzt und demnach der Sedimentation unterworfen ist, muss zwischen ökologisch-physiologisch und rein mechanisch bedingten Individuenmaxima unterschieden werden. Das beobachtete stetige Aufsteigen des Oscillatoria rubescens-Maximums aus tieferen Schichten gegen die Oberfläche im Verlauf der zweiten Jahreshälfte im Vierwaldstättersee (siehe S. 26ff.), dem Thunersee (siehe S. 28) und in andern Seen $[1,20,22]$ zeigt jedoch klar, dass die Alge ihren Standort infolge äusserer Einflüsse zu verändern sucht. Ausgehend von der Tatsache, dass in dieser Schicht offenbar ökologisch optimale Bedingungen herrschten, sollen in der Folge die hier angetroffenen Umweltbedingungen analysiert werden.

\subsection{Oscillatoria rubescens-Maximum und Temperatur}

Die Temperaturen in den Tiefen maximaler Oscillatoria rubescens-Konzentration bewegten sich im Vierwaldstättersee zwischen den Extremwerten von 9,5 und $14,6^{\circ} \mathrm{C}$. Die durchschnittliche Temperatur, aus elf Werten berechnet, betrug $11,6^{\circ} \mathrm{C}$. Diese Beobachtungen stimmen mit denjenigen der Jahre 1962-1967 an der Stelle Kreuztrichter im Vierwaldstättersee [48] weitgehend überein (durchschnittliche Temperatur $11,0^{\circ} \mathrm{C}$ ). Diese Abweichung von $0,6^{\circ} \mathrm{C}$ ist angesichts der bedeutend zahlreicheren Messwerte [36] gering.

Im Thunersee betrug die Durchschnittstemperatur dieser Schichten $11,1^{\circ} \mathrm{C}$ und lag demzufolge in demselben Bereich wie im Vierwaldstättersee. Die höchsten bzw. tiefsten Temperaturen wurden im Oktober 1966 mit $13,8^{\circ} \mathrm{C}$ bzw. im Juni 1965 mit $8,0^{\circ} \mathrm{C}$ [49] gemessen, ein Temperaturunterschied, der mit $5,8^{\circ} \mathrm{C}$ in derselben Grössenordnung liegt wie im Vierwaldstättersee. Im Luganersee wurde eine Einschichtung der Alge im August 1966 in 7,5 m beobachtet; dort herrschte eine Temperatur von $16,3^{\circ} \mathrm{C}$. Diese stellt den absolut höchsten Wert aller in Wasserschichten maximaler Oscillatoria rubescens-Konzentration beobachteten Temperaturen dar, soweit es sich nicht um Oberflächentemperaturen handelte. Bemerkenswert war eine im Juli 1967 beobachtete Anhäufung der Alge im Oberflächenwasser, dessen Temperatur $25,3^{\circ} \mathrm{C}$ betrug. Da zwischen $1 \mathrm{~m}$ und $10 \mathrm{~m}$ keine Fäden festgestellt wurden, und ein Austausch zwischen Oberfläche und tieferen Schichten angesichts der stabilen Wassermassen unwahrscheinlich war, muss eine begrenzte Entwicklung der Alge bei diesen ungewöhnlichen Verhältnissen angenommen werden.

Die Oberflächentemperaturen zur Zeit der Massenentwicklung von Oscillatoria. 
rubescens lagen im Mauensee mit 18,1 bzw. $15,0^{\circ} \mathrm{C}$ im Bereich der im Luganersee (August 1966) beobachteten Temperatur von $16,3^{\circ} \mathrm{C}$.

Die prozentuale Verteilung der Oscillatoria rubescens-Maxima bei verschiedenen Temperaturen wurde in Tabelle 23 und Abb. 24 analysiert. Es zeigte sich, dass diese Maxima in $85 \%$ aller berücksichtigten Fälle bei Temperaturen unter $14,0^{\circ} \mathrm{C}$ lagen. Im Thunersee [49], Wörthersee [18], Wolfgangsee [18], Traunsee [18] und dem Lago di Levico [8] lagen sogar 100\%, im Vierwaldstättersee noch 93\% der Maxima unterhalb dieser willkürlich gewählten Temperaturgrenze. Im Zürichsee $[19,20]$ jedoch wurden diese Oscillatoria rubescens-Maxima in 41\%, im Murtensee [50] in 50\%, im Luganer- und Mauensee gar in 100\% aller Fälle bei höheren Temperaturen beobachtet. $\mathrm{Ob}$ Oscillatoria rubescens in diesen bekannterweise eutrophen bis polytrophen Gewässern durch Beschattung, hervorgerufen durch andere Phytoplankter, in höhere und dadurch wärmere Schichten aufzusteigen gezwungen war [1], kann bei der relativ kleinen Anzahl von Beobachtungen und weitgehenden Ermangelung von gleichzeitigen Angaben über die Lichtverhältnisse nicht stichhaltig beurteilt werden.

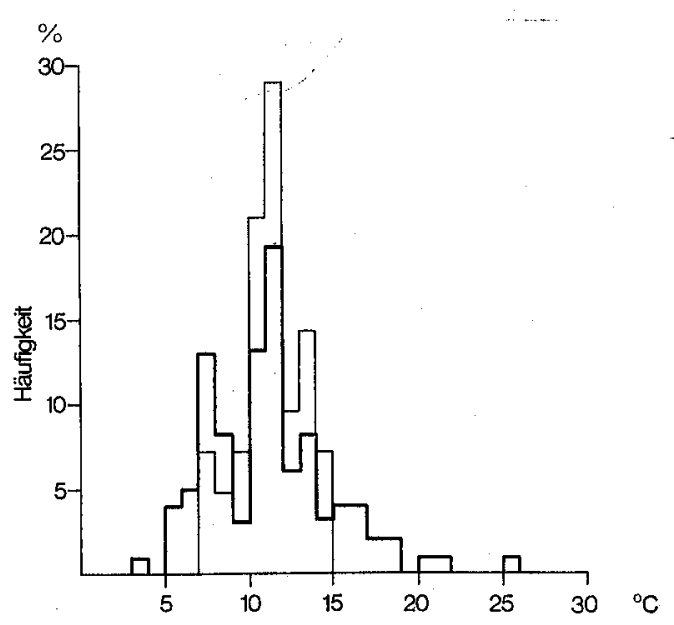

Abb. 24. Häufigkeitsverteilung der Oscillatoria rubescens-Maxima bei verschiedenen Temperıturen. - alle berthcksichtigten Fälle. Vierwaldstättersee.

\subsection{Oscillatoria rubescens-Maximum und Lichtklima}

Im Vierwaldstättersee fielen die Oscillatoria mbescens-Maxima meistens mit jener Tiefe zusammen, in der nur noch der grüne Teil des Lichtès (VG9) mehr als $1 \%$ des Oberflächenwertes $\left(I_{0,05}\right)$ ausmachte, wobei Werte zwischen knapp $1 \%$ und $9 \%$ gemessen werden konnten. Zur Zeit der Probenahmen vom Mai, September und Oktober 1966 lag das Maximum noch im stärkeren Einflussbereich des blauen (BG 12) und roten $(R G 2)$ Lichtes, während in allen andern Monaten diese Anteile unter $1 \%$ des Oberflächenwertes sanken. Im Juli und August 1967 wurden die über mehrere Meter reichenden Maxima nur noch in den oberen Teilen von grünem Licht mit mehr als $1 \%$ des $I_{\mathbf{0}, 05}$ erreicht. 


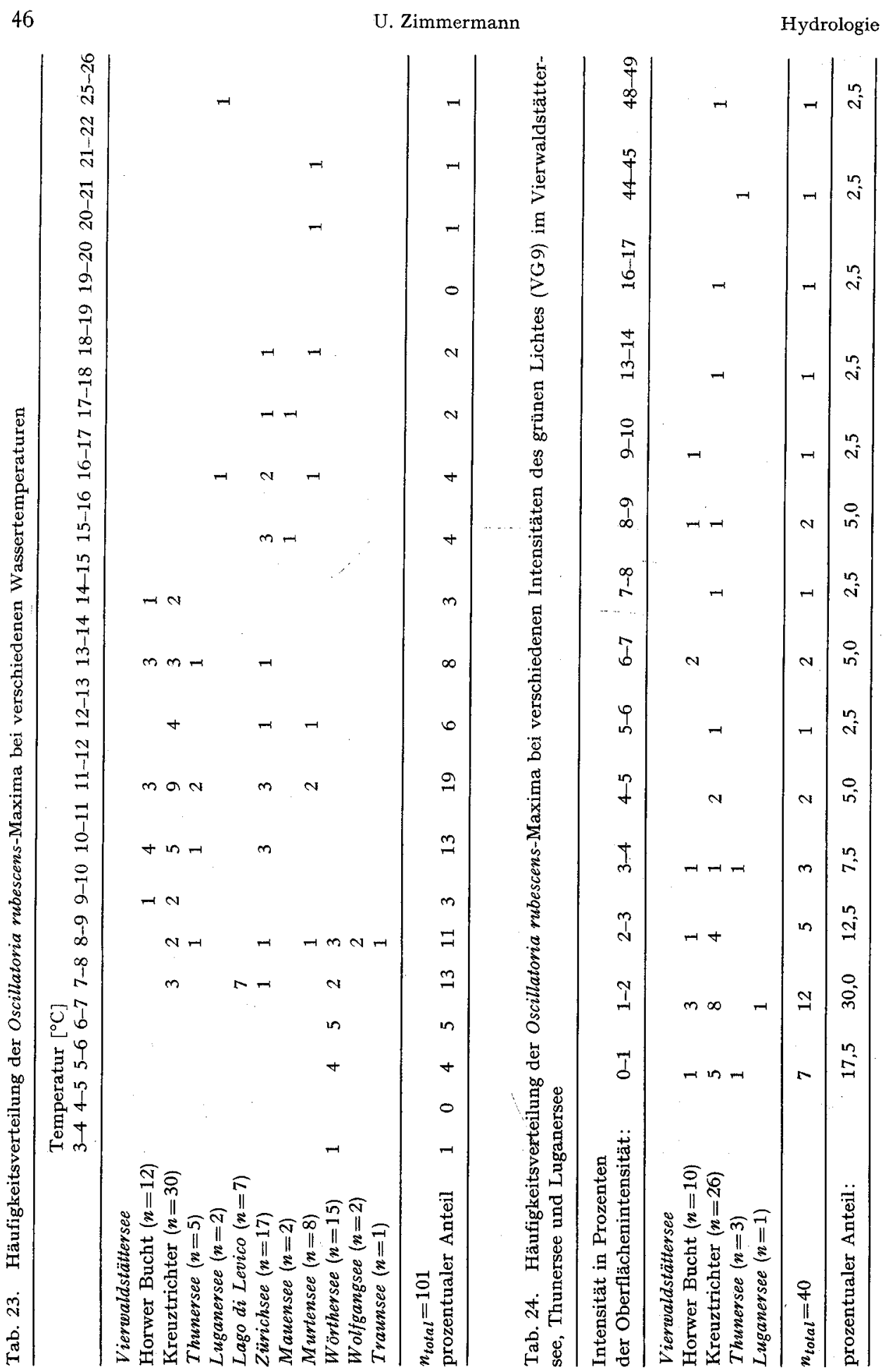


Bei der im Thunersee in allen Spektralbereichen beobachteten grösseren Transparenz (siehe S. 10) wurden teilweise höhere Intensitäten festgestellt. Im Oktober 1966 lagen die Intensitäten aller gemessenen Spektralbereiche noch über $3 \%$ von $I_{\mathbf{0}, \mathbf{0 5}}$. Im Luganersee lag das Oscillatoria rubescens-Maximum im Juli 1967 an der Oberfläche, im August 1966 in einem Lichtklima, das vorwiegend aus dem Spektralbereich von OG $1(11 \%)$ und VG9 (1,8\%) bestand. Die kürzer- und längerwelligen Lichtanteile erreichten die Intensität von $1 \%$ bei weitem nicht.

Die im Mauensee beobachtete Wasserblüte von Oscillatoria rubescens bewirkte in allen Spektralbereichen sehr grosse Absorptionskoeffizienten. Die 1\%-Grenze des $I_{m p c}$ lag im Mai 1967 zwischen $0,5 \mathrm{~m}$ und 0,75 m, im Juni in etwa 1,5 m Tiefe. Von der Oberfläche bis zu diesen Tiefen wurden praktisch gleiche Oscillatoria rubescens-Konzentrationen festgestellt. Diese Algenblüte drängte die trophogene Zone auf eine sehr enge Wasserschicht zusammen. Im Vierwaldstättersee und im Thunersee wurde die stärkste Oscillatoria rubescens-Entwicklung in einer etwas höheren Lage als die Kompensationstiefe beobachtet. Es wäre durchaus denkbar, dass sich diese Alge zwar auch im Mauensee unter ähnlichen optischen Bedingungen optimal entwickelt hatte, dass sie aber durch turbulente Strömungen über die ganze, sehr eng begrenzte trophogene Schicht verteilt wurde.

Die prozentuale Verteilung der Oscillatoria rubescens-Maxima bei verschiedenen relativen Intensitäten des grünen Spektralbereiches (VG9) wurde in Tabelle $24 \mathrm{zu}$ sammengestellt und analysiert (Abb. 25) $(100 \%=$ Intensität an der Oberfläche $\left.\left[I_{\mathbf{0}, 05}\right]\right)$. Die Werte vom Kreuztrichter (Vierwaldstättersee) [40] wurden nach VoLLENWEIDER [51] aus den Sichttiefen ermittelt. In über $70 \%$ aller Fälle konnten relative Intensitäten unter $4 \%$ beobachtet werden. Die $10 \%$-Grenze wurde nur noch von $10 \%$ aller Fälle überschritten, wobei die beiden höchsten Werte $(44 \%$ bzw. 48\%) im Monat Oktober der Jahre 1965 und 1966 gemessen wurden, zu einer Zeit also, während der die Oscillatoria rubescens-Maxima nahe der Seeoberfläche lagen.

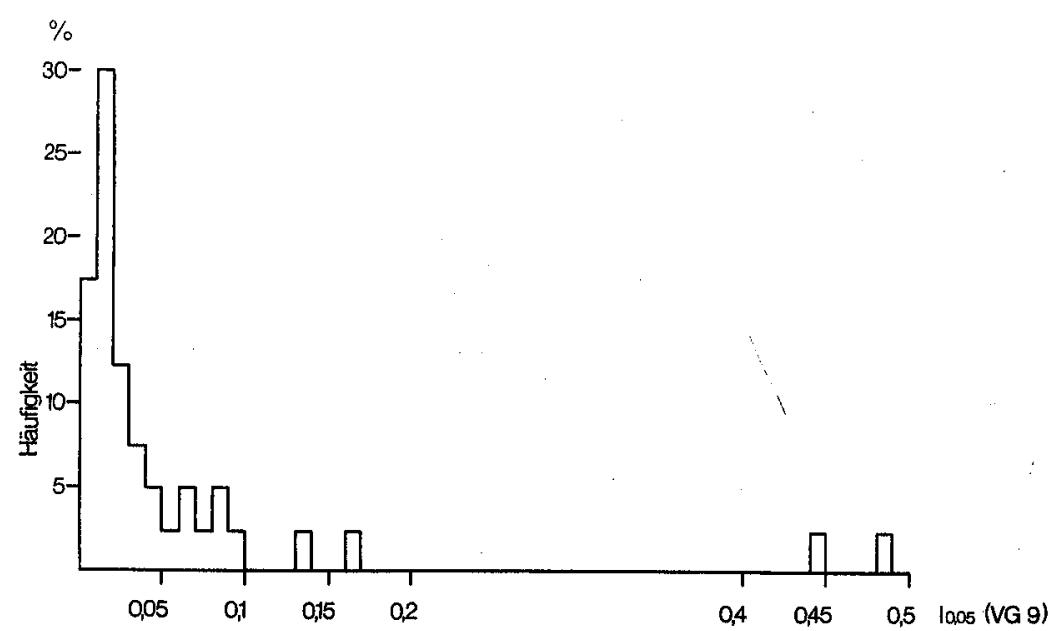

Abb. 25. Häufigkeitsverteilung der Oscillatoria rubescens-Maxima bei verschiedenen Intensitäten des grünen Lichtes (VG9) im Vierwaldstättersee, Thunersee und Luganersee. 


\section{Experimentelle Untersuchungen}

Auf Grund ökologischer Erhebungen wurde Oscillatoria rubescens als eine oligotherme Alge bezeichnet $[1,8,10,11,12,13,18,21]$, obschon physiologische Untersuchungen fehlten. Staub [24] beobachtete aber bei physiologischen Experimenten gutes Wachstum zwischen 20 und $25^{\circ} \mathrm{C}$. Die im Abschnitt "Seeuntersuchungen" (siehe S. 3ff.) ermittelten Daten liessen eine im ökologischen Sinne streng oligotherme Charakterisierung fraglich erscheinen. Das Ergebnis unserer ökologischen Untersuchungen sowie dasjenige von STAUB gaben den Anlass zu quantitativen Temperaturexperimenten in vitro.

Ökologische Untersuchungen über die Lichtansprüche von Oscillatoria rubescens $[1,10,12,19]$ führten zu einer als Schwachlichtform bezeichneten Charakterisierung. Die im Abschnitt "Seeuntersuchungen» aufgefuihrten Ergebnisse und Angaben bestätigten im allgemeinen diese Bezeichnung, wobei aber auch dies nur im ökologischen Sinne Gültigkeit haben mag. Zur Untersuchung der Lichtansprüche von Oscillatoria rubescens wurden quantitative Experimente in vitro durchgeführt, die es ermöglichten, den Einfluss der unter natürlichen Bedingungen meist streng gekoppelten Faktoren Licht und Temperatur zu trennen:-

\subsection{Methodik}

Kulturraum: Es wurde ein Licht-Brückenthermostat der Firma Autofrigor mit sechs Abteilen verwendet. Die einzelnen thermostatisierten Abteile sind vorne und unten verglast und gestatten eine Beleuchtung der Kulturen von aussen. Um eine unerwünschte Wärmeakkumulation in den Abteilen $z u$ verringern, wurden zwischen Lichtquelle und erwähnter Verglasung mit Wasser gefüllte Küvetten aufgestellt, die einen Grossteil der Infrarotstrahlung absorbierten. Um ein Algenwachstum in diesen Küvetten zu verhindern, wurde das Wasser mit «Desogen» (Geigy) versetzt. Als Lichtquellen wurden 65 Watt Leuchtstoffröhren der Firma Philips vom Typ TL65W/33 verwendet.

Kulturgefässe: Es wurden $200 \mathrm{ml}$ Erlenmeyerkolben aus Jenaer Glas G20 verwendet.

Impfmaterial: Steilbrustflaschen (Jenaer Glas G 20) mit $300 \mathrm{ml}$ Nährlösung wurden mit je $20 \mathrm{ml}$ des bakterienfreien Oscillatoria rubescens-Klones EAWAG $51 \mathrm{R}$ beimpft. Diese Kulturen wurden bei einer Lichtintensität von 550 Lux und einer Temperatur von $22^{\circ} \mathrm{C}$ auf einer Schüttelmaschine 10 Minuten pro Stunde geschüttelt. Sie dienten als Impfmaterial für die Versuche, sobald die Konzentration etwa 100000 Fäden pro $\mathrm{ml}$ erreicht hatte.

Nährlösung: Verwendet wurde die von STAUB [24] modifizierte Z8-Lösung nach ZEHNDER [52].

Messung der Primärproduktion (Kurzzeitversuche): In Jenaer Glasflaschen (G 20) wurden $100 \mathrm{ml}$ Nährlösung abgefüllt und sterilisiert. Nachdem diese im Thermostat auf die dem nachfolgenden Versuch entsprechenden Temperaturen angeglichen waren, wurden $10 \mathrm{ml}$ Impfmaterial mittels einer sterilen Injektionsspritze zugeimpft, mit $1 \mathrm{ml}$ einer sterilen Lösung von markiertem $\mathrm{NaHC}^{14} \mathrm{O}_{3}$ versetzt und im entsprechenden Thermostatabteil bei einer bestimmten Lichtintensität exponiert (Ampullenaktivität $=1440 \mathrm{cps}$ ). Nach zwei Stunden wurden $25 \mathrm{ml}$ davon filtriert (Göttinger 
Membranfilter MF30) und die Filter in Aluminiumschälchen geklebt. Bevor die Aktivitätsmessung mit dem Methandurchflusszähler FH407 der Firma Frieseke und Höpfner vorgenommen wurde, wurden die Schälchen während 20 Minuten über rauchender Salzsäure exponiert, um Störungen durch adsorbiertes anorganisches C14 $\mathrm{zu}$ eliminieren.

Trockengewichtsbestimmung (Langzeitversuche) : Gewichtskonstante Filter (Göttinger Membranfilter MF50) wurden während 30 Minuten in destiliertem Wasser gekocht, im Trockenschrank getrocknet und anschliessend gewogen. $100 \mathrm{ml}$ der Kultur wurden daraufhin filtriert, eine Stunde bei $100^{\circ} \mathrm{C}$ getrocknet und anschliessend gewogen.

\subsection{Vorversuche}

Da alles Impfmaterial bei $22^{\circ} \mathrm{C}$ und 550 Lux angezogen wurde, musste vor Beginn der Kurzzeitversuche die Frage der Akklimatisation an die verschiedenen Versuchsbedingungen geklärt werden. Auf Grund der gewonnenen Erfahrungen aus LangzeitStandkulturen [24] war zu Beginn der Kulturdauer ein minimaler Zuwachs oder eine minimale Assimilisationsrate (Lag-Phase) zu erwarten.. Bei längerer Versuchsdauer sollten diese über längere Zeit einen konstanten, maximalen Wert erreichen (logarithmische Phase), um anschliessend wieder'soweit abzufallen, dass sich Assimilation und Dissimilation die Waage halten (stationäre Phase).

Ziel der Vorversuche war es, jene Zeitspanne zu ermitteln, welche die Kultur benötigt, um in den Bereich der maximalen Wachstumsrate zu gelangen. Um die Dauer der Akklimatisation zu ermitteln, wurde die Kohlenstoffassimilationsrate (cps) nach verschiedenen Versuchsdauern gemessen. Dabei ergaben sich die in Tabelle $25 \mathrm{zu}-$ sammengestellten Resultate. Die Tatsache, dass mit fortschreitender Versuchsdauer die Kohlenstoffaufnahme (cps) immer kleiner wird, könnte durch folgende Annahmen erklärt werden:

1. Bei den gewählten Versuchsbedingungen wirkt mindestens ein Faktor rasch begrenzend.

2. Bei den gewählten Versuchsbedingungen wirkt ein Faktor hemmend.

3. Mit fortschreitender Belichtungsdauer werden Assimilationsprodukte in zunehmendem Masse wieder ausgeschieden. Da zwischen der Anzuchtsphase und dem Beginn des beschriebenen Versuches keine Dunkelphase lag, kann diese Annahme die oben beschriebene Verminderung der Kohlenstoffaufnahme bei fortschreitender Versuchsdauer nicht erklären.

Um die Wirkung der erwähnten Einflüsse abzuklären, wurden folgende Versuche angestellt:

Sollte die Tatsache zutreffen, dass die Konzentration èines Nährstoffes derart rasch absinkt, dass die Wachstumsrate bereits nach zwei Stunden Versuchsdauer deutlich abfällt, so müsste eine Erhöhung der Nährstoffkonzentration in der Kulturlösung eine erhöhte Assimilationsrate ergeben. Es wurden daher Z 8-Nährlösungen folgender Konzentration hergestellt: $50 \%, 100 \%, 200 \%, 300 \%$ und $400 \% . \mathrm{Zu}$ je $100 \mathrm{ml}$ dieser auf $20,5^{\circ} \mathrm{C}$ vortemperierten Lösungen wurden $10 \mathrm{ml}$ Impfmaterial gegeben, mit $\mathrm{NaHC}^{14} \mathrm{O}_{3}$ versetzt und während zwei Stunden bei 550 Lux exponiert. Dabei ergaben sich die folgenden Resultate: 


\begin{tabular}{llllll}
\hline Konzentration & $50 \%$ & $100 \%$ & $200 \%$ & $300 \%$ & $400 \%$ \\
$\mathrm{mg} \mathrm{C}$ ass $/ \mathrm{m}^{3} \cdot \mathrm{h}$ & 250 & 279 & 250 & 250 & 165 \\
\hline
\end{tabular}

Aus diesen Resultaten lässt sich schliessen, dass in originaler Z 8-Lösung zu Beginn der Versuchsdauer weder ein Faktor begrenzend noch hemmend wirkt. Es muss aber auch die Möglichkeit in Betracht gezogen werden, dass von den Algen mit fortschreitender Versuchsdauer ein oder mehrere Stoffe ausgeschieden werden, die sich auf die Wachstumsgeschwindigkeit hemmend auswirken. Ausgehend von dieser Arbeitshypothese wurde folgender Versuch angesetzt:

Eine 12 Stunden alte Kultur wurde filtriert und das Filtrat, das den postulierten Hemmstoff enthielt, bei $35^{\circ} \mathrm{C}$ unter Vakuum auf den 10 . Teil des ursprünglichen Volumens eingeengt. Eine gleich grosse Menge einer nichtbeimpften, ursprünglichen Nährlösung wurde in der gleichen.Weise behandelt. Aus den beiden Lösungen wurden die in Tabelle 26 zusammengestellten Kulturlösungen hergestellt, mit $10 \mathrm{ml}$ frisch angezogener Kultur beimpft und mit der $\mathrm{C}^{\mathbf{1 4}}$-Methode die Photosyntheseleistung unter Standardbedingungen $\left(23,5^{\circ} \mathrm{C}, 550 \mathrm{Lux}\right)$ gemessen.

Tab. 25. Kohlenstoffaufnahme (cps) einer Oscillatoria rubescens-Kultur in Abhängigkeit der Akklimatisationsdauer $t$ (Temperatur: $23,5^{\circ} \mathrm{C}$, Lichtintensität: $550 \mathrm{Lux}$ )

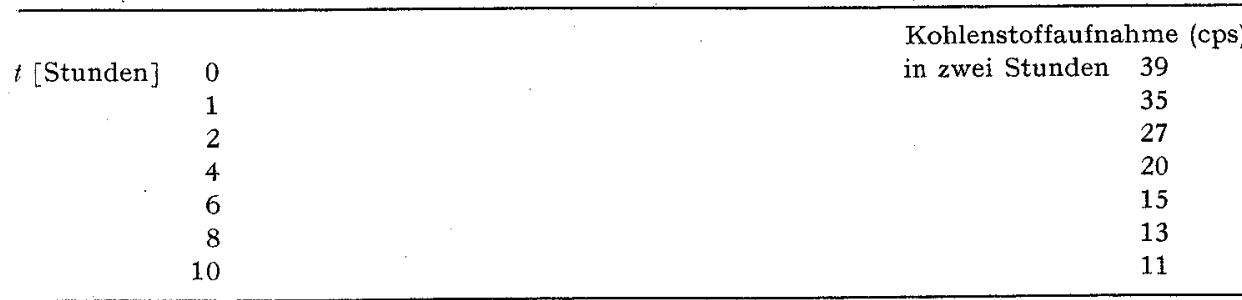

Tab. 26. Zusammensetzung der Nähvlösungen I-IV

\begin{tabular}{llll}
\hline Bezeichnung & $\begin{array}{l}\text { eingeengte } \\
\text { Z8-Lösung } \\
{[\mathrm{ml}]}\end{array}$ & $\begin{array}{l}\text { eingeengte } \\
\text { Kulturlösung } \\
{[\mathrm{ml}]}\end{array}$ & $\begin{array}{c}\mathrm{H}_{2} \mathrm{O} \text { dest. } \\
{[\mathrm{ml}]}\end{array}$ \\
\hline I & 20 & 0 & 80 \\
II & 17 & 3 & 80 \\
III & 9 & 11 & 80 \\
IV & 0 & 20 & 80 \\
\hline
\end{tabular}

Die Nährstoffkonzentration der verwendeten $\backslash$ Lösung war ungefähr doppelt so gross wie die einer normalen Z8-Lösung. Es ergaben sich daraus folgende Resultate:

\begin{tabular}{lllll}
\hline Nährlösung & I & II & III & IV \\
cps & 18,9 & 15,3 & 12,9 & 10,5 \\
\hline
\end{tabular}

Auf Grund des oben beschriebenen Versuches kann eine nährstoffbegrenzende Wirkung ausgeschlossen werden, da die Kombinationen I-III zu Versuchsbeginn 
mehr als $100 \%$ aller Nährstoffe einer normalen $Z 8$-Lösung enthielten. Die Tatsache, dass mit steigendem Anteil an eingedickter Kulturlösung die Assimilationsraten kleiner wurden, deutet darauf hin, dass die oben beschriebene Abnahme der Kohlenstoffassimilation zumindest zu einem Teil auf einen ausgeschiedenen Hemmstoff zurückzuführen ist. Tabelle 27 zeigt, dass sich die beobachtete Hemmung der Kohlenstoffassimilation nach längerer Versuchsdauer bei allen vorgewählten Temperaturen einstellte.

Um in der Phase minimaler Hemmung zu bleiben, wurde in Kurzzeitversuchen so vorgegangen, dass die Nährlösungen auf die gewählte Versuchstemperatur vortemperiert, mit $10 \mathrm{ml}$ Impfmaterial beimpft, sofort mit $\mathrm{C}^{14}$ versetzt und während zwei Stunden exponiert wurden.

Tab. 27. Kohlenstoffaufnahme einer Oscillatoria rubescens-Kultur nach 0 und 4 Stunden Akklimatisationsdauer (550 Lux)

\begin{tabular}{lccccc}
\hline Temperatur $\left[{ }^{\circ} \mathrm{C}\right]$ & 2,0 & 7,5 & 14,5 & 22,0 & 26,0 \\
cps nach 0 Stunden & 14,4 & 21,2 & 31,0 & 40,0 & 48,0 \\
cps nach 4 Stunden & 8,2 & 15,8 & $22,7^{\cdots}$ & 21,4 & 25,4 \\
\hline
\end{tabular}

\subsection{Kurzzeitversuche}

In Kurzzeitversuchen von zwei Stunden Dauer wurde mit Hilfe der C ${ }^{14}$-Methode (siehe S. 48) die Reaktion von Oscillatoria rubescens auf verschiedene Temperaturen und Lichtintensitäten gemessen. Die gewonnenen Resultate sind in Abb. 26 graphisch dargestellt. Es geht daraus hervor, dass im Temperaturbereich 3,5 bis $8,0^{\circ} \mathrm{C}$ Lichtintensitäten zwischen 500 Lux und 2000 Lux optimal waren, und dass in diesem Bereich bei den gewählten Versuchsbedingungen offenbar nur die Temperatur begrenzend wirkte. Bei einer weiteren Temperaturerhöhung bis $16^{\circ} \mathrm{C}$ wirkte sich eine Steigerung der Lichtintensität über 500 Lux hinaus deutlich in einer erhöhten Photosyntheseleistung aus. Jedoch konnten auch hier keine signifikanten Unterschiede bei den Lichtstärken 1000 Lux bis 2000 Lux nachgewiesen werden. Wurde die Temperatur noch weiter erhöht, so blieben die Wachstumsraten der 1000 Lux-Kulturen jedoch deutlich hinter den 1500 und 2000 Lux-Kulturen zurück, ohne dass die beiden letzteren bis $29^{\circ} \mathrm{C}$ voneinander abwichen. Oberhalb $29^{\circ} \mathrm{C}$ wirkte sich eine Steigerung der Lichtintensität über 1500 Lux und oberhalb $38^{\circ} \mathrm{C}$ über 1000 Lux hinaus wieder eher wachstumshemmend aus. Zusammengefasst kann qualitativ gesagt werden, dass eine Steigerung der Temperatur ein Ansteigen der optimalen Lichtwerte nach sich zog. Das aus ökologischen Untersuchungen gefolgerte Resultat, dass Oscillatoria $r u$ bescens kaltstenotherm sei, wurde durch dieses Experiment nach den Beobachtungen von Staub [24] ein weiteres Mal widerlegt. Dagegen konnten die aus Freilandbeobachtungen $[1,10,12,19]$ geschlossenen Folgerungen, Oscillatoria rubescens sei, verglichen mit anderen Algen, eine Schwachlichtform, bestätigt werden.

\subsection{Langzeitversuche}

Die Kurzzeitversuche ergaben Temperaturoptima, die zwischen 29 und $32^{\circ} \mathrm{C}$ lagen. Es stellte sich die Frage, ob diese Beobachtung auch bei länger dauernden Ver- 


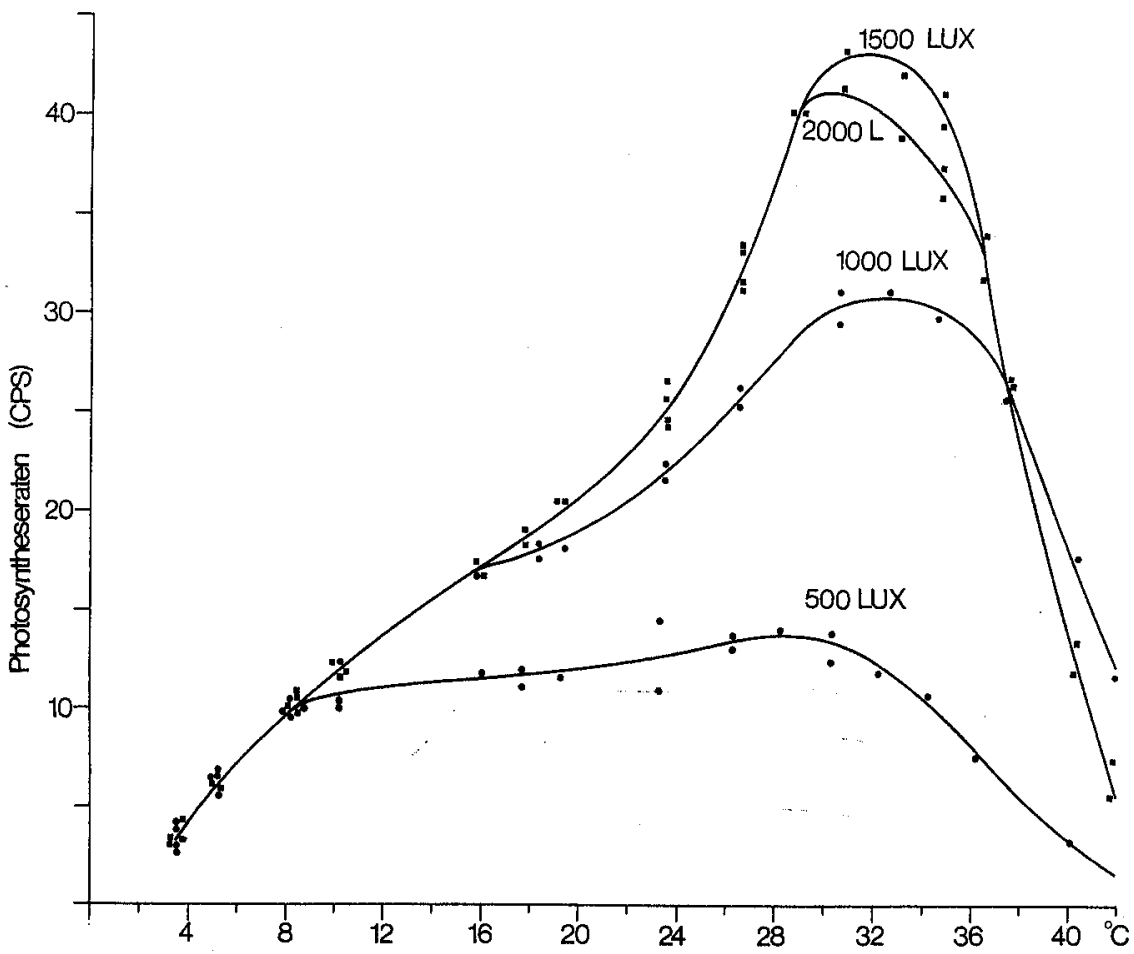

Abb. 26. Abhängigkeit der Photosyntheseraten von Lichtintensität und Temperatur bei Oscillatovia rubescens.

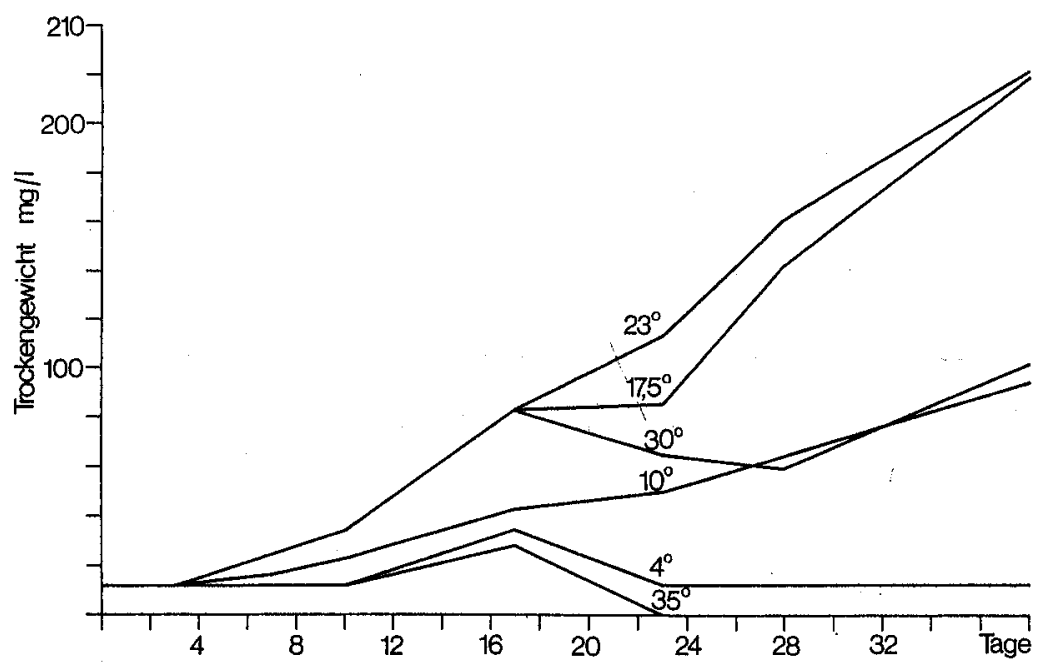

Abb. 27. Temperaturabhängigkeit des Wachstums von Oscillatoria rubescens (500 Lux). 
suchen bestätigt würde. Deshalb wurden zwei sich über eine Dauer von 31 bzw. 38 Tagen erstreckende Versuche durchgeführt, bei denen Lichtintensitäten von 1000 Lux bzw. 500 Lux gewählt wurden. Im Laufe eines 24-Stunden-Tages wurden die Kulturen 14 Stunden beleuchtet und 10 Stunden im Dunkeln gelassen. In Abb. 27 und 28 ist der Verlauf des Wachstums bei verschiedenen Temperaturen dargestellt. Bei einer Lichtintensität von 500 Lux (Abb. 27) verhielt sich das Trockengewicht bei Temperaturen von $17,5,23$ und $30^{\circ} \mathrm{C}$ bis zum 17. Versuchstag fast gleich. Bis $\mathrm{zu}$ diesem Zeitpunkt konnten auch in allen andern Temperaturbereichen Trockengewichtszunahmen verzeichnet werden. Nach diesem Zeitpunkt verfielen die Trichome in den $35^{\circ} \mathrm{C}-$ Kulturen rasch. Bei allen andern Temperaturen vermochte sich die Alge bis zum Versuchsabbruch zu vermehren oder, wie es bei der $4^{\circ} \mathrm{C}$-Kultur der Fall war, auf demselben Stand zu halten. Das höchste Trockengewicht bei Versuchsabbruch wurde bei den Temperaturen von 23 und $17,5^{\circ} \mathrm{C}$ erreicht. Knapp die Hälfte dieses Betrages wurde bei Temperaturen von 10 und $30^{\circ} \mathrm{C}$ beobachtet. Verglichen mit der 500 Lux-Kurve in Abb. 26 (Kurzzeitversuche) kann gesagt werden, dass bis zum 17. Tag zumindest qualitativ gute Ubereinstimmungen festgestellt wurden, nämlich im Temperaturbereich 17,5 bis $30^{\circ} \mathrm{C}$ eine maximale, temperaturunabhängige Wachstumsrate, und eine Beeinflussung des Wachstums durch die Temperatur in niedrigen $\left(4,0\right.$ und $\left.10,0^{\circ} \mathrm{C}\right)$ und hohen $\left(34,5^{\circ} \mathrm{C}\right)$ Temperaturbereichen. Für den Zusammenbruch des Wachstums bei Temperaturen über $30^{\circ} \mathrm{C}$ nach dem 17. Tag konnte keine Erklärung gefunden werden. Bei einer Lichtintensität von $1000 \mathrm{Lux}$ (Abb. 28) stieg das Trockengewicht bei den Temperaturen von 10,0, 17,5 und $23,0^{\circ} \mathrm{C}$ während der ersten Tage weitaus stärker an, als dies bei der vorhergehenden Versuchsanordnung der Fall war. Bei $4,0^{\circ} \mathrm{C}$ konnte jedoch trotz der höheren Lichtintensität (1000 Lux) gegenüber dem vorhergehenden Versuch (500 Lux) kein stärkerer Zuwachs beobachtet werden. Dies stimmt gut mit den aus den Kurzzeitversuchen

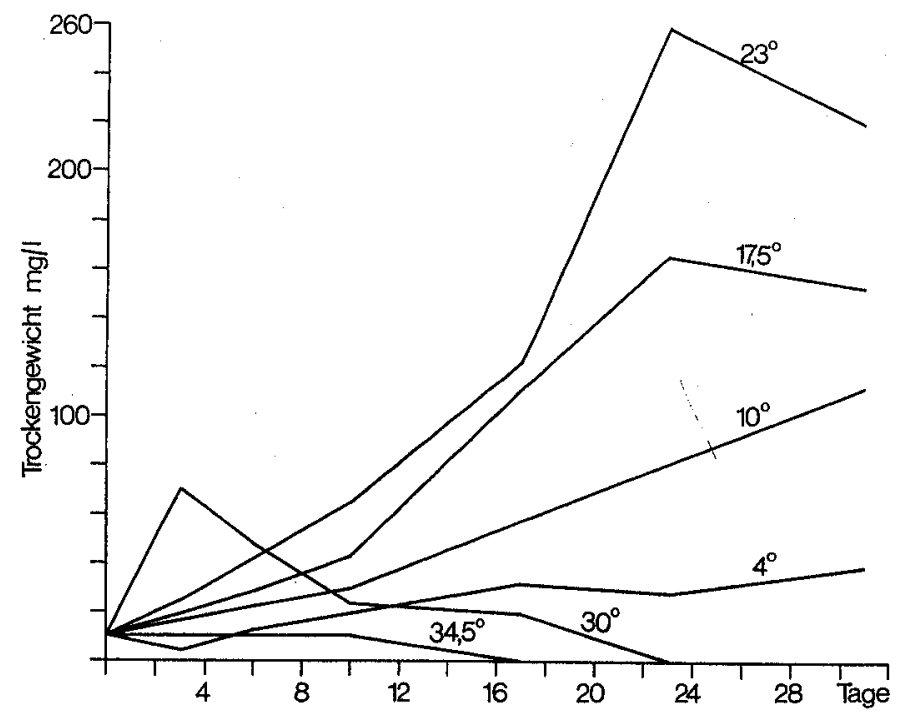

Abb. 28. Temperaturabhängigkeit des Wachstums von Oscillatoria rubescens (1000 Lux). 
ermittelten Resultaten (Abb. 26) ïberein. Das Trockengewicht der $30^{\circ} \mathrm{C}-\mathrm{Kultur}$ hatte sich nach drei Tagen versiebenfacht. $Z$ u diesem Zeitpunkt begann jedoch die Farbe der Fäden bereits zu verblassen, was auf den Beginn des Zerfalls hinwies. Bis zum 23. Tag hatte sich diese Kultur aufgelöst. Bei der $35^{\circ} \mathrm{C}$-Kultur konnte nie eine Trokkengewichtszunahme beobachtet werden; schon nach dem 3. Tag begann der Zerfall der Fäden, der bis zum 17. Tag zur Auflösung der Kultur führte. Die 4- und $10^{\circ} \mathrm{C}$ Kulturen wiesen am Ende des 31 Tage dauernden Versuches ihr höchstes Trockengewicht auf. Das absolut höchste Trockengewicht dieses Versuches konnte bei der $23^{\circ} \mathrm{C}$-Kultur am 23. Tag beobachtet werden. $\mathrm{Zu}$ diesem Zeitpunkt zeigte diese Kultur jedoch schon Anzeichen des Zerfalls, welcher durch schwache Rotfärbung der Nährlösung und Verblassen der Algenfarbstoffe manifestiert wurde. Es wurde denn auch am Ende des Versuches eine verminderte Menge an Trockensubstanz gewogen. Die $17,5^{\circ} \mathrm{C}$-Kultur zeigte bei allgemein geringerem Wachstum eine der $23^{\circ} \mathrm{C}$-Kultur parallele Entwicklung, der Trockengewichtsabfall nach dem 23. Tag war jedoch weniger gross. Auch konnte keine sichtbare Verfärbung der Nährlösung oder der Fäden beobachtet werden.

\section{Diskussion und Schlussfolgerungen}

Die aus ökologischen Untersuchungen gewonnenen und durch Resultate anderer Autoren $[8,18,19,20,22,48,49,50]$ ergänzten Temperaturwerte, in deren Bereich Oscillatoria rubescens maximale Entwicklung zeigte, lagen in der grossen Mehrzahl unter $14^{\circ} \mathrm{C}$. In einer kleineren Anzahl von Fällen lagen diese Temperaturen wesentlich höher. Besondere Beachtung verdienen unsere Beobachtungen im Mauensee, wo es bei Temperaturen von 15,0 bis $18,1^{\circ} \mathrm{C} \mathrm{zu}$ einer Massenentfaltung von Oscillatoria rubescens kam. Obwohl der Massenentfaltung ein fast vollständiges Verschwinden der Alge folgte, mussten zu Beginn günstige Bedingungen für diese enorme Entwicklung geherrscht haben. Auf Grund dieser Beobachtungen, die durch Messungen im Luganersee (Oscillatoria rubescens-Maximum bei $16,3^{\circ} \mathrm{C}$ ) bestätigt wurden, kann Oscillatoria rubescens auf keinen Fall mehr als oligotherm bezeichnet werden.

Die Auswertung unserer quantitativen Temperaturversuche mit Reinkulturen bestätigt den eurythermen Charakter von Oscillatoria rubescens. Eine Überraschung bedeutete das recht hohe Temperaturoptimum, das - abhängig von der jeweiligen Beleuchtungsstärke - im Bereich um $30^{\circ} \mathrm{C}$ lag (Abb. 26). Die Tatsache, dass Oscillatoria rubescens unter natürlichen Verhältnissen, im Zusammenwirken aller ökologischen Faktoren, in der überwiegenden Anzahl aller Fälle maximale Entwicklung unterhalb $14,0^{\circ} \mathrm{C}$ aufweist, sich im physiologischen Experiment aber um $30^{\circ} \mathrm{C}$ optimal vermehrt, zeigt einmal mehr, dass aus Resultaten ökologischer Untersuchungen nicht direkte Rückschlüsse auf die physiologischen Eigenschaften gezogen werden können. Offenbar sind demnach unter Freilandbedingungen andere Faktoren wesentlich dafür verantwortlich, dass sich Oscillatoria rubescens weit unterhalb ihres physiologischen Temperaturoptimums maximal entwickelt. Da niedrige Temperaturen in einem See während der Sommerstagnation stets mit geringen Lichtintensitäten zusammenfallen, liegt die Vermutung nahe, dass es sich bei dieser Alge zwar nicht um eine oligotherme, aber um eine oligophote Form handelt. 
Im Gegensatz zu den meisten andern Formen des Phytoplanktons entwickelte sich Oscillatoria rubescens in jenem Tiefenbereich maximal, in dem nur noch geringe Lichtintensitäten vorhanden waren. Die in Abb. 25 ausgewerteten Messungen vom Vierwaldstätter-, Thuner- und Luganersee zeigen, dass das Oscillatoria rubescensMaximum im überwiegenden Teil aller Fälle im Intensitätsbereich von 1-4\% der Oberflächenintensität des Spektralbereiches von VG9 $\left(I_{m p c}\right)$ lag. EBERLY [53] stellte fest, dass in den beiden amerikanischen Seen Myers und McLish die Populationsmaxima von Oscillatoria agardhii, deren vertikale Verteilung im Laufe der Vegetationsperiode dieselbe Charakteristik aufweist wie Oscillatoria rubescens, im relativen Intensitätsbereich (Gesamtenergie) von 1-5\% lagen. Auch bei Berücksichtigung des wertmässigen Unterschiedes zwischen dem Spektralbereich von VG9 und der Gesamtenergie stimmen unsere Beobachtungen mit jenen von EBERLY zumindest qualitativ überein.

Im physiologischen Experiment zeigte sich, dass bis zu $29^{\circ} \mathrm{C}$ Intensitäten zwischen 1500 Lux und 2000 Lux optimal waren. In physiologischen Experimenten anderer Autoren $[55,56,57,58]$ wurde die Abhängigkeit der optimalen Lichtintensität von der Temperatur an verschiedenen Algen untersucht. Es zeigte sich, dass höhere Temperaturen höhere $I_{k}$-Werte bedingten (Tabelle 28). Die Lichtintensität $I_{k}$ ist definiert als Schnittpunkt der beiden Tangenten an die Isotherme im PhotosyntheseLichtintensitäts-Diagramm im untersten suboptimalen und im optimalen Bereich. Dieses Verhalten konnte auch an Oscillatoria rubescens beobachtet werden (Tabelle 29); die $I_{k}$-Werte der entsprechenden Temperaturen lagen jedoch wesentlich tiefer als jene von Asterionella sp., Scenedesmus sp. und Chlorella ellipsoidea.

Tab. 28. $\quad I_{k^{-} \text {Werte verschiedener Algen }}$

\begin{tabular}{|c|c|c|c|}
\hline Art & $\begin{array}{l}\text { Versuchstemperatur } \\
{\left[{ }^{\circ} \mathrm{C}\right]}\end{array}$ & & $I_{k}$ \\
\hline Chlorella ellipsoidea & $\begin{array}{r}30 \\
25 \\
20 \\
15 \\
10 \\
5\end{array}$ & {$[\operatorname{Lux}]$} & $\begin{array}{l}11000 \text { (ARUGA [54]) } \\
9000 \\
6000 \\
3500 \\
3000 \\
2500\end{array}$ \\
\hline Scenedesmus sp. & $\begin{array}{l}30 \\
20 \\
10\end{array}$ & {$[\operatorname{Lux}]$} & $\begin{array}{l}9000(\text { ARUGA }[54]) \\
5000 \\
2000\end{array}$ \\
\hline A sterionella sp. & $\begin{array}{r}17 \\
11 \\
5\end{array}$ & {$\left[\mathrm{kerg} / \mathrm{cm}^{2} \cdot \mathrm{s}\right]$} & $\begin{array}{l}20 \quad \text { (TALLING [57]) } \\
12,5 \\
7,5\end{array}$ \\
\hline
\end{tabular}

Tab. 29. $I_{k}$-Werte von Oscillatoria rubescens

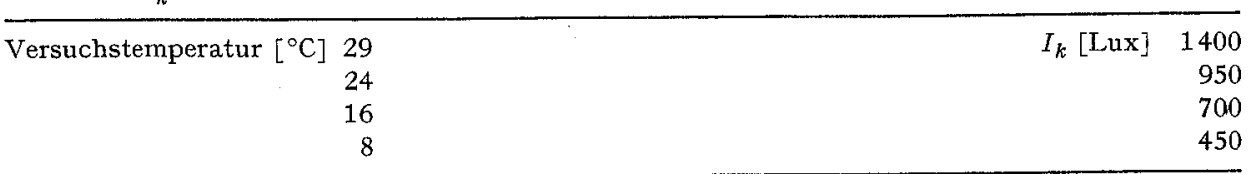


Oberhalb $29^{\circ} \mathrm{C}$ wirkten sich $2000 \mathrm{Lux}$ bereits hemmend aus. Obwohl aus versuchstechnischen Gründen nicht mit noch höheren Intensitäten gearbeitet werden konnte, glauben wir annehmen zu dürfen, dass sich eine noch weitere Steigerung der Lichtintensität bereits bei niedrigeren Temperaturen hemmend ausgewirkt hätte. Auf den See übertragen heisst dies, dass die hohen Lichtintensitäten ( $>2000 \mathrm{Lux}$ ) in oberflächennahen Wasserschichten von Oscillatoria rubescens sicher nicht ausgenützt werden können, dass sich diese aber bei den gleichzeitig höheren Temperaturen in diesen Tiefenbereichen höchst wahrscheinlich wachstumshemmend auswirken.

Zusammenfassend kann gesagt werden, dass das Zustandekommen optimaler Wachstumsbedingungen für Oscillatoria rubescens im unteren Bereich der trophogenen Schicht, vom besseren Nährstoffangebot abgesehen, auf das Zusammenspiel der beiden Faktoren Licht und Temperatur zurückgeführt werden kann.

\section{Zusammenfassung}

Der Vierwaldstättersee (Horwer Bucht), Thunersee (Höhe Faulensee), Luganersee (Bucht von Lugano) und Mauensee (ein Kleingewässer im Schweizerischen Mittelland) wurden im Zeitabschnitt 1965 bis 1967 periodisch untersucht. Durch die chemische Analyse wurden die folgenden Komponenten erfasst: Sauerstoff, Nitrat Stickstoff, Phosphat - Phosphor $\left(\mathrm{PO}_{4}-\mathrm{P}\right)$, partikulärer Phosphor (PP), SBV und pH-Wert. Das Phytoplankton wurde im umgekehrten Mikroskop ausgezählt, wobei der quantitativen Verteilung von Oscillatoria rubescens D.C. in den verschiedenen Tiefenstufen besondere Beachtung geschenkt wurde. Gleichzeitig wurden Temperatur und subaquatische Veränderungen des Lichtes gemessen sowie mit der $\mathrm{C}^{\mathbf{1 4}}$-Methode die Primärproduktion bestimmt.

In mehr als $80 \%$ aller Fälle fielen die Oscillatoria rubescens-Maxima mit jenen Tiefenstufen zusammen, in denen weniger als $14^{\circ} \mathrm{C}$ gemessen wurde. In diesen Tiefenstufen wurde gleichzeitig in mehr als $65 \%$ aller Fälle weniger als $4 \%$ der Oberflächenintensität des grünen Lichtes (VG9) beobachtet.

Der Einfluss von Licht und Temperatur auf das Wachstum von Oscillatoria rubescens wurde in einem Lichtthermostat experimentell untersucht. Bei temperaturabhängigen $I_{k}$-Werten zeigte sich, dass sich diese Alge bei einer Lichtintensität von 1500 Lux erst im Bereich von $30^{\circ} \mathrm{C}$ optimal entwickelt. Oberhalb $29^{\circ} \mathrm{C}$ wirkte sich eine Steigerung über 1500 Lux hinaus wieder hemmend aus.

Aus diesen Beobachtungen wurde abgeleitet, dass es sich bei Oscillatoria rubescens um eine eurytherme und oligophote Form handelt, und dass das Auftreten von Oscillatoria rubescens-Maxima in der vertikalen Verteilung des Phytoplanktons in einem See durch das Zusammenspiel der beiden Faktoren Licht und Temperatur bedingt wird.

\section{SUMMARY}

The Lakes of Lucerne (Horw Bay), Thoune (Faulensee region), Lugano (Lugano Bay) and Lake Mauen, a small lake in central Switzerland, were investigated periodically from 1965 to 1967. The water was analysed in view of determining the following components: oxygen, nitratenitrogen, phosphate-phosphorus $\left(\mathrm{PO}_{4}-\mathrm{P}\right)$, phosphorus incorporated in cell mass (PP), Langlier index. Phytoplankton was counted in an inverted microscope with special consideration to quanti- 
tative distribution of Oscillatoria rubescens D.C. at various depths. Temperature and light variations in function of depth were measured simultaneously and the production rate was determined by means of the $\mathrm{C}-14$ method.

In over $80 \%$ of all cases, the Oscillatoria rubescens-maxima coincided with depths showing temperatures under $14{ }^{\circ} \mathrm{C}$. In over $65 \%$ of all cases, the intensity of green light (VG9) in such depths was less than $4 \%$ of the surface intensity. The influence of light and temperature on the growth of Oscillatoria rubescens was tested with a light thermostat. It was shown that maximum growth occurred at temperatures around $30^{\circ} \mathrm{C}$ and light intensities of $1500 \mathrm{Lux}$. Increase of light intensities above $1500 \mathrm{Lux}$ had a negative effect on the growth rate at temperatures higher than $29^{\circ} \mathrm{C}$.

Our investigations lead to the conclusion that Oscillatoria rubescens is a eurythermal, oligophotic species and that the occurrence of Oscillatoria rubescens-maxima in the vertical distribution of the phytoplankton in a lake is caused by the combined effects of light and temperature.

\section{LITERATURVERZEICHNIS}

[1] Findenegg I., Sitz. Ber. Akad. Wiss. Wien [math.-naturw. K1. I] 155, 159-171 (1947).

[2] AmbÜHL H., Schweiz. tech. Z., 60, 414-428 (1963).

[3] Pelletier J., Rev. algologique [Nouv. Sér.] 9 (2), 186-192 (1968).

[4] JAAG O., MÄrki E., Wasser- u. Energ. wirt. 60, 7/8, 1-14 (1968).

[5] Pavoni M., Schweiz. Z. Hydrol. 25, 219-341 (1963).

[6] Edmondson W. T., Anderson G. C., Peterson D. R., Limnol. Oceanogr. 1, 47-53 (1956).

[7] Edmondson, W. T., Trend Eng., Univ. Kash., 8 (2), 11-13 (1956).

[8] Marchesoni V., Boll. Pesca, Piscicolt. Idrobiol. 3, H. 2 (1948).

[9] Marchesoni V., Ricerca scient. 78, 1023-1028 (1948).

[10] FindenegG I., Int. Revue ges Hydrobiol. Hydrogr. 32, 369-423 (1935).

[11] Findenegg I., Int. Revue ges. Hydrobiol. Hydrogr. 40, (1940).

[12] Findenegg I., Mitt. naturw. Ver, Kärnten 736, 77-93 (1947).

[13] Findenegg I., Z. Fisch. [N.F.] 11, (1962/63).

[14] Findenegg I., Int. Revue ges. Hydrobiol. Hydrogr. 49, 318-416 (1964).

[15] Findenegg I., Mem. Ist. ital. Idrobiol. 78, Suppl., 271-289 (1965).

[16] Findenegg I., Vjschr. naturf. Ges. Zürich 110, 289-300, (1965).

[17] Findenegg I., Schweiz. Z. Hydrol. 28, 148-172 (1966).

[18] Ruttner F., Arch. Hydrobiol. 32, 167-319 (1937).

[19] Thomas E. A., Schweiz. Z. Hydrol. 12, 1-24 (1950).

[20] Thomas E. A., Märkr E., Verh. int. Verein. theor. angew. Limnol. 10, $476-488$ (1949).

[21] Findenegg I., Int. Revue ges. Hydrobiol. Hydrogr. 43, 368-429 (1943).

[22] Waser E., Blöchlinger E., Unters. öff. Gewässer Kt. Zürich 5, (1939).

[23] Steiner H., Veröff. geobot. Inst., Zürich, 3, 459-475 (1925).

[24] Staub R., Schweiz. Z. Hydrol. 23, 82-198 (1961).

[25] BachmanN H., Verh. schweiz. naturf. Ges. 1, 1-2 (1910).

[26] Bachmann H., Schweiz. Z. Hydrol. 5, 39-81 (1931).

[27] Winkler L. W., Chem. Ber. 21, 2843-2855 (1888).

[28] Utermör H., Mitt. internat. Verein. theor. angew. Limnol. 9, 1-38 (1958).

[29] АмвüHL H., Schweiz. Z. Hydrol. 22, 23-39 (1960).

[30] Nydegger P., Beitr. Geol. Schweiz [Hydrol.] 9, (1957).

[31] Alsterberg G., Biochem. Z. 170, (1926).

[32] HaRvey H. W., RHode W., The Chemistry and Fertility of Sea Waters (Cambridge University Press, London 1955).

[33] OHLE W., Z. anorg. Chem. 49, 206 (1936).

[34] АмвÜhL H., Schmid M., Schweiz. Z. Hydrol. 27, 172-183 (1965).

[35] Schmid M., Амвühl H., Schweiz. Z. Hydrol. 27, 184-192 (1965).

[36] Müller R., Widemann O., Jb. Wass. 22, 247-271 (1955).

[37] Steemann-Nielsen E., J. Cons. 18, 117-140 (1952).

[38] Krogh A., Pennsylvania Press, Philadelphia, 172 (1941).

[39] Mrtscherlich L., Schr. Königsb. gelehrt. Ges. naturw. Kl. 3, 1-29 (1927). 
[40] Eidg. Anstalt für Wasserversorgung, Abwasserreinigung und Gewässerschutz an der ETH, unveröffentlicht.

[41] Årerg B., Rodhe W., Uber die Milieufaktoven in einigen südschredischen Seen, Symb. bot. upsal. 5 (3), (1942).

[42] Rutrner F., Grundriss dev Limnologie, 3. Auflage (Verlag Walter de Gruyter \& Co., Berlin 1962).

[43] Strickland J. D. H., Parsons T. R., Bull. Fish. Res. Bd. Can. 125, 1-85 (1960).

[44] GÄchtER R., Schweiz. 2. Hydrol. 30, 1-66 (1968).

[45] Nydegger P., Beitr. Geol. Schweiz [Hydrol.], 16 (1967)

[46] Lohmann H., Wiss. Meeresunters. Kiel, 10, 1815 (1908).

[47] Rodhe W., Mem. Ist. ital. Idrobiol. 18, Suppl., 365-381 (1965).

[48] PaVoni M., (in Vorbereitung).

[49] Eidg. Anstalt für Wasserversorgung, Abwasserreinigung und Gewässerschutz an der ETH, Gutachten Nr. 3435 (1967).

[50] Eidg. Anstalt für Wasserversorgung, Abwasserreinigung und Gewässerschutz an der ETH, Gutachten Nr. 1877 (1960).

[51] Vollenweider, R., Mem. Ist. ital. Idrobiol. 12, 201-244 (1960).

[52] ZEHNDER A., zit. nach R. Staub (24) (1961).

[53] EberLy.W. R., Invest. Indiana Lakes Streams 6, (3), 103-139 (1964).

[54] Aruga Y., Bot. Mag. Tokyo, 78, 360-365 (1965).

[55] Steemann-Nielsen E., Hansen V. K., Physiologia Pl. 12, 353-370 (1959).

[56] Steemann-Nielsen E., Hansen V. K., Jørgensen E. G., Physiologia Pl. 75, 505-517 (1962)

[57] Taliing J. F., New Phytol. 56, 133-149 (1957).

[58] Yentsch C. S., Lee R. W., J. Mar. Res. 24. 319-337 (1966).

Anschrift des Autors:

Dr. U. Zimmermann, Center for Great Lakes Studies, University of Wisconsin-Milwaukee, Milwaukee, Wisconsin 53201, USA. 


\section{Lebenslauf}

Am 6. März 1937 wurde ich als Bürger von Schwändi und Mitlödi GL in Zürich geboren. Nach Absolvierung der Volksschulen bereitete ich mich in Schaffhausen und Zürich auf die eidg. Maturitätsprüfung Typus C vor, die ich 1960 bestand. Anschliessend trat ich in die Eidg. Techn. Hochschule in Zürich, Abteilung für Naturwissenschaften, ein. 1965 bestand ich die Schlussdiplomprüfung als Naturwissenschafter. Seither arbeitete ich an der vorliegenden Dissertation und war als Vorlesungsassistent von Herrn Prof. Dr. O. Jaag angestellt. 